LBL $-\mathbf{2 7 0 4 5}$

DE90 016618

\title{
A Review of Near-Field Mass Transfer in Geologic Disposal Systems
}

\author{
T. H. Pigford, P. L. Chambre and W. W.-L. Lee \\ Department of Nuclear Englneering \\ University of California
}

\author{
and \\ Earth Sciences Divinion, Lawrence Berkeley Laboratory \\ University of California \\ 1 Cyclotion Road \\ Berkeley, CA 94720
}

Feb 1990

This work was supported by the Director. Office of Civillan Radioactive Waste Management, Office of Systems Integration and Regulations, Licensing and Compliance Division. of the U.S. Department of Energy under Contract No. DE-AC03-76SF00098. 
The authore invite comments and would appreciate belng notiled of any errors in the report.

T. H. Pigford Department of Nuclear Englineering University of Callfornia Berkeles. CA 94720 


\section{A REVIEW OF NEAR-FIELD MASS TRANSFER IN GEOLOGIC DISPOSAL SYSTEMS}

I.0 INTRODUCTION

\section{CONTENTS}

\subsection{LOW-SOLUBILITY SPECIES}

2.1 Dissolution from Waste into Porous Rock with Solubility Boundary Condition . . . . . . 2

2.1.1 Stcady-State Results

2.1.1.1 Diffusive

2.1.1.2 Diffusive-Advective

2.1.2 Transient. Results

2.1.2.1 Diffusive-Advective

2.1.2.2 Diffusive

2.2 Dissolution from Waste into Rock: Solid-Liquid Reaction Rate

2.3 Mass Transfer from Waste into Backfill and Rock

2.3.1 Transient Diffusion-Contro!led Dissolution . . . . . . . . . . . . . . . . . . 16

2.3.2 Steady-State Mass Transfer Through Backfill into Flowing Ground Water . . . . 21

2.4 Mass Transfer into Fractured Rock . . . . . . . . . . . . . . . . . . . . . . . 23

2.5 Temperature Effects . . . . . . . . . . . . . . . . . . . . . . . . 26

2.6 Effect of Non-Linear Sorption on Mass Transfer Through Backfill . . . . . . . . . . . . . 28

2.7 Effect of a Stationary Precipitation Front on Dissolution and Transport . . . . . . . . 34

2.8 Isotopic Effects on Solubility-Limited Dissolution . . . . . . . . . . . . . . . . . 39

3.0 SOLUBLE SPECIES . . . . . . . . . . . . . . . . . . . . . . . . . . . . . . .41

3.1 Mass Transfer from Waste into Porous Rock . . . . . . . . . . . . . . . . . . . 41

3.2 Mass Transfer of Soluble Species into Backfill ard Porous Rock . . . . . . . . . . . 45

3.3 Temperature Effects . . . . . . . . . . . . . . . . . . . . . . . . 49

4.0 DISCUSSION OF THEORY AND LIMITAT!ONS . . . . . . . . . . . . . . . . . . . . . . . 52

4.1 Effect of a Liquid-Filled Annulus Between Waste and Rock . . . . . . . . . . . . . . 52

4.2 Eflect of Flow Direction and Geometry . . . . . . . . . . . . . . . . . . 52

4.3 Ilydrodynamic Dispersion . . . . . . . . . . . . . . . . . . . . . . . . . . . . . . 52

4.4 Elfect of Radioactive Decay . . . . . . . . . . . . . . . . . . . . . . . . . . . 52

4.5 Local Sorption Equilibrium . . . . . . . . . . . . . . . . . . . . . . . . . . 53

4.6 Surface Diffusion . . . . . . . . . . . . . . . . . . . . . . . . . . . . . . 53

4.7 Inter ference from Other Waste Packages . . . . . . . . . . . . . . . . . . 53

4.8 Porous or Fractured Rock . . . . . . . . . . . . . . . . . . . . . . . . . . . . 54

4.9 Constant Temperature . . . . . . . . . . . . . . . . . . . . . . . . . 54

4.10 Constant and Uniform Chemical Environment . . . . . . . . . . . . . . . . . . 54

4.11 Release of Other Species From a Low-Solubility Waste Matrix . . . . . . . . . . . 54

5.0 TRANSPORT OF CHAINS, CONCENTRATION BOUNDARY CONDITION . . . . . . . . . 57

6.0 NEAR-FIELD MASS TRANSFER IN A SALT REPOSITORY . . . . . . . . . . . . . . . 59

6.1 Brine Migration . . . . . . . . . . . . . . . . . . . . . . . . 62

6.2 Relcase Rates in Salt by Diffusion . . . . . . . . . . . . . . . . . . . . . . . . 68

6.3 Steady-State Mass Transport in Salt Interbeds . . . . . . . . . . . . . . . . . . 71

6.4 Transient Diffusion from a Waste Cylinder into an Interbed . . . . . . . . . . . . 73

7.0 MASS TRANSFER FROM WASTE PACKAGES IN AN UNSATURATED TUFF REPOSITORY 79

7.1 The Wet-Drip Scenario . . . . . . . . . . . . . . . . . . . . 81

7.2 The Wet-Continuous Scenario . . . . . . . . . . . . . . . . . . . 86

8. SUMMARY

ACKNOWLEDGEMENTS . . . . . . . . . . . . . . . . . . . . . . . . . . . . . . . . . . . . . . . . . . . . . . 9

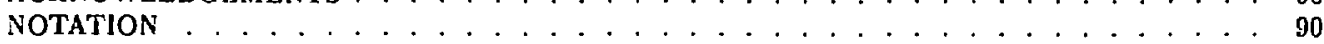

REFERENCES . . . . . . . . . . . . . . . . . . . . . R-1 


\section{Nearfild Mase Tranafer}

\section{MIGURES}

Figure 2.1 Mass Transfer from Buried Waste . . . . . . . . . . . . . . . . . . . . . . . . . . 3

Figure 2.2 Valid and Invalid Extensions of Dissolution Rate as Function of Ground-Water Velocity . . 5

Figure 2.3 Normalized Mass-transfer Rate as a Function of Time and Retardation Coefficient, Diffusion from a Waste Sphere . . . . . . . . . . . . . . . . . . . . . . . . . . . . . . . . . . 7 Figure 2.4 Normalized Mass-transfer Rate as a Function of Time and Damköhler number, Flow around a Waste Cylinder . . . . . . . . . . . . . . . . . . . . . . . . . . . . . 8 Figure 2.5 Normalized Dissolution Rate and Surface-Liquid Concentration as a Function of Dimensionless 'lime for Various Values of the Flux Ratio . . . . . . . . . . . . . . . . . . . . . . . . . . 12 Figure 2.0 Normalized Dissolution Rate and Concentration of Silica at the Waste Surfuce from Borosilicate Glass as a Function of Time, Compared with Dissolution Rate for Constant Saturation Concentration at the Surface . . . . . . . . . . . . . . . . . . . . . . . . . . 13

Figure 2.7 The Sherwood Number as a Function of the Peclet Number by Two Methods . . . . . . 15 Figure 2.8 Normalized Mass-transfer Rate as a Function of Time and Backfill Porosity, Diffusion from a Waste Sphere, No Decay . . . . . . . . . . . . . . . . . . . . . . , 18 Figure 2.9 Normalized Mass Transfer Rate by Diffusion from a Waste Sphere as a liunction of Time and Retardation Coefficient . . . . . . . . . . . . . . . . . . . . . . . . . 19 Figurs 2.10 Normalized Mass Transfer Rate by Diffusion from a Waste Sphere as a Function of Time and Half Life . . . . . . . . . . . . . . . . . . . . . . . . . . . . . . . . . . . . . . . . . 20 Figure 2.11 The Mass-transfer Rate as a Function of Backfill Thickness, Backfill/Rock Porosity Ratio and Peclet Number . . . . . . . . . . . . . . . . . . . . . . . . . . . . . . . . 22

Figure 2.12 Waste Cylinder Intersected by a Fracture . . . . . . . . . . . . . . . . . . . . . 24

Figure 2.13 Nuelide Migration from a Waste Cylinder into a Fracture and Rock . . . . . . . . . . 27

Figure 2.14 The Effect of Repository Heating on the Rate of Silica Dissolution . . . . . . . . . . 29

Figure 2.15a A pproximate Langmui: Isotherm . . . . . . . . . . . . . . . . . . . . 31

Figure 2.15b Movement of a Saturation Front in Backfill . . . . . . . . . . . . . . . . . . . . 31

Figure 2.16 The Breakthrough Time in Backfill as a Function of Normalized Critical Concentration and Retardation Coefficient . . . . . . . . . . . . . . . . . . . . . . 33

Figure 2.17a The Stationary Precipitation Front . . . . . . . . . . . . . . . . . . . 35

Figure 2.17b Schematic of Concentration Profiles . . . . . . . . . . . . . . . . . . . . . . . . . . . . . . 35

Figure 2.18 Dimensionless Mass Transfer Rate Out of a Waste Sphere and the Precipitation Front . . 38

Figure 2.19 Fractional Release Rate of Sr-90 Assuming Constant Fraction and Accounting for Decay 42

Figure 3.1 a Release of Soluble Species into Rock . . . . . . . . . . . . . . . . . . . . . . . 43

Figure 3.1b Release of Soluble Species into Backfill and Rock . . . . . . . . . . . . . . . . . . 43

Figure 3.2 Fractional Release Rates of Some Soluble Species . . . . . . . . . . . . . . . . . . . 46

Figure 3.3 Fractional Release Rates of Some Soluble Species Through $30 \mathrm{~cm}$ of Backfill . . . . . . 48

Figure 3.4 Time-Femperature-Dependent Concentration of Cs-135 in the Void . . . . . . . . . . 50

Figure 3.5 Time-Temperature-Dependent Fractional Release Rate of Cs-135 . . . . . . . . . . . 51

Figure 4.1 The Effect of Number of Sources . . . . . . . . . . . . . . . . . . . . . . . . . 54 Figure 5.1 Normalized Concentration Profile for U-234 $\rightarrow$ Th-230 $\rightarrow \mathrm{Ra}-226$ in Backfill as Functions of Distance at 1000 years, Bateman-tyje boundary condition . . . . . . . . . . . . . . . . . . 60 Figure 5.2 Normalized Mass Fluxes for U-234 $\rightarrow$ Th-230 $\rightarrow \mathrm{Ra}-226$ at both ends of the Backfill as Functions of Time, Bateman-type boundary condition . . . . . . . . . . . . . . . . . . . . . . 61

Figure 6.1 Relative Temperature in Salt Aner Emplacement . . . . . . . . . . . . . . . . . . 65

Figurc 6.2 Pressure Profile in Consolidated Salt . . . . . . . . . . . . . . . . . . . . . . . . 66

Figure 6.3 Darcian Brine Migration Velocity in Consolidated Salt . . . . . . . . . . . . 67 
Figure 6.4 Fractional Release Rates of Some Low-Solublility Species in Salt . . . . . . . . . . . . 69

Figure 6.5 Fractional Release Rates of Some Soluble Species in Salt . . . . . . . . . . . . . . . 70

Figure 6.6 A Wiste Package in Crushed Salt Intersecting an Interbed . . . . . . . . . . . . . . 72

Figure 6.7 Fractional Release Rates as a Function of Interbed Porosity . . . . . . . . . . . . . . . 74

Figure 6.8 Comparison of Fractional Release Rate of U-238 for Different Interber Thicknesses . . . 75

Figure 6.9 Effect of Decay and Time on Mass Flux to the Interbed . . . . . . . . . . . . . . . 77

Figure 6.10 Diffusive Flux from the Waste Cylinder Directly into Salt . . . . . . . . . . . . . . 78

Figure 6.11 Total Mass Flux of a Stable Nuclide from a 3.65-m Long Waste Cylinder in Salt and Granite 80

Figure 7.1 The Wet-Drip Fractional Release Rate of Plutonium . . . . . . . . . . . . . . . . . 82

Figure 7.2 The Wet-Drip Fractional Release Rate of Soluble Species . . . . . . . . . . . . . . . 84

Figure 7.3 'The Wet-Drip Fractional Releasn Rato of 'l'c-99 . . . . . . . . . . . . . . . . . . . 85)

Pigure 7.4 'The Wet-Continuous Fractional Release Rates of Plutonium . . . . . . . . . . . . . . . . . . 87

Figure 7.5 The Wet-Continuous Fractional Release Rates of Plutonium, with a $0.2 \mathrm{~m}$ backfill . . . . 88

Figure 7.6 The Wet-Continuous Fractional Release Rates of Plutonium, with a $0.2 \mathrm{~m}$ backfill, in which the difusion coefficient has been reduced 1,000-fold . . . . . . . . . . . . . . . . . . . . . . . 89

\section{TABLES}

Table 2.1. Data used for Isotopic Effect Illustration . . . . . . . . . . . . . . . . . . . . . 41

Table 6.1. Pararneter Values Used in Salt Calculations . . . . . . . . . . . . . . . . . . . . . 68

Table 6.2. Input Data for Salt Interbed Calculations . . . . . . . . . . . . . . . . . . . . . . 73

Table 6.3. Salt Properties used in Transient Diffusion Illustration . . . . . . . . . . . . . . . . 76

Table 6.4. Nuclides Studied in Transient Diffusion Illustration . . . . . . . . . . . . . . . . 76

Table 6.5. Salt and Granite Data used in Comparison . . . . . . . . . . . . . . . . . . . . . 79

Table 7.1 Release Modes at Yucca Mountain . . . . . . . . . . . . . . . . . . . . . . . 81 


\title{
A REVIEW OF NEAR-FIELD MASS TRANSFER IN GEOLOGIC DISPOSAL SYSTEMS
}

\author{
T. H. Picford, P. L. Chambre and W. W.-L. Leo \\ Department of Nuclear Enpineering, Univereity of Callfornia \\ and \\ Lawrence Derkeley Laborctory, Univerity of Calfornia \\ Derkoloy, CA 04720
}

\section{INTRODUCTION}

In this report we summarize the analyses of the time-dependent mass transfer of rudionuclides from is waste solid into surrnunding porous or fractured media that have been developed at the University of California, Berkeley. For each analysis we describe the conceptual model, we present the governing equations and the resulting analytic solutions, and we illustrate the results.

Designers of geologic disposal systems for solid waste must predict the long-term time-dependent rate of dissolution of toxic contaminants in ground water, to provide the source term for predicting the later transport of these contaminants to the environment. Mass-transfer analysis is being used to predict rates of dissolution and release of radioactive constituents in future repositories for high-level radioactive waste, and it has been applied to predict the life of a copper container for high-level radioactive waste.

The U.S. Nuclear Regulatory Commission (USNRC) [1983] has specified numerical limits for the rate of release of radioactive constituents into rock surrounding packages for ligh-level waste, including unreprocessed spent fuel and reprocessing waste, and it has specified the required time for substantially complete containment of the radioactive constituents by the waste container. Other nations have not imposed such specific requirements on the waste package, but prediction of these same features will be needed for the overall prediction of repository performance [Campbell and Cranwell 1988].

Mechanistic analysis of mass-transfer is based on well-established theory of diffusive-convective transport. Its application requires experimental measurement of well-defined parameters such as porosity, solubility, diffusion coefficient, and pore velocity. It relies on no arbitrary and adjustable parameters from empirical rate measurements; reliance on such parameters would undermine the reliability of the theory to predict dissolution rates in the long-term future. Mass-transfer theory can be used to predict the long-term steady-state dissolution rate in a repository, as well as the higher transient dissolution rates that can exist for hundreds and thousands of years after the waste-solid comes in contact with water. Our first analysis assumed a waste solid in direct contact with porous rock. Subsequently we analyzed the more realistic situations of backfill between the waste and rock, rock with discrete fractures as well as pores, and the effects of waste constituents of high solubility. Those dealing with specifically with mass transfer in the near field are presented here. In order to have a consistent set of notation within this review, some of the notation here is different than in the reports cited. 


\section{$2.0 \mathrm{LOW}$-SOLUBILTY SPLCILS}

The dissolution rate of waste solids in a geologic repository is a complex function of waste solid geometry, chemical reaction rate, exterior flow field, and chemical environment. Our analysis of dissolution rates is divided into those of low soiubility and readily soluble.

\subsection{Diesolution from Wate into Sorous Rock vith a solubility Boundary Condition}

We are concerned with the transfer of a diffusing species from a waste form into porous rock. The governing equation in the most general selse, without accounting for losses, is

$$
K \frac{\partial c}{\partial t}+v \nabla c=D \nabla^{2} c
$$

where $c$ is the concentration of the species in ground water, $v$ is the ground water velocily, $D$ the diffusion or dispersion coefficient and $K$ is the apecies retardation coefficient. The solubility boundary condition is

$$
c=c
$$

on the surface of the waste form the concentration is that of the species solubility $c_{\text {. }}$ (Figure 2.1), and the other boundary condition is

$$
c=0, \quad \text { at infinity }
$$

and the initial condition

$$
c=0, \quad t=0
$$

We shall be concerned with solving this set of governing equations in various forms throughout the remainder of this paper.

\subsubsection{Steady-State Resulto}

\subsubsection{Diffuntre}

The steady-state form of the equation for for mass transfer by molecular diffusion a low-solubility longlived species, assuming constant saturation concentration $c_{3}$ in the liquid at the waste surface and assuming that the waste solid is surrounded by porous rock, is

$$
f=\frac{B c D c_{2}}{\mathcal{N}}
$$

where $f$ is the fractional diseolution rate of the species, $\epsilon$ is the porosity of the rock, $D$ is the diffusion coefficient in pore water, and $\mathcal{N}$ is the bulk density of the elemental species in the waste. $B$ is a geometrical factor that can be calculated from the waste-form dimensions. For a spherical waste solid of radius $R$

$$
\boldsymbol{B}=\frac{3}{R^{2}}
$$

For a prolate spheroid approximating a cylindrical waste form

$$
B=\frac{3 \mathcal{E}}{b_{1}^{2} \log [\operatorname{coth}(\boldsymbol{p} / 2)]}
$$



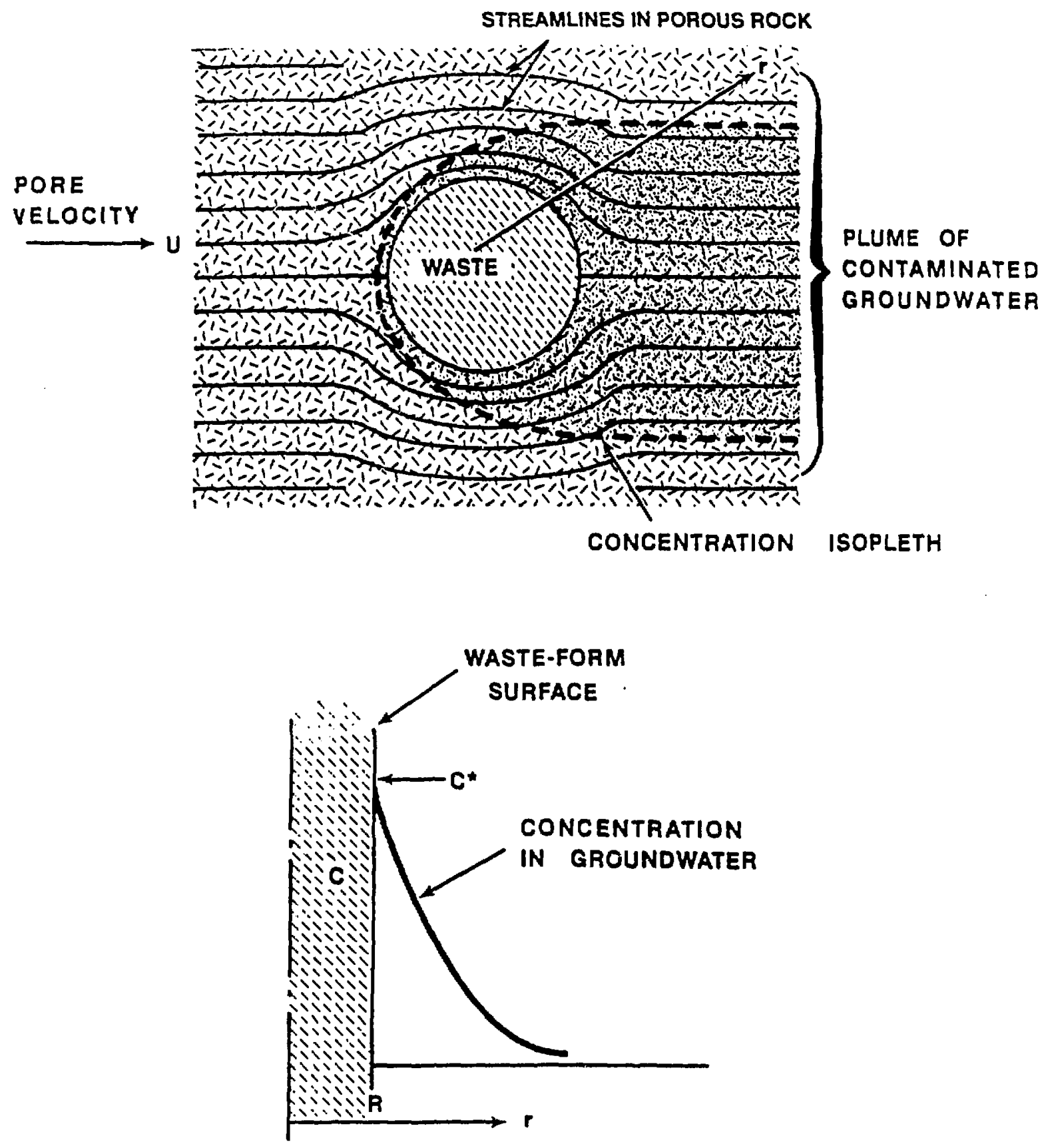

Figure 2.1 Mass Transfer from Buried Waste 
where $b_{1}$ is the semi-minor axis, $\mathcal{E}$ is the eccentricity, and $\boldsymbol{p}$ is a parameter that defines the spheroid surface

$$
\wp=\cosh ^{-1}(1 / \mathcal{E})
$$

These equations for steady-state dissolution rate help focus on the principal parameters that control dissolution rate. It is also important to examine the higher releage rates that occur before steady state is reached and that can occur with radioactive species, as predicted by the exact analytical solutions [Chambré et al. 1982].

\subsubsection{Diffuilre-Adrectire}

Chambre et al. [1982] have also developed the exact analytic solution for mass transfer when both diffusive and convective transport are important. The mathematical analysis makes use of the known distribution of ground water velocities around an infinite cylinder and through the pores of the surrounding rock. An asymptotic form of that analytical solution, applicable to ateady-state mass transfer of a solubility-limited stable species with steady flow around a long waste cylinder of radius $R_{1}$ surrounded by porous rock, and ussuming constiant saturation concentration $c_{2}$ in the liquid at the waste surface meaning $c\left(R_{1}\right)=c_{a}$, is

$$
f=\frac{8 \epsilon c_{s}(D U)^{\frac{1}{2}}\left(1+R_{1} / L\right)}{\left(\pi R_{1}\right)^{\frac{3}{3}} \mathcal{N}}, \mathrm{Pe}>4
$$

where $\mathrm{Pe}$ is the Peclet number, given by

$$
\mathrm{F}_{\mathrm{t}}=\frac{U R}{D}
$$

Here $U$ is the ground-water pore velocity upstream of the waste solid, and $L$ is the length of the waste cylinder. The other boundary condition is $c(\infty)=0$. The analytical solution does not depend on boundarylayer approximations.

Equations for the steady-state dissolution rate that are similar in form, but not icientical, to Eq. (2.1.1.2.1) have been obtained by others [Neretnieks 1978; Kerrisk 1984; 1985; Scott and Koplik 1984] using boundary-layer approximations. However, only the exact time-dependent solution provides a criterion of validity of the asymptotic steady-state equation. Ignoring the limit of validity and applying the steady-state asymptotic equation, or its equivalent [Kerrisk 1984; 1985; Scott and Koplik 1984], to predict mass transfer rate at the very low velocities expected in wet-rock repositories is not valid and will give nonconservatively low estimates of the dissolution rate.

Correct and incorrect predictions of fractional dissolution rate over a wide range of Peclet numbers are illustrated in Figure 2.2, calculated for solubility-limited mass transfer. The values at near-zero velocity have been calculated from the equations for diffusion from a prolate spheroid, with dimensions that approximate a finite cylinder. Incorrect extrapolation of the $\mathrm{Pe}^{1 / 2}$ dependency from the high Pe region to the pore velocities of a few millimeters per year, expected in the tuff and basalt repositories, can result in underestimates of the release rate by everal orders of magnitude.

For an assumed waste radius of $15 \mathrm{~cm}$ and an upper-limit value of the diffusion coefficient of $10^{-6}$ $\mathrm{cm}^{2} / \mathrm{s}$, which neglects tortuosity corrections, the ground-water pore velocity must be about $1 \mathrm{~m} / \mathrm{a}$ or greater for the steady-state equation to be applicable. For lcwer velocities the equation for diffusion-controlled release is applicable. 


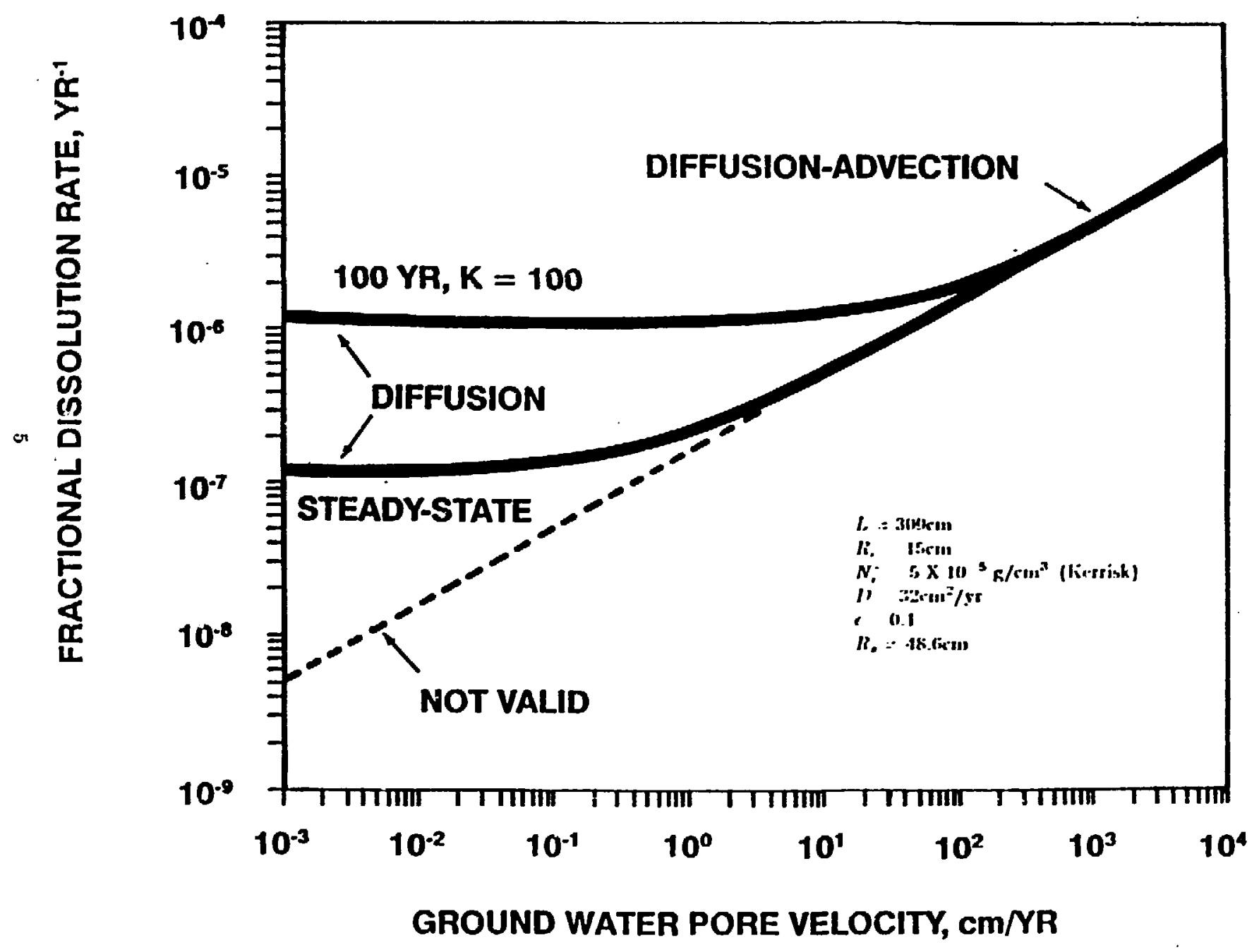

Figure 2.2 Valid and Invalid Extensions of Dissolution Rate as Function of Ground-Water Velocity 


\subsubsection{Translent Resulte}

Time-dependent mass transfer rates have been obtained for both diffusive-advective systems and diffusion-dominated systems.

\subsubsection{Diffusire-Adrectlve}

Chambré and Pigford [1984] give the following equation for the time-dependent mass transfer rate per unit length of an infinite cylinder for a radioactive species with a constant-concentration boundary condition, provided the Peclet nun:ber is greater than 4

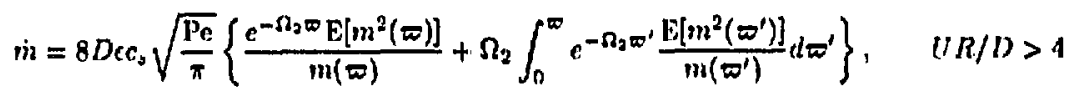

where

$\Omega_{2}=K \lambda R / U$ is the Thiele modulus for convective mass transport, and

$\mathbf{E}(x)$ is the complete elliptic integral of the second kind, and

$m(\varpi)=\sqrt{1-\exp (-4 \sigma)}$ and $\sigma=U t / K R$

The equation for the time-dependent fractional rslease rate for a long cylinder in ground water where the Peclet number is greater than 4 is

$$
f=\frac{8 \epsilon c_{3} \sqrt{D U}(1+R / L)}{(\pi R)^{3 / 2} \mathcal{N}}\left\{\frac{e^{-\lambda t} \mathrm{E}\left[m^{2}(\varpi)\right]}{m(\varpi)}+\Omega_{2} \int_{0}^{\varpi} e^{-\Omega_{2} \varpi^{\prime}} \frac{\mathrm{E}\left[m^{2}\left(\varpi^{\prime}\right)\right]}{m\left(\varpi^{\prime}\right)} d \varpi^{\prime}\right\}, \quad U R / D>4
$$

Typical results for a waste solid surrounded by porous rock, with ground water flowing at pore velocity of $1 \mathrm{~m} / \mathrm{a}$, are shown in Figure 2.3, where the normalized fra .ional dissolution rate $f / c$, for a stable species is plotted against the time since the waste is first exposed to ground water at the waste surface.

The early rate of mass transfer will be high, and it will decrease as the concentration profile penetrates farther from the waste surface. With no decay, and for the parameters chosen for Figure 2.3, steady state is reached in as little as a year or not until a few hundred years, depending on the magnitude of the retardation coefficient $K$. Greater sorption retardation increases the time to steady state, and it increases the transient dissolution rate because sorption steepens the transient concentration gradient. Advective transport shortens the time :o reach steady state.

Radioactive decay can increase the rate of mass transfer by steepening the concentration gradiant near the waste surface. This is shown in Figure 2.4 by curves for various values of the modified Thiele modulus $\Omega_{2}$. Increasing the Thiele modulus from zero, to 10 for no decay causes a nore than fourfold increase in the steady-state dissolution sate, and it decreases the time to reach steady state. For a mixture of atable and unstable isotopes of a given element, the appropriale half life is the effective half life of the isotcpic mixture at the time the decay correction is to be applied. Decay corrections are more important when mass transfer is controlled by diffusion, i.e., when the pore velocity is so low that convection does nut affect dissoiution.

\subsubsection{Diffusive}

Chambré et al. [1985] have obtained the trancient solution for mass transfer from prolate spheroids ineluding spheres and cylinders, over all times of interest. The complete solution is complicated, and the 


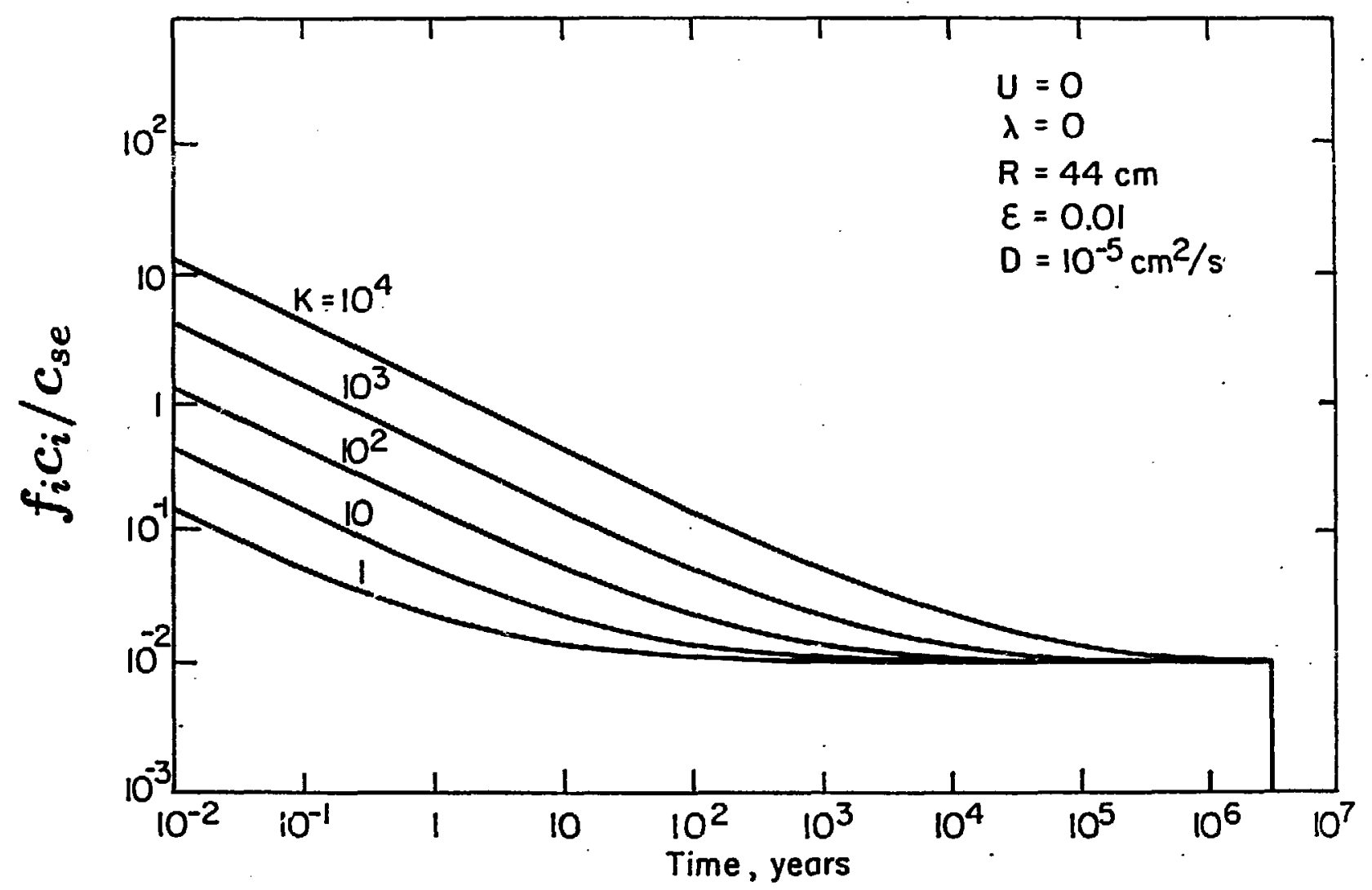

Figure 2.3 Normalized Mass-transfer Rate as a Function of Time and Retariation Coefficient, Diffusion from a Waste Sphere 


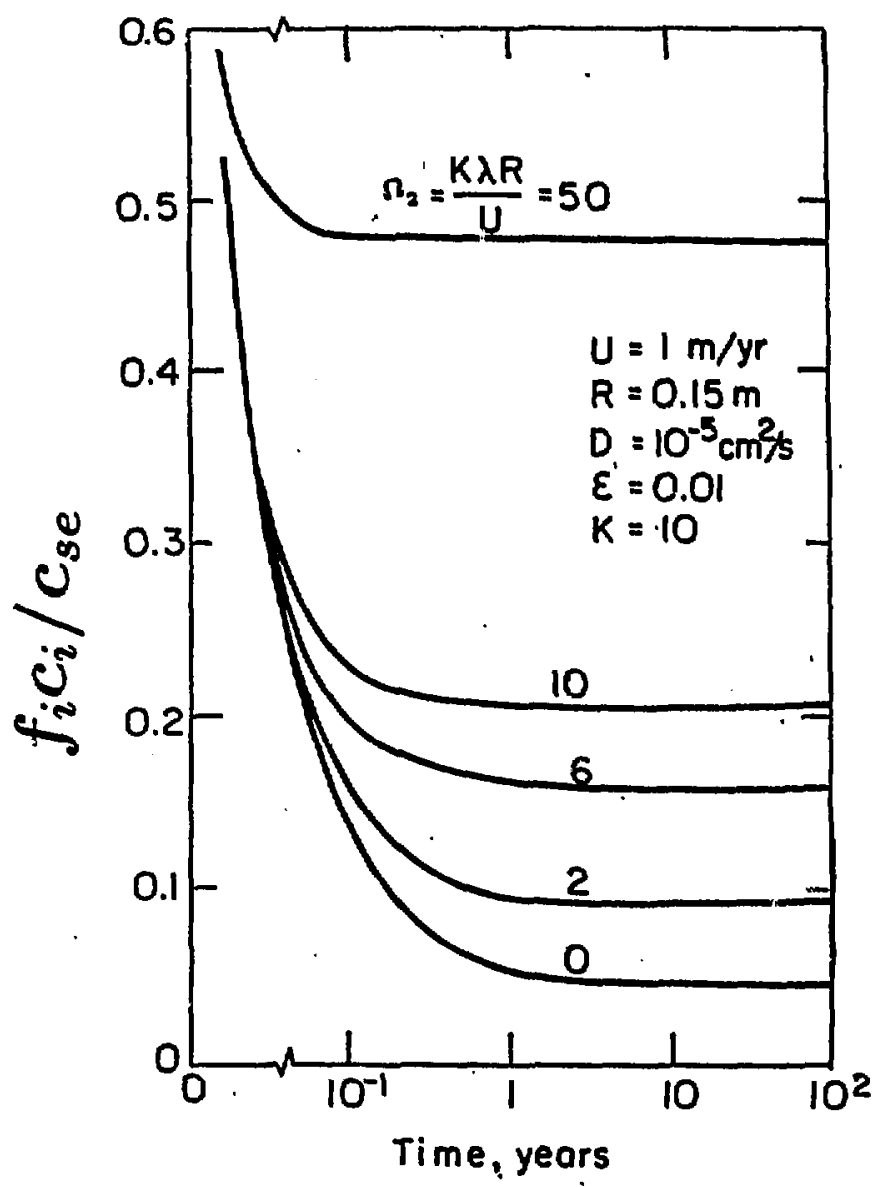

Figure 2.4 Normalixed Mass-transfer Rate as a Function of Time and Damkbhler Number, Flow around a Waste Cylinder 
governing equations are in prolate spheroid coordinales. Therefore, only the results for a sphere will be shown here. The surface mass fux from the waste sphere for a stable species is

$$
\dot{m}(t, 0)=\frac{D \epsilon c_{2}}{R}\left\{\sqrt{\frac{K R^{2}}{\pi D t}}+1\right\}, \quad t>0
$$

\subsection{Diseolution from Waste Into Rock: solld-Lquid Reactlon Rate}

The analytical solutions discussed above for solubility-limited mass transfer have a clear meaning for a single-component waste solid that has a well-defined solubility appropriate to the chemical environment at the waste surface. Solubility is a conservative upper-limit boundary concentration, if effects of colloids can be neglected. The result is a bounding estimate of the release rate from the waste solid and is not dependent on the particular chemical form of the wate solid unless that chemical form itself affects the solubility of the single-component species. Effects on other constituents within the waste solid will be discussed later.

In many studies it has been aseumed that waste formu can be developed that will perform better in a repository because of low rates of chemical reaction of the waste solid with ground water. The proposition is reasonable but has been made without quantification of the effect of chemical reaction rate on the performance of a waste solid in a repository. In the mass-transfer analyses discussed above for solubility-limited species, it has been implicitly assumed that the solid-liquid reaction rate is rapid enough so that the dissolved material is at, or very near, the solubility limit at the waste surface. Actual chemical reaction rates do not enter those analyses, and the bounding results are not affected by factors which can affect solid-liquid reaction rate, such as interior cracks in the waste solid, devitrification if a glass, and other such mechaniams that could increase the surface area for solid- liquid reactions.

To illustrate an approach to determine the effect of solid-liquid reaction rate on the rate of mass transfer to ground water in a geological environment, Zavoshy et al. [1985] developed the analytical solution for the rate of diffusive mass transfer of a dissolved waste into surrounding porous rock, using chemical reaction rate as a boundary condition instead of assuming a solubility-limit boundary concentration. Leach-rate data [Pederson, Euckwalter and McVay 1983] for borosilicate glass waste suggest that the solid-liquid reaction rate can be approximated by zero-order forward reaction and a back reaction that is first order with respect to the concentration of dissolved silica. Assuming low ground-water velocity so that mass transfer is controlled by diffusion, the governing equation for diffusive mass transfer is

$$
K \frac{\partial c}{\partial t}=D \frac{1}{r^{2}} \frac{\partial}{\partial r}\left(r^{2} \frac{\partial c}{\partial r}\right), \quad t>0, R<r<\infty
$$

with the initial condition

$$
c(r, 0)=0, \quad R<r<\infty
$$

The continuily boundary condition at the waste-liquid interface in a repository specifies that the current of dissolved species at the waste surface equal the net rate of dissolution by solid-liquid reaction. Assuming that the reaction rate is given by a zero-order forward reaction and a first-order back reaction.

$$
-c D \frac{\partial c(R, t)}{\partial r}=j_{0}\left(1-\frac{c(R, t)}{c_{2}}\right), \quad t>0
$$


where $j_{0}$ is the experimental forward reaction rate of the dissolved species per unit surface area. The forward reaction rate is measured when the surface is in contact with a liquid that contains none of the dissolved species being considered in Eq. (2.2.1).

Using the above boundary condition together with the diffusion equation and with the other side condition $c(\infty, t)=0, t>0$, we obtain the time-dependent concentration $c(R, \tau)$ in the liquid adjacent to the outer surface of the waste

$$
c(R, \tau)=c_{\mathrm{J}} \frac{\alpha\left(1-e^{\tau} \operatorname{erfc} \sqrt{ } \tau\right)}{1+\alpha}
$$

and the time-dependent rate of mass transfer into the rock at $R$

$$
j\left(r_{0}, \tau\right)=j_{0} \frac{1+\alpha e^{\tau} \text { erfc } \sqrt{ } r}{1+\alpha}
$$

where the dimensionless time $r$ is defined as

$$
\tau \equiv \frac{(1+\alpha)^{2} D t}{K R^{2}}
$$

The dimensionless "flux ratio" $\alpha$ is defined as

$$
\alpha=\frac{j_{0} R}{\epsilon D c_{2}}
$$

and can be interpreted as

$$
\alpha=\frac{\text { forward reaction rate per unit area at } R}{\text { steady - state diffusive mass transfer rate at } R}
$$

We can interpret the forward reaction rate $j_{0}$ in terms of a reaction-rate constant $k_{2}$

$$
j_{0}=k_{2} c_{\text {。 }}
$$

which results in

$$
\alpha=\frac{k_{2} R}{\epsilon D}
$$

Thus $\alpha$ is a Thiele modulus.

At steady state the concentration and mass-transfer rate at the surface are

$$
c(R, \infty)=c, \frac{\alpha}{1+\alpha}
$$

and

$$
j(R, \infty)=\frac{j_{0}}{1+\alpha}
$$

Eq. (2.2.11) and (2.2.12) show that when the fux ratio $\alpha$ is large $c(R, \infty)=c_{\text {, }}$ and $j(R, \infty) \approx c D c_{s} / \alpha$. Under these conditions the net dissolution rate is controlled by diffusion in the exterior field. When $\alpha \ll 1$ the surface concentration $c(R, \infty)$ is much less then the saturation concentration, and the net mass-transfer rate is controlled by the solid-liquid reaction and is equal to $j_{0}$. For intermediate values of $\alpha$ one must use Eq. (2.2.11) and (2.2.12). 


\section{Near-fold Mane Tranofor}

Another quantify of interest is the time $t$, necessary for the mass flux at the surface to reach within five percent of the steady-state value. From Equation (2.2.6) it is found that

$$
t_{s}= \begin{cases}0 & \text { for } \alpha \leq 0.01 \\ 4 \times 10^{2} K R^{2} / \pi D & \text { for } \alpha>1\end{cases}
$$

Chambre has shown that if radioactive decay is included in Eq. (2.2.1) the above results are affected by both decay and retardation. The analysis of the surface concentration and dissolution rale, including the effects of species decay within the waste form, has also been treated.

The normalized dissolution rais $j(R, \tau) / j_{0}$ and the normalized surface concentration $c(R, \tau) / c_{2}$ are shown in Figure 2.5 as a function of the dimensionless time $\tau$ and the dimensionless parameter $\alpha$.

To illustrate, we assume a waste glass cylinder of radius $0.15 \mathrm{~m}$ and length $2.4 \mathrm{~m}$, resulting in an equivalent sphere of radius $0.44 \mathrm{~m}$. From the laboratory leach data of Pederson et al. [1983] for PNI 76-68 borosilicate glase we derive the following effective values for silica at $00 \mathrm{C}$

$$
\begin{gathered}
j_{0}=1.18 \mathrm{~g} \mathrm{SiO}_{2} / \mathrm{m}^{2}-\text { day } \\
c_{8}=200 \mathrm{~g} \mathrm{SiO} 2 / \mathrm{m}^{3}
\end{gathered}
$$

For an estimated diffusion coefficient of silicic acid in water at $90 \mathrm{C}$ of $2 \times 10^{-2} \mathrm{~m}^{2} / \mathrm{d}$ and neglecting tortuosity corrections, and for rock porosity of 0.01 , we estimate $\alpha_{\mathrm{SiO}_{2}}=1240$. Assuming no sorption of silica on the rock $(K=1)$, the estimated time to steady state is 320 years. From Eq. $(2.2 .11) c(R, \infty)=0.999 c$, for silica. The steady-state mass transfer of silica will be controlled by exterior-field diffusion, and assuming saturation concentration $c_{\mathrm{d}}$ of silica at the waste surface is not only conservative but is also realistic.

Figure 2.6 shows the normalized surface mase flux of silica and the normalized surface concentration as a function of the dimensionless time and chronolozical time $t$. Also shown are the resulta predicted by assuming that saturation concentration always exists in the surface liquid, as in our earlier conservative estimates of mass-transfer rate in Section 2.1.2. For assumed constant saturation the early mass-transfer rate is infinite, a result not physically reasonable. It is in these early times that the solid-liquid reaction rate is important for the discolution of a low-solubility solid matrix. The actual surface concentration is initially zero, and it grows with time at a inite rate delermined by the solid-liquid reaction rate. Within about seven minutes after bare glass waste has been placed in contact with saturated rock $(\epsilon=0.01)$ the concentration of silica in the surface liquid will have reached 82 percent of saturation and the mass-transfer rate will be within 5 percent of that predicted for constant saturation at the surface, assuming no silica sorption in the rock. If silica sorbs with an assumed retardation coefficient of 100 , this time is increased to 700 minutes.

The time to reach near-saturation concentration will be longer if there is stagnant liquid between the waste surface and the exterior porous medium. This time delay is easily added to the theory because the intervening liquid is likely to be well mixed.

Van Iuik et al. [1987] list values of $j_{0}$ for unirradiated and irradiated $\mathrm{UO}_{2}$ in deionized water and in brine at various temperatures. They adopt a conservatively low value of

$$
j_{0}=0.005 \mathrm{~g} / \mathrm{m}^{2}-\mathrm{day}
$$




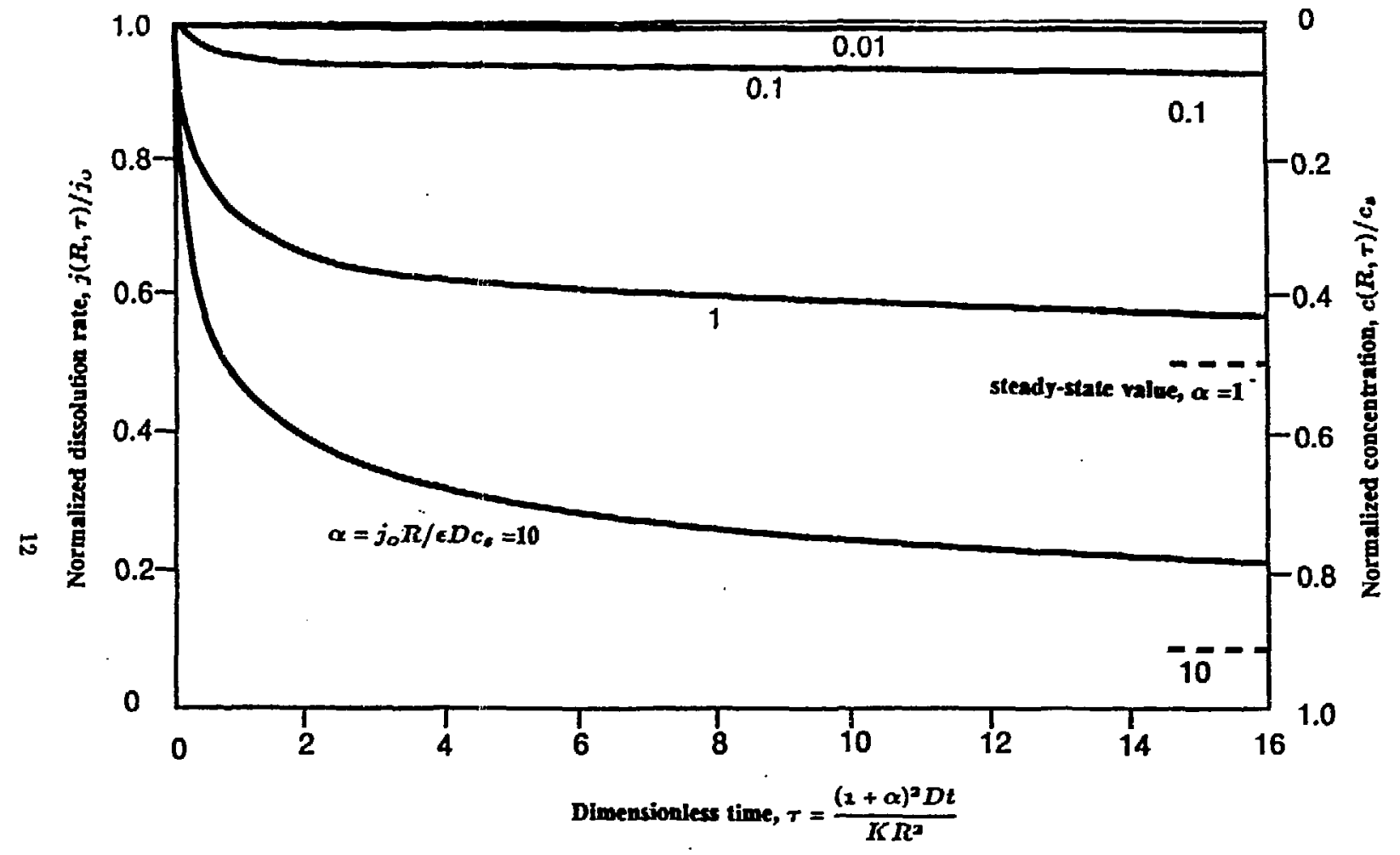

Figure 2.5 Normallzed Dissolution Rate and Surface-Liquid Concentration as a Function of Dimensionless Time for Various Values of the Flux Ratio 


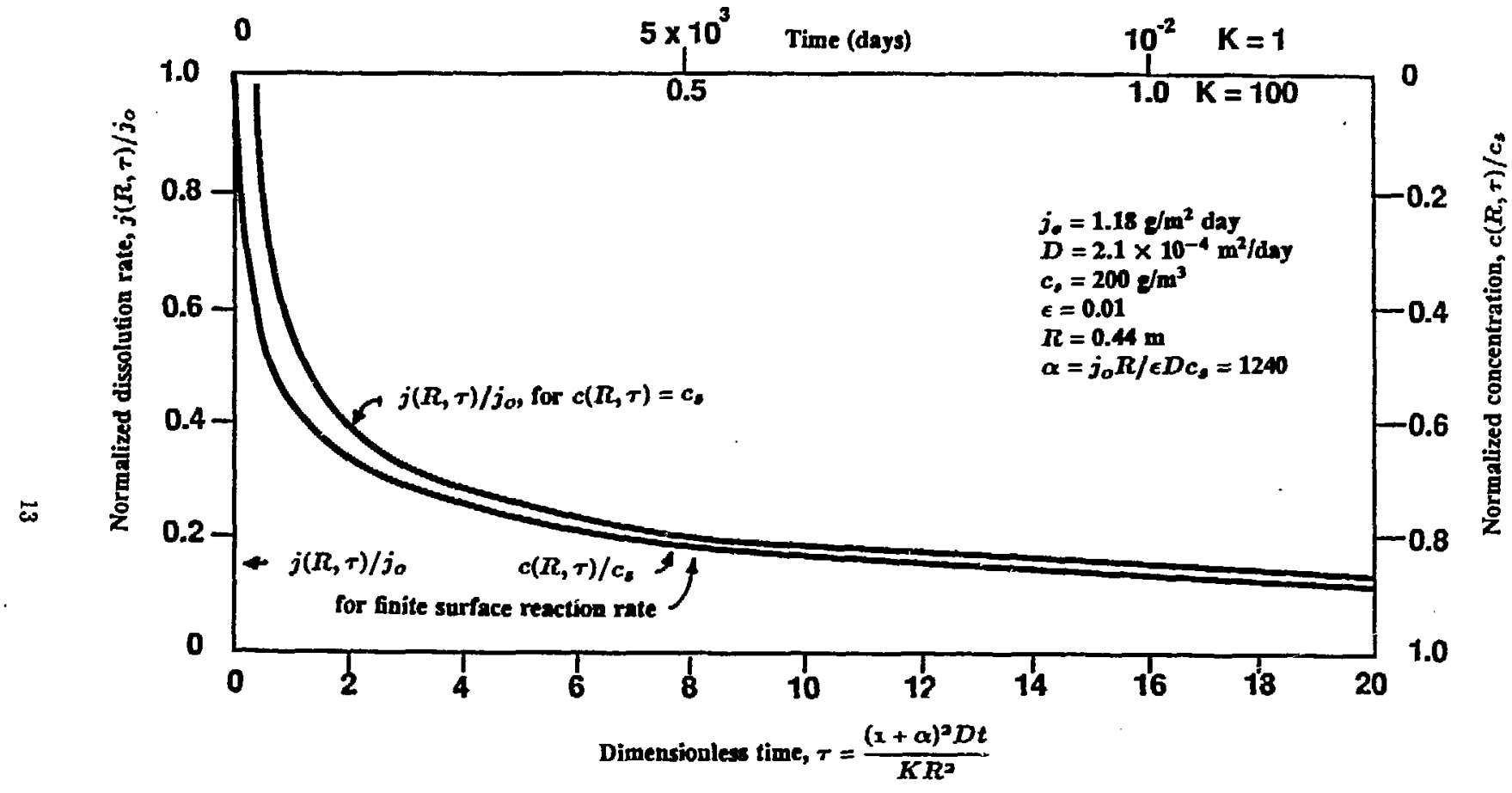

Figure 2.6 Normalized Dissolution Rate and Surface-Liquid Concentration of Sillica from Borosilicate Glass as a Function of Time, Compared with Dissolution Rate for Constant Saturation Concentration at the Surface 
Assuming that uranium dissolution obeys a simple concentration dependence as described in Eq. (2.2.3), adopting uranium solubilities ranging from $2 \times 10^{-2} \mathrm{~g} / \mathrm{m}^{3}$ at $\mathrm{pH} 11$ to $2 \times 10^{-8} \mathrm{~g} / \mathrm{m}^{3}$ at $\mathrm{pH} 6$ [van Luik et al. 1987, $\mathrm{p}$ 4.77], and for other parameters the same as used in the above example for silica, we obtain an estimated flux ratio for the spent-fuel matrix

$$
\alpha=5 \times 10^{4} \text { to } 5 \times 10^{10}
$$

which is abcut one to seven orders of magnitude greater than that estimated for silica from borosilicate glass. If these data are correct, uranium dissolution in a basalt or granite repository is likely to be controlled by exterior-field mass transfer and not by chernical reaction rate. More data are needed on solid-liquid reaction rate as a function of concentration of dissolved uranium and of temperature.

A more recent result [Chambré et al. 1988] shows the relationship between steady-state mass transfer from a spherical wate solid, the exterior flow field and chemical reaction or leaching rate. The steady-state governing equation is

$$
v \frac{d c}{d r}=D \frac{1}{r^{2}} \frac{d}{d r}\left(r^{2} \frac{d c}{d r}\right), \quad R<r<\infty
$$

The boundary and initial conditions of (2.2.2) and (2.2.3) apply. The result relates the Sherwood number, $\mathrm{Sh}$, and the Peclet number, Pe, with the square of the Thiele modulus, $\alpha$, which is defined as the ratio of the forward reaction rate per unit area at $R$ to the oteady-state diffusive mass-transfer rate per unit area at $R$.

$$
\begin{aligned}
\mathrm{Sh} & =\frac{h R}{\epsilon D} \\
\mathrm{Pe} & =\frac{U R}{D} \\
\alpha & =\frac{j_{0} R}{\epsilon D c_{0}}
\end{aligned}
$$

Here $h$ is the mass-transfer coefficient for the opherical waste surface

$$
h=\frac{j(R, \infty)}{c(R, \infty)-c(\infty)}
$$

where $c(\infty)$ is the ambient concentration of the diasolving constituent in ground water, here taken to be zero. The following interpolation formula is valid for the entire range of Peclet numbers.

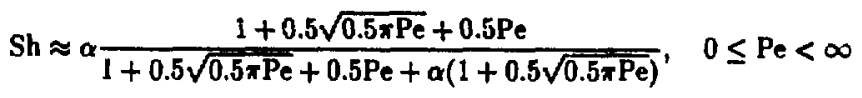

This formula has been tested by comparing it with two other solution methods and shown to provide predictions reasonably close to the other methods. For very small Peclet, when advection is unimportant, the Sherwood number becomes

$$
S h \rightarrow \frac{\alpha}{1+\alpha}, \quad \operatorname{Pe} \rightarrow 0
$$

When the Peclet numbers are very large,

$$
\mathrm{Sh} \rightarrow \alpha, \quad \mathrm{Pe} \rightarrow \infty
$$

Figure 2.7 shows the Sherwood number as a function of the Peclet number, for various values of the square of the modified Thiele modulus $\alpha$, obtained by the interpolation formula, Eq. (2.2.18) and an integral 


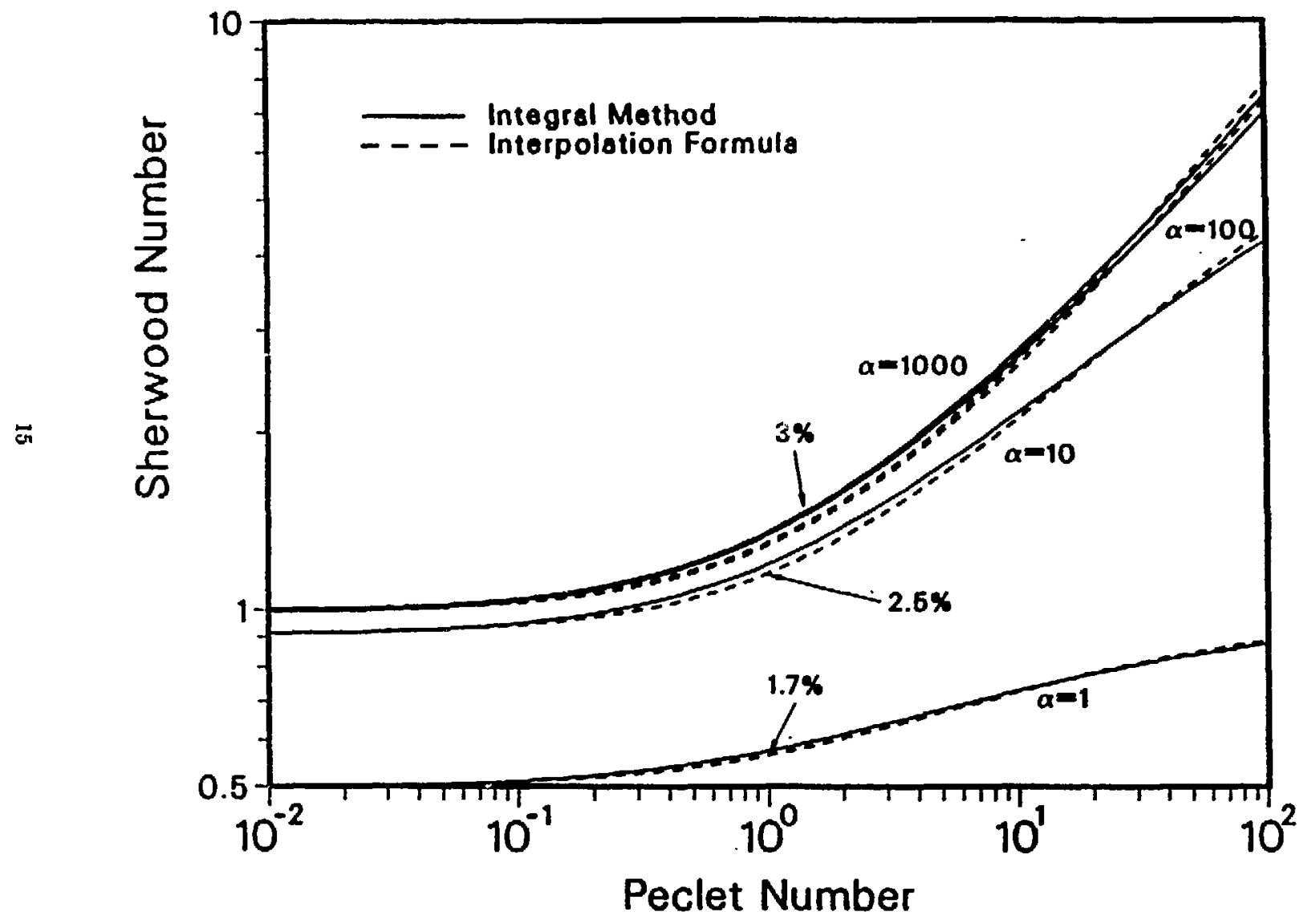

Figure 2.7 The Sherwood Number as a Function of the Peclet Number by Two Methods 
approximation method. In the range of $0.01 \leq \mathrm{Pe} \leq 1$ it can be seen that the Sherwood number is almost constant for fixed values of $\alpha$, see Eq. (2.2.19). In this same range of Peclet number, a hundred-fold increase in $\alpha$, say from 10 to 1,000 , results in only a 10 per cent increase in Sherwood number. At $P e=100$, increasing $\alpha$ from 10 to 1,000 almost doubles the mass-transfer rate. For $40<\mathrm{Pe}<10^{8}$, well outside the range of Peclet numbers and flow speeds anticipated in geologic repositories, and for values of $\alpha$ of about 100 and greater, the Sherwood number is approximately proportional to the square root of the Peclet number, showing that diffusive-advective mass-transfer controls [Chambré et al. 1982]. At even larger Pe, see Eq. (2.2.20), well beyond the range of this figure, the curves level out when the exterior-field mass-transfer is so intense that chemical reaction rate controls the dissolution rate. For $\alpha=1$, as can obtain for small separated graius of a dissolving solid or for dissolution at very low temperature, chemical reaction rate reduces the influence on the modified Sherwood number over the entire range of $P e$ and causes the dissolution rate to be less affected by advective transport.

For the ground-water velocities, wate dimensions, and temperatures expected in geologic repositorjes, the steady-state dissolution of borosilicate glass is predicted to be controlled by exterior field mass transfer. The ground-water velocities required for chemical-reaction rate of borosilicate glass to control dissolution rate are far beyond any ressonably expected in a repository. Chemical reaction rate and rate of diffusion from a borosilicate glass waste form $c$ an control the dissolution rate at temperatures much lower than are expected in a nuclear waste repository, i.e., when $\alpha \leq 1$. Preliminary data indicate that similar conclusions may be applicable for spent fuel, but more data are needed on solid-liquid reaction rate as a function of concentration of dissolved uranium and of temperature.

\subsection{Mass Transfer from Waste Into Bachall and Rock}

\subsubsection{Transient Diffunlon-Controlled Dissolution}

In many nuclear waste repositories, a backfill layer of low-permeability material is part of the engineered barrier system. The backfill layer is assumed to be sufficiently impermeable that liquid in backfill pores is stagnant. More recently analysis of this problem with flow in backfill as well as in rock has been completed at Berkeley [Chambré, Kang and Pigford 1986; Kang 1989]. We summarize here the analysis for a sphericalequivalent waste, and for a diffusive environment only [Chambre, Lung and Pigford 1984; Chambré et al. 1985]. The analytic solutions give the iime-dependent species concentrations and fluxes, from which steadystate conditions are readily obtained. The waste is a sphere of radius $R$, surrounded by a layer of backfill of thickness $b=R_{0}-R$. At the waste surface, a constant species concentration $c_{\text {, }}$ is specified. The subscript 1 refers to the backfill layer, and the subscript 2 refers to the rock layer. The porosities of the layers are denoted by $\epsilon$ and the species concentration in ground water in the layers are $c_{1}$ and $c_{2}$ respectively.

By defining $\nabla^{2}=\frac{\partial^{2}}{\partial r^{2}}+\frac{2}{r} \frac{\partial}{\partial r}$ we can write the governing equations as

$$
\begin{array}{ll}
\frac{\partial c_{1}}{\partial t}=D_{1} \nabla^{2} c_{1}-\lambda c_{1}, & R<r<R_{0}, t>0, D_{1}=\frac{\sigma_{1} D_{f}}{K_{1}} \\
\frac{\partial c_{2}}{\partial t}=D_{2} \nabla^{2} c_{2}-\lambda c_{2}, & R_{0}<r<\infty, t>0, D_{2}=\frac{\sigma_{2} D_{f}}{K_{2}}
\end{array}
$$

where $D_{f}$ is the diffusion coefficient in a liquid continuum and $\sigma_{1}$ and $\sigma_{2}$ are tortuosity correction factors. The side conditions are

$$
c_{1}(r, 0)=0, \quad R_{o}<r \leq R,
$$




$$
\begin{aligned}
& \text { Near-ield Mee Tramior } \\
c_{2}(r, 0) & =0, \quad R_{0} \leq r<\infty \\
c_{1}(R, t) & =c_{3}, \quad t \geq 0 \\
c_{1}\left(R_{0}, t\right) & =c_{2}\left(R_{0}, t\right), \quad \quad t \geq 0 \\
-\epsilon_{1} \sigma_{2} D_{f} \frac{\partial c_{1}}{\partial r} & =-\epsilon_{2} \sigma_{2} D_{f} \frac{\partial c_{2}}{\partial r} \quad \text { at } \quad r=R_{0}, \quad t \geq 0 \\
c_{2}(\infty, t) & =0, \quad t \geq 0
\end{aligned}
$$

The solution to (2.3.1.1) through (2.3.1.8) is given in Chambrè et al. [1985]

$$
\frac{c_{1}(r, t)}{c_{1}}=f(r)+\int_{0}^{\infty} \frac{I(r, \eta)}{1+\frac{D_{1} \eta^{2}}{\lambda}} d \eta+e^{-\lambda t} \int_{0}^{\infty} \frac{e^{-D_{1}\left(\eta^{2}\right.}}{1+\left(\frac{\lambda}{D_{1} \eta^{2}}\right)} I(r, \eta) d \eta, \quad R \leq r \leq R_{0}, t \geq 0
$$

where

$$
\begin{gathered}
\left.\left.f(r)=\frac{R}{r} \frac{1+\delta\left(r / R_{0}\right)}{1+\delta\left(R / R_{0}\right)}, \quad I(r, \eta)=-\left(\frac{2 R \epsilon_{1}^{\prime} \epsilon_{2}^{\prime} \beta_{1}}{\pi r}\right) \frac{\eta \sin (\eta[r}{H(\eta)}-R\right]\right) \\
H(\eta)=\left[\epsilon_{1}^{\prime} \eta \cos (\eta b)+\frac{\epsilon_{2}^{\prime}-\epsilon_{1}^{\prime}}{R_{0}} \sin (\eta b)\right]^{2}+\left[\beta_{1} \epsilon_{2}^{\prime} \eta \sin (\eta b)\right]^{2} \quad \beta_{1}=\sqrt{K_{3}^{\prime} / K_{1}^{\prime}} \\
K_{\ell}^{\prime}=K_{\ell} / \sigma_{\ell}, \quad \delta=\frac{\epsilon_{2}^{\prime}-\epsilon_{1}^{\prime}}{\epsilon_{2}^{\prime}} \\
\epsilon_{\ell}^{\prime}=\epsilon_{\ell} / \sigma_{\ell}, \quad \ell=1,2
\end{gathered}
$$

If $\lambda=0$ in (2.3.1.9), we obtain the solution for a stable species.

The above equations are applicable for a radioactive species with no decay precursor and for diffusiondominated mass transfer through the backfill and the surrounding porous rock.

With the concentration profile $c(r, t)$ known, the surface mass fluxes $\epsilon \sigma D, \frac{\partial c}{\partial r}$ at the waste surface and at the backfill/rock interface can be computed. A computer program, UCB-NE-101 [Lee 1989a] implements eq. (2.3.1.9) and is available from the National Energy Software Center.

Illustrative results [Chambré et al. 1985] for species limited by solubility are shown in Figures 2.82.10. Figure 2.8 shows the time-dependent mass transfer rate (mass/time) of a stable species divided by the saturation concentration of that species, assumed to exist at the inner surface of the backfill. $A$ similar norl..alized rate of mass transfer across the backfill-rock interface is shown by the broken curves. A retardation coefficient of 1000 is assumed for backfill and rock. Curves for two values of the backfill porosity are shown, corresponding to backfill-to-rock porosity ratios of unity and 20. During the early times of the transient the higher backfill porosity greatly increases the dissolution rate, because the early resistance to mass transfer is entirely within the backfill. The mass-transfer rate into the rock closely approaches that into the backfill after about 104 years, and steady state is reached after about $10^{5}$ years. The steady-state mass transfer rate is little affected by backfill porosity, as demonstrated in Figure 2.9.

Figure 2.9 shows the effect of retardation on mass transfer rate of a stable species, for a backfillto-rock porosity ratio of 20 . Retardation increases with increasing sorption, which sleepens the transient concentration gradient and increases the rate of diffusive mass transfer. Steady-state rates of mass transfer are not affected. For a given backfill retardation, increasing sorplion by rock increases the maximum rate of mass transfer into the rock, showing that the rock properties and finite backfill must be included in the 


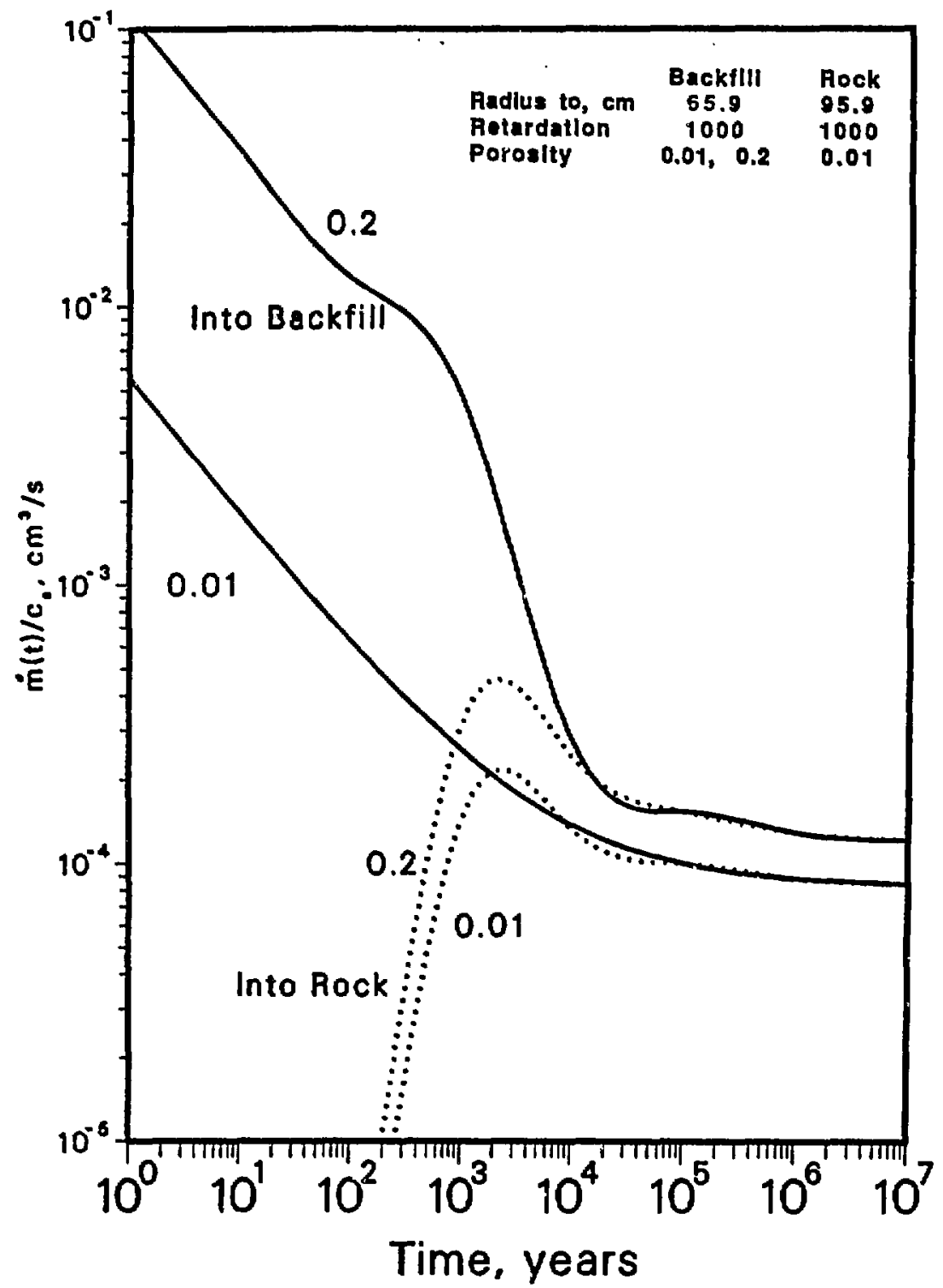

Figure 2.8. Normalized mass-transfer rate as a function of time and backill porosity 


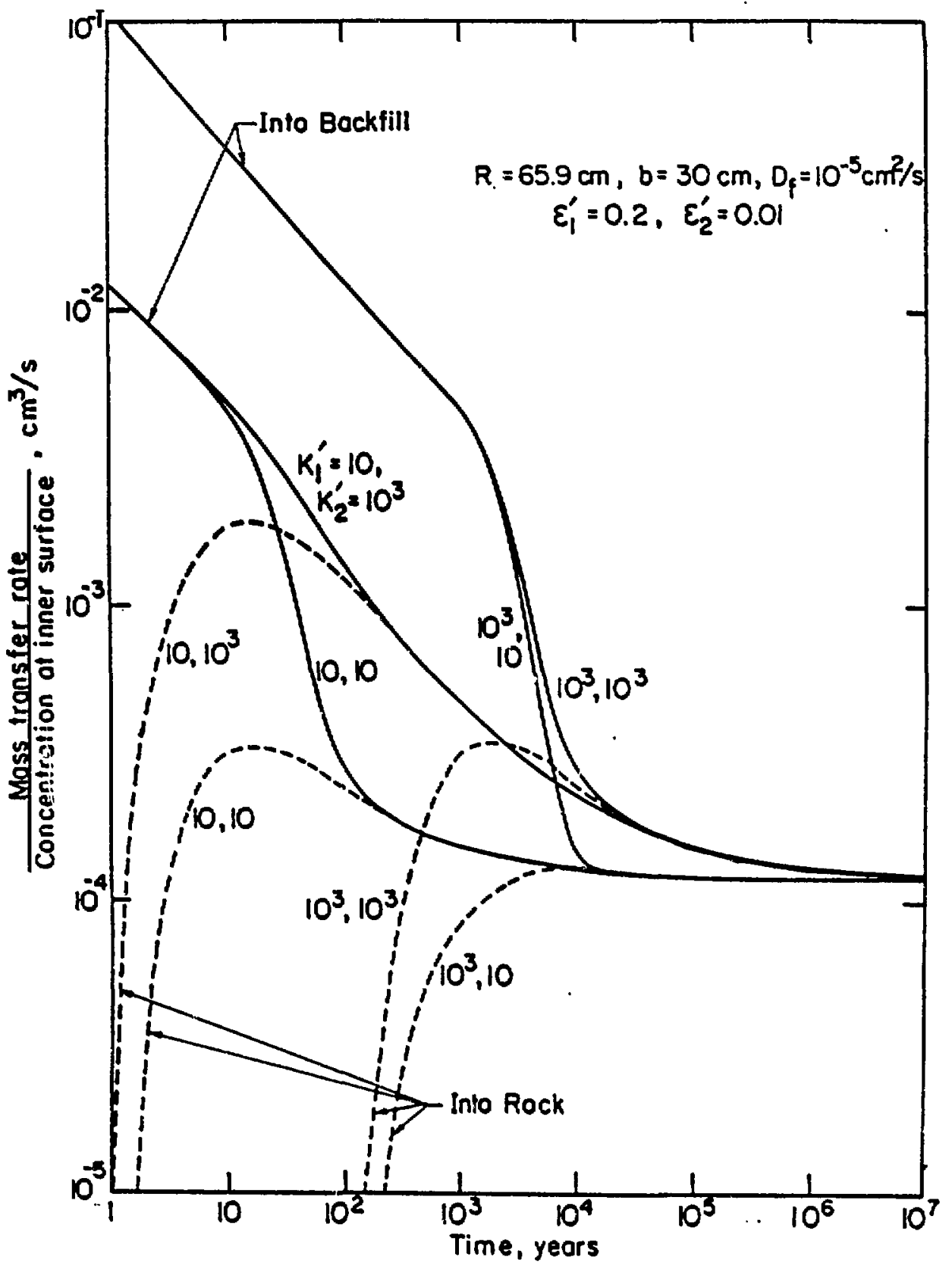

Figure 2.9 Normalized Mass Transfer Rate by Diffusion from a Waste Sphere as a Function of Time and Retardation Coefficient 


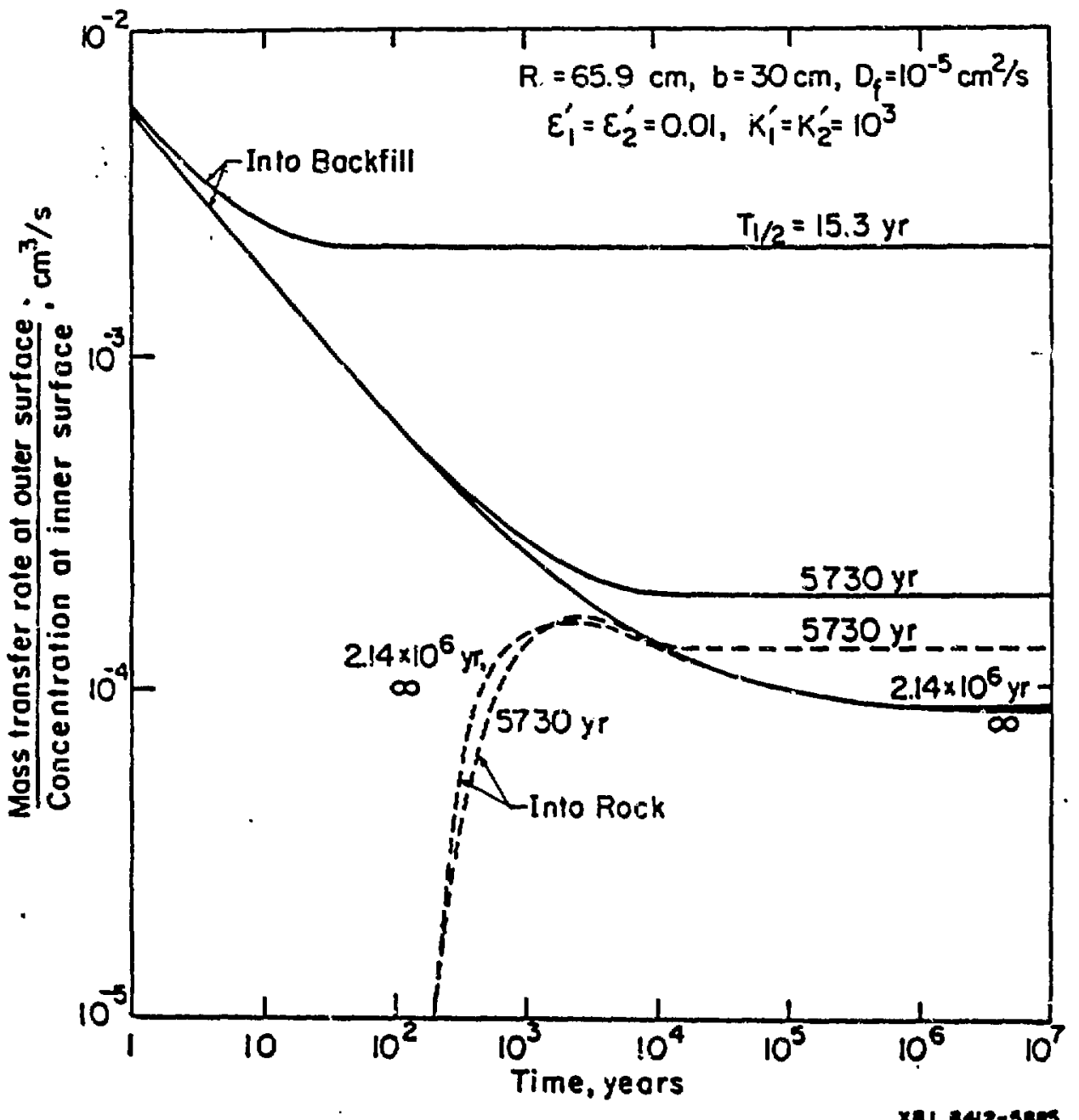

Figure 2.10 Normalized Mass Transfer Rate by Diffusion from a Waste Sphere as a Function of Time and Half Life 


\section{Noer-fold Man Tranufer}

analysis, as has been done here. The time for the maximum rate of mass transfer into the rock depends mainly on the backfill retardation, for the parameters assumed here.

Figure 2.10 shows the effect of radioactive decay on the time-dependent mass transfer rate for various assumed half lives of the diffusing species. For neptunium-237, with a half life of $2.1 \times 10^{6}$ years, corrections for decay are minor. For ${ }^{14} \mathrm{C}$, with a half life of 5730 years, decay not only increases the rate of mass transfer into the backfill, because it steepens the concentration profile, but it also increases the transient and steady-state rates of mass transier into the rock. For a radionuclide half life as short as 15.3 years, decay considerably increases the mass transfer rate into the backfill, but the half life is short enough that the species all decays while diffusing in the backfill. Thus, there is a range of half lives for which the rate of mass transfer into the rock is greater than the steady-state value for no decay. As illustrated liere for ${ }^{14} \mathrm{C}$, some radionuclides important in repository performance analysis will fall within this range.

Previous backfill analyses [Nowak 1979; Alin el al. 1982a, b] have calculaled the "breakthrough" time for a stable species at a specified distance in infinile backfill and have used that time to estimale the amount of radioactive decay that will occur during diffusion through finite backfill in a reposilory. This has led to considerable overestimates of the posible retention of radionuclides in backfill, as has bcen demonstrated in Figure 2.10 for ${ }^{14} \mathrm{C}$. Mass-transfer analysis that take into account the diffusive properties of the rock should be used to predict releave of radionuclides through finite backfill.

\subsubsection{Bteady-State Mase Trancfor Through Backell into Mowing Ground Water}

For the case of a waste container surrounded by a backfill layer in flowing ground water, we give a solution of the steady-state tinass transfer rate for a stable species. Here the wasle is approximated by a prolate spheroid with a semiminor axis $b_{1}$ at the backfill/rock interface, as shown in the insert in Figure 2.11. The prolate spheroid coordinate is $p$, defined in eq.( 2.1.1.1.4), and $p=p$, is the location of the inner surface of the backfill and $p=p_{I}$ is the interface of the backfill and the rock. The species is at solubility $c$, ut the surface of the container. The backfill is asumed to be suficiently impermeable that liquid in the backfill pores is stagnant. Ground water flows at a velocity $U$ in the porous rock. The mass transfer rate is

$$
\dot{m}=\frac{4 \pi c_{1} c_{2} \sigma_{2} D_{j} b_{1}}{\left(\epsilon_{2} \sigma_{2} / \epsilon_{1} \sigma_{1}\right)\left[Q_{0}\left(p_{1}\right)-Q_{0}\left(p_{1}\right)\right] \cosh \left(p_{1}\right)+[\operatorname{Sh}(\mathrm{Pe})]^{-1}}
$$

where

$$
Q_{\circ}(p) \equiv \ln (\operatorname{coth} p / 2)
$$

The mass-transfer rate in the exterior medium is proportional to the Sherwood number, as follows,

$$
\operatorname{Sh}\left(P_{e}\right)= \begin{cases}\frac{1}{Q_{0}\left(\varsigma_{1}\right) \cosh \left(\varsigma_{1}\right)}\left[1+\frac{P_{e}}{2 \mathcal{E}_{2}\left(\varsigma_{1}\right) \cosh \left(\varsigma_{1}\right)}\right], & \text { Pe small } \\ \sqrt{\frac{P_{e}}{\pi} \tanh \left(\varsigma_{1}\right)}, & \text { Pe }>4 \text { coth } p_{r} .\end{cases}
$$

Figure 2.1.1 shows the mass-transport rate as a function of backfill thickness, the backfill/rock poroaity ratio, and $\mathrm{Pe}$, assuming $\sigma_{1}=\sigma_{2}=1$. For equal porosities of backfill and rock, backfill reduces the mass transfer rate because of the assumed zero flow in the backfill. For a given backfill thickness, decreasing the backfill porosily decreases the mass transfer rate. A decrease in the backfill/rock porosity ratio from 20 (solid curves) to 1 (broken curves) causes much of the exterior-medium resistance to shift to that of the backfill. For a backfill/rock porosity ratio of 20 , increasing backfill thickness causes the rate of mass transfer into the rock to increase, because low-porosity rock is being replaced with more porous backfill. lncreasing the ground-water 


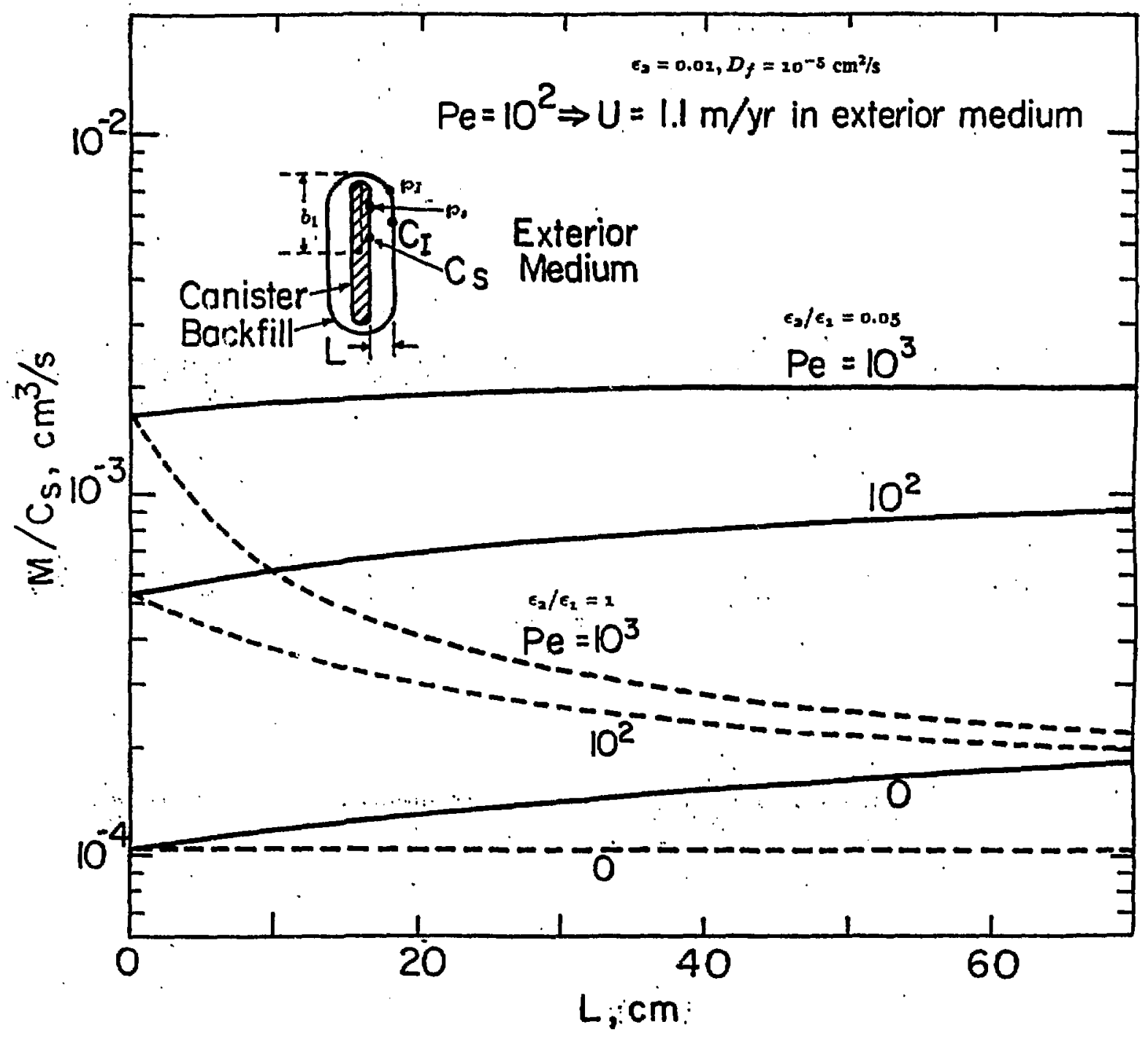

Figure 2.11 The Mass-transfer Rate as a Function of Backfill Thickness, Porosity Ratio and Peclet Number 
flow outside the backfill from the pure diffusive transport of Peclet of zero to a Peclet of 1000 shows an expected increase in the mass transfer rate.

\subsection{Mass Transfer into Fractured Rock}

In constructing nuclear waste repositories in rock, it may be necessary to place a waste package in a hole intersected by one or more rock fractures, or rock fractures may develoy after waste packages have been emplaced. Predicting the spatial and temporal distribution of contaminant species can be important, because such fractures can be preferential pathways for released radionuclides to re-enter the biosphere.

Recently Aln, Chambré and Pigford [1989] obtained the solution for disgolution of species in a diffusive environment from a waste cylinder interaccted by a planar rock fracture (Figure 2.12). Consider an infinitely long waste sylinder with radius $\hat{R}_{1}$, surrounded by infinite rock containing a planar fracture intersecting the cylinder and normal to the cylindrical axis. We conservatively asoune bare waste and the surface concentration is at the solubility limit of each species. The fracture width or thickness is $2 \hat{b}$ and complete mixing across the fracture width is assumed. Retardation is treated by equilibrium sorption. 'The mass balance for the time-dependent species concentrations in the rock and in the fracture are

$$
\begin{array}{cc}
\hat{K}_{3} \frac{\partial \hat{c}_{3}}{\partial \hat{t}}=\frac{\hat{D}_{3}}{\hat{r}} \frac{\partial}{\partial \hat{r}}\left(\frac{\partial \hat{c}_{3}}{\partial \hat{r}}\right)-\hat{\lambda} \hat{K}_{3} \hat{c}_{3}-\frac{\hat{q}(\hat{r}, \hat{t})}{\epsilon_{3} \hat{b}}, & \hat{r}>\hat{R}_{1}, \hat{t}>0 \\
\hat{K}_{1} \frac{\partial \hat{c}_{1}}{\partial \hat{t}}=\frac{\hat{D}_{1}}{\hat{r}} \frac{\partial}{\partial \hat{r}}\left(\hat{r} \frac{\partial \hat{c}_{1}}{\partial \hat{r}}\right)+\hat{D}_{1} \frac{\partial_{1} \hat{c}_{1}}{\partial \hat{z}^{2}}-\hat{\lambda} \hat{K}_{1} \hat{c}_{1}, & \hat{t}>0, \hat{r}>\hat{R}_{1}, \hat{z}>0
\end{array}
$$

in which

$$
\hat{q}(\hat{r}, \hat{\imath})=-\left.c_{1} \hat{D}_{1} \frac{\partial \hat{c}_{1}}{\partial \hat{z}}\right|_{i=0,} \quad \hat{\imath}>0, \hat{r}>R_{1}
$$

is the diffusive flux from the fracture to the rock through the interface $\left[M / L^{2}-t\right]$

where

subscript $I$ denotes the rock

subscript 9 denoles the fracture

$r$ is the distance from the centerline of the waste cylinder [L]

$\hat{z}$ is the distance from the rock/fracture interface [L]

$\hat{t}$ is time [t]

The side conditions are

$$
\begin{aligned}
& \hat{c}_{\mathbf{3}}(\hat{r}, 0)=0, \quad \hat{r}>\hat{R}_{1} \\
& \hat{c}_{1}(\hat{r}, \hat{z}, 0)=0, \quad \hat{r}>\hat{R}_{1}, \hat{z}>0 \\
& \hat{\mathbf{c}}_{\mathbf{3}}\left(\hat{R}_{1}, \hat{t}\right)=\hat{\boldsymbol{c}}_{\mathrm{d}}, \quad \hat{\boldsymbol{t}}>0 \\
& \hat{c}_{3}(\infty, \hat{t})=0, \quad \hat{i}>0 \\
& \hat{c}_{1}\left(\hat{R}_{1}, \dot{z}, \hat{t}\right)=\hat{c}_{k}, \quad \hat{z}>0, \hat{t}>0 \\
& \hat{c}_{1}(\infty, \hat{z}, \hat{t})=0, \quad \hat{z}>0, \hat{i}>0 \\
& \hat{c}_{1}(\hat{r}, 0, \hat{t})=\hat{c}_{3}(\hat{r}, \hat{t}), \quad \hat{r}>\hat{R}_{1}, \hat{t}>0 \\
& \left.\frac{\partial \hat{c}_{1}}{\partial \bar{z}}\right|_{i \rightarrow \infty}=0, \quad \hat{\boldsymbol{r}}>\hat{R}_{1}, \hat{i}>0
\end{aligned}
$$




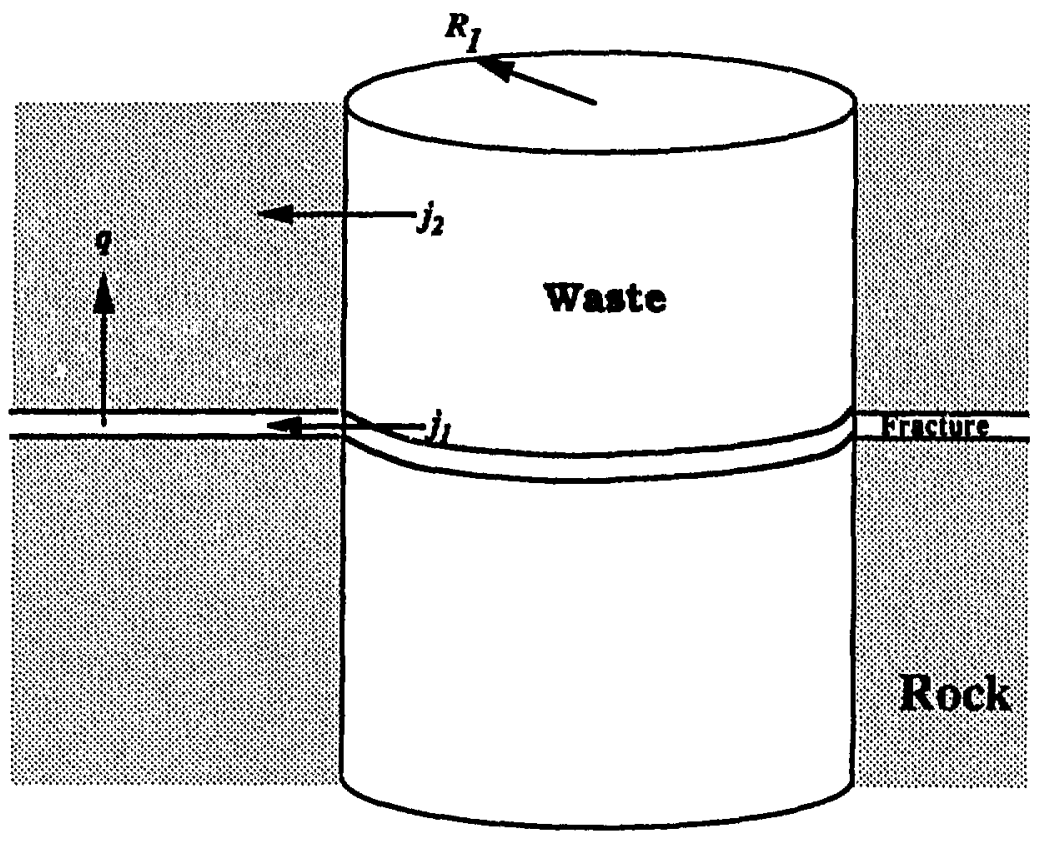

Nigure 2.12 Waste package intersected by a fracture 
By introducing the following transformations

$$
\begin{aligned}
r & \equiv \frac{\hat{r}}{\hat{R}_{1}} \\
z & \equiv \frac{\hat{z}}{\hat{R}_{1}} \\
t & \equiv \frac{\hat{D}_{1} \hat{t}}{\hat{K}_{1} \dot{R}_{1}^{2}} \\
\Delta & \equiv \frac{\hat{D}_{3} \hat{K}_{1}}{\hat{D}_{1} \hat{K}_{3}} \\
b_{2} & \equiv \frac{\epsilon_{3} \hat{b}_{3}}{\epsilon_{1} \hat{R}_{1} \hat{K}_{1}} \\
\lambda & \equiv \frac{\hat{R}_{1}^{2} \dot{\lambda} \hat{K}_{1}}{\hat{D}_{1}} \\
c_{3}(r, t) & \equiv \frac{\hat{\epsilon}_{3}(\hat{r}, \hat{t})}{\hat{c}_{0}} \\
c_{1}(r, z, t) & \equiv \frac{\hat{c}_{1}(\hat{r}, \hat{z}, t)}{\hat{c}_{2}} \\
q & \equiv \frac{\hat{R}_{1} \dot{q}}{\epsilon_{1} \hat{D}_{1} \dot{c}_{1}}
\end{aligned}
$$

where $t$ is the Fourier number, eq. (2.4.1) and (2.4.2) can be made dimensionless as

$$
\begin{array}{cc}
\frac{\partial c_{3}}{\partial t}=\frac{\Delta}{r} \frac{\partial}{\partial r}\left(r \frac{\partial c_{3}}{\partial r}\right)-\lambda c_{3}-\frac{q}{b_{2}}, & r>1, t>0 \\
\frac{\partial c_{1}}{\partial t}=\frac{1}{r} \frac{\partial}{\partial r}\left(r \frac{\partial c_{1}}{\partial r}\right)+\frac{\partial^{2} c_{1}}{\partial z^{2}}-\lambda c_{1}, & r>1, z>0, t>0
\end{array}
$$

The full derivations and solutions are shown in Ahn, Chambre and Pigford [1989] and only the analytic solution will be given here. The normalized diffusive flux from the waste cylinder to the fracture is

$$
j_{3}(t)=-\left.\frac{\partial c_{3}}{\partial r}\right|_{r=1}=\sqrt{\lambda} \frac{K_{3}(\sqrt{\lambda})}{K_{0}(\sqrt{\lambda})}-\frac{2}{\pi}\left[I_{1}^{\prime}(0, t)+I_{2}^{\prime}(0, t)+I_{4}^{\prime}(0, t)\right], \quad t>0
$$

And the normalized diffusive flux from the waste cylinder directly into the rock is

$$
j_{1}(z, t)=-\left.\frac{\partial c_{1}}{\partial r}\right|_{r=1}=\sqrt{\lambda} \frac{K_{3}(\lambda)}{K_{0}(\sqrt{\lambda})}-\frac{2}{\pi}\left[I_{1}^{\prime}(z, t)+I_{2}^{\prime}(z, t)-I_{3}^{\prime}(z, t)+I_{4}^{\prime}(z, t)\right]_{1} \quad z>0, t>0
$$

where

$$
\begin{gathered}
I_{i}^{\prime}(z, t)=\int_{0}^{\infty} \bar{W}_{i}(s ; z, t) \frac{s d s}{\left[M_{0}(s)\right]^{2}} \\
M_{0}(s)=\sqrt{\left[J_{0}(s)\right]^{2}+\left[Y_{0}(s)\right]^{2}} \\
\tilde{W}_{3}(s ; z, t)=\frac{1}{\pi} \frac{(\Delta-1) \lambda}{\mu_{2}^{2}\left(\mu_{1}^{2}-\frac{\mu_{2}}{s}\right)} e^{z \mu_{2}} \operatorname{erfc}\left(\frac{z}{2 \sqrt{t}}+\mu_{2} \sqrt{t}\right)
\end{gathered}
$$




$$
\begin{gathered}
\text { Near-iald Mene Tranafer } \\
\vec{W}_{1}(s ; z, t)=\frac{1}{x} \frac{(\Delta-1) \lambda}{\mu_{2}^{2}\left(\mu_{1}^{2}+\frac{\mu_{2}}{b}\right)} e^{-z \mu_{2}} \operatorname{erfc}\left(\frac{z}{2 \sqrt{t}}-\mu_{2} \sqrt{t}\right) \\
\vec{W}_{3}(s ; z, t)=\frac{2}{\pi} \frac{1}{\mu_{2}^{2}} e^{-\mu_{2}^{2} t} \operatorname{erf}\left(\frac{z}{2 \sqrt{t}}\right) \\
\vec{W}_{4}(s ; z, t)=\frac{2}{\pi} \frac{\exp \left\{-\frac{z^{2}}{4 t}-\mu_{2}^{2} t\right\}}{\beta-\alpha} \frac{\beta \Delta-1 / b_{2}}{\beta^{2}-\mu_{2}^{2}} \mathrm{~F}\left(\beta \sqrt{t}+\frac{z}{2 \sqrt{t}}\right)-\frac{\alpha \Delta-1 / b_{2}}{\alpha^{2}-\mu_{2}^{2}} \mathrm{~F}\left(\alpha \sqrt{t}+\frac{z}{2 \sqrt{t}}\right) \\
\alpha=\frac{1-P}{2 b_{2}} \\
\beta=\frac{1+P}{2 b_{2}} \\
P=\sqrt{1-t_{2}^{2}(\Delta-1) s^{2}} \\
\mu_{1}^{2}=s^{2} \Delta+\lambda \\
\mu_{2}^{2}=s^{2}+\lambda \\
\mathrm{F}(x)=e^{x^{2}} \operatorname{erfc}(x),
\end{gathered}
$$

The results are illustrated in Fig. 2.13, which shows instantaneous concentration isopleths, mass flux across the fracture surface, and mass fluxes from the waste into the fracture and into the rock matrix. The diffusion coefficient $D$ is conservatively chosen as that for a liquid continuum. Concentrations are normalized to the quantity $D_{c_{s}} / R_{1}$ defined in Fig. 2.13. The mass flux into the fracture is calculated to be about two orders of magnitude greater than that into the rock matrix, beause of the assumed hundredfold grealer porosity in the fracture.

\subsection{Temperature Exfects}

In the foregoing analysis, we have made the asumption that the nuclide and geologic properties are constant in space and time. In a geologic repository of nuclear waste this will not be true. Heat from buried waste will have significant influence on transport processes. The parameters that characterize transport, such as diffusion coefficient, solubility, and retardation coefficient, are functions of temperature. We will now show how variations in such parameters can be treated, through an example of temperature dependence [Pigford, Chambré and Zavoshy 1983; Chambré et al. 1984; 1985].

Let the temperature as a function of space and time be known. If we know the functional dependence of the diffusion coefficient, solubility, and relardation coefficient on temperature, we can obtain their time dependence also. We will now show how to treat the variation of diffusion coefficient, solubility, and retardation coefficient as functions of time. Let $c(r, t)$ be the concentration of the species in ground water, diffusing from a waste in contact with rock of porosity $\epsilon$, with no backfill layer. The governing equation for diffusive transport is

$$
\frac{\partial K(t) c}{\partial t}=D(t) \frac{1}{r^{2}} \frac{\partial}{\partial r}\left(r^{2} \frac{\partial c}{\partial r}\right)-K(t) \lambda c, \quad R<r<\infty, t>0
$$

Here $K(t), D(t)$ and $c_{2}(t)$ are time-temperature dependent functions with reference values $K_{0}, D_{0}$, and $c_{s 0}$ $R$ is the radius of the waste sphere, and $\lambda$ the species decay constant. The initial condition is

$$
c(r, 0)=0, \quad r>R
$$




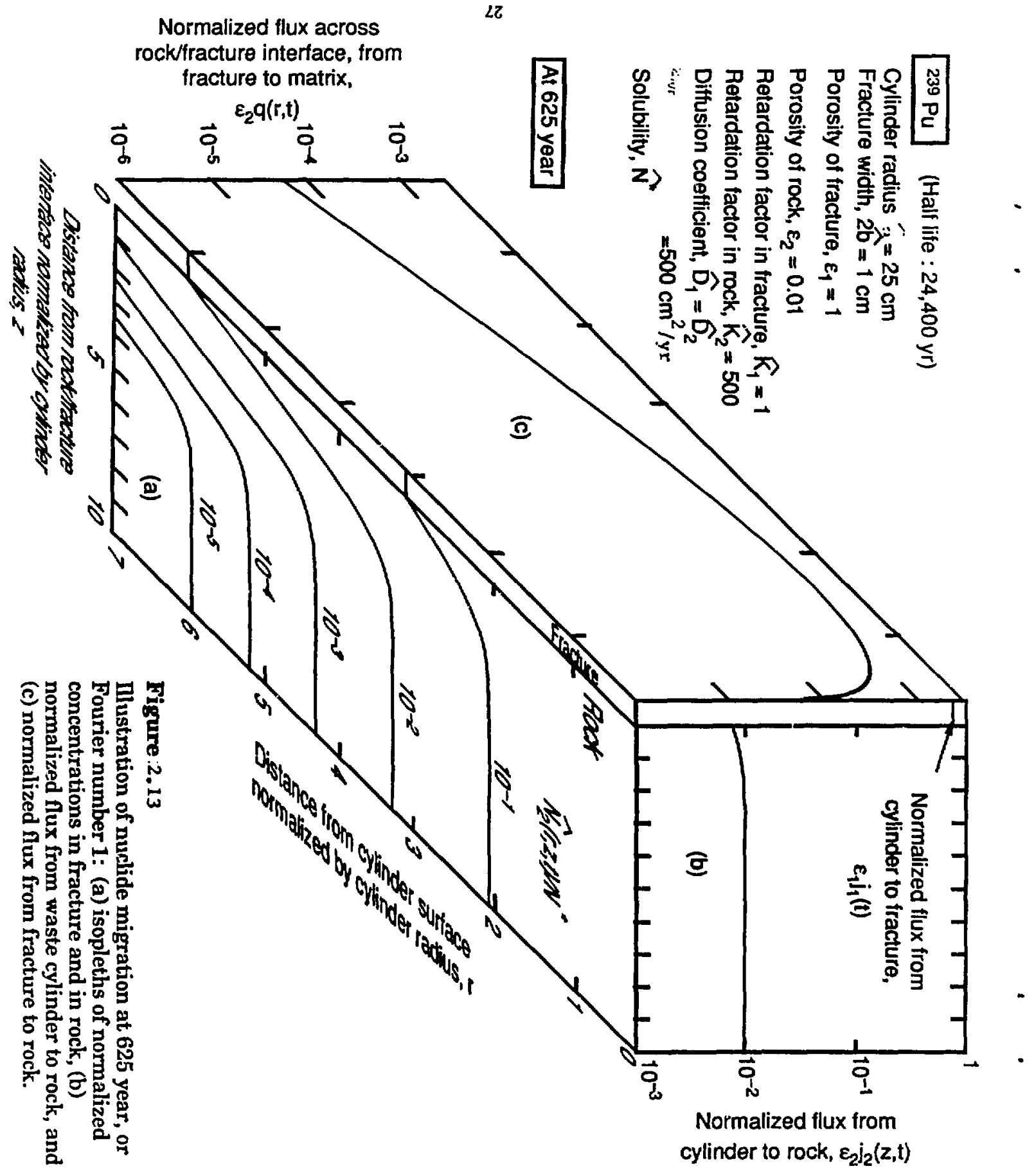


and the boundary conditions are

$$
\begin{gathered}
c(R, t)=c_{s}(t), \quad t \geq 0 \\
c(\infty, t)=0, \quad t \geq 0
\end{gathered}
$$

Now we define two dimensionless functions $f(t), g(t)$ as

$$
\begin{gathered}
\frac{D(t)}{K(t)}=\frac{D_{0}}{K_{0}} g(t) \\
K(t) c_{0}(t)=c_{0,0} f(t), \quad t \geq 0
\end{gathered}
$$

representing the known time dependence of $K^{\prime}(t) c_{0}(t)$ and $D(t) / K(t)$ respectively. The solution is given in terms of the mass transfer rate $\dot{m}(t ; \lambda)$ from the waste sphere per unit area

$$
\dot{m}(t ; \lambda)=-D(t) \epsilon \frac{\partial c(R, t)}{\partial r}=\frac{D(t) c_{10}\left(e^{-\lambda t}\right.}{R K^{\prime}(t)}\left[\tilde{f}(r(t))+\frac{1}{\sqrt{\pi}}\left\{\frac{\tilde{f}(0+)}{\sqrt{r(t)}}+\int_{0}^{r(1)} \tilde{f}^{\prime}(\tau(t)-\eta) \frac{d \eta}{\sqrt{\eta}}\right\}\right]
$$

where

$$
\tilde{f}(\tau)=f(t(\tau)) e^{\lambda t(r)} \quad \tau(t)=\frac{D_{0}}{K_{0} R^{2}} \int_{0}^{t} g\left(t^{\prime}\right) d t^{\prime}, \quad t \geq 0
$$

To obtain the diffusion coefficient as a function of temperature, we use the Nernst-Einstein equation

$$
D \mu / T=\text { constant }
$$

where $\mu$ is the absolute viscosity and $T$ the temperature. The above approach was illuatrated for the case of simultaneous dependence of solubility and diffusion coefficient on temperature in congruent dissolution from borosilicate glass [Chambré et al. 1985].

From data on temperature-dependent diffusion coefficients and silica solubilities, we predict the timedependent dissolution rates of silica from borouilicate glass waste in basalt, for $K=1$ and 100 . Normalizing to the dissolution rate $\dot{m}$ that would occur at steady state and ambient temperature $58 \mathrm{C}$ yields the results in Figure 2.14. The dissolution rate at 1 year and $K=100$ is 154 times the steady-state ambient rate because of the temperature-increased solubility and diffusion coefficient and because of the ateeper concentration gradie at at the waste surface near the beginning of dissolution. The transient gradient and dissolution rate are reduced in the absence of sorption $(K=1)$.

\subsection{Effect of Non-Llnear Borption on Mase Transfer Through Backent}

In the previous analyses we have assumed linear sorption in the backfill, as expressed by a retardation constant independent of concentration. However, if the species concentration in the liquid phase is sufficiently large so that the solid phese cannot absorb all the species, then sorption saturation is said to occur. Some data slow nonlinear sorption in bentonite, with a tendency towards saturation of the sorption sites [Chambre $e t$ al. 1985], For such backfill materials, the mass-transfer characteristics can be far different than those analyzed above for linear sorption, corresponding to a concentration-independent retardation coefficient.

A sorption distribution coefficient $K_{d}$ relates $\mathrm{c}$ the species concentration in the liquid, and $c_{a}$ the mass of the species adsorbed on the solid phase per unit bulk dry mass of the porous material

$$
K_{d}=\frac{c_{a}}{c}
$$




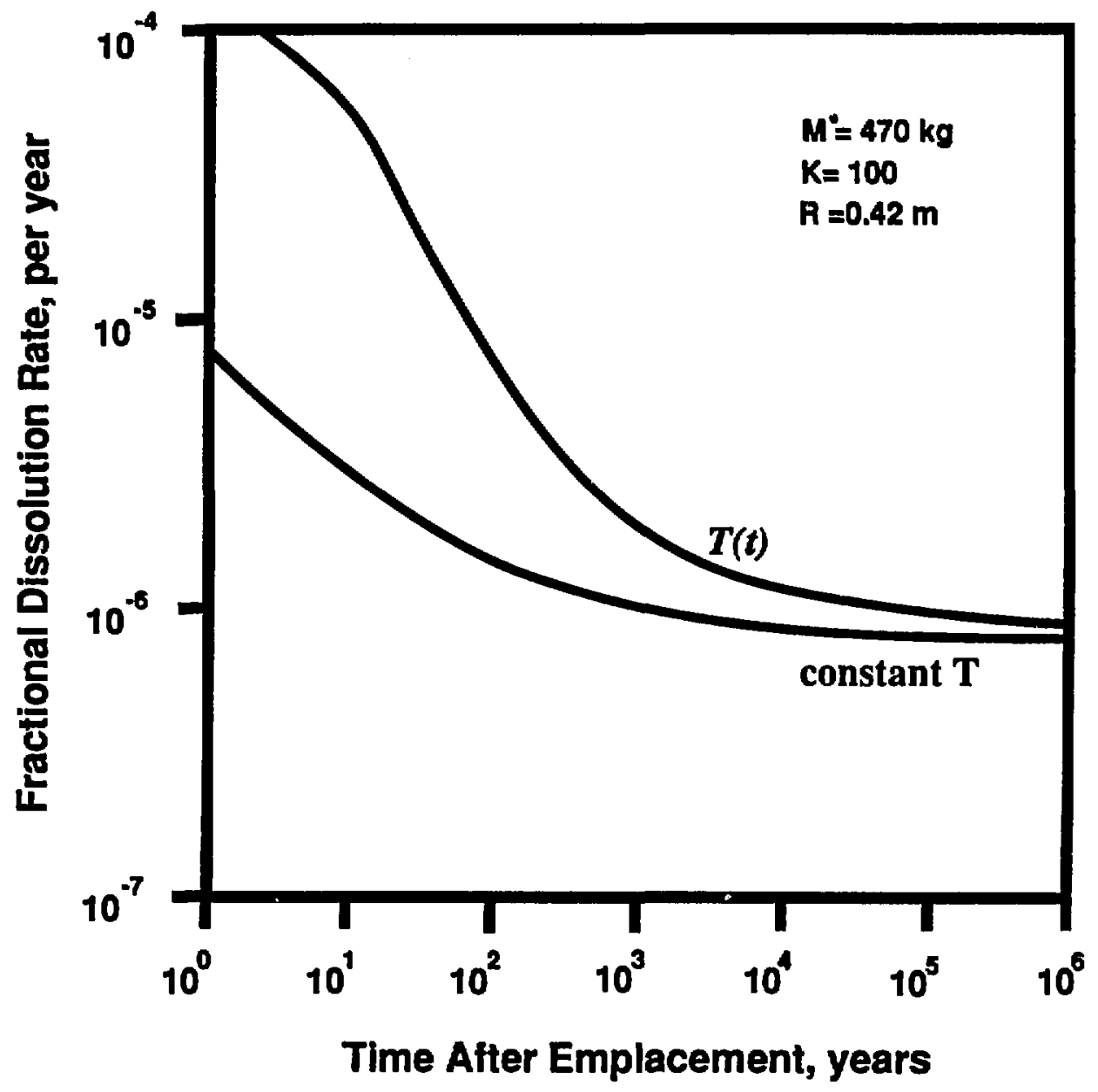

Figure 2.14. Effect of Repository Heating on the Rate of Silica Dissolution 
A Langmuir isotherm can be used to account for sorption saturation. Figure 2.15(a) shows $\mathcal{F}$ the saturation concentration in the solid phase. The Langmuir isotherm can be approximated by two linear segments: for $c<c^{*}$, we have the common linear isotherm, and for $\left.c\right\rangle c^{*}$, the solid is saturated and $c_{a}=\mathcal{F}$ for all $c$ [Lung et al. 1983]. $c^{*}$ is called the critical concentration.

The retardation coefficient $K$ is defined as

$$
K(c)=1+\rho \frac{1-\epsilon}{\epsilon} K_{d}(c)
$$

where $\epsilon$ is the backfill porosity and $\rho$ is the bulk density. Assuming diffusive transport in the liquid phase and none on the solid, the governing equations for one-dimensional transport of the species are

$$
\begin{aligned}
& \frac{\partial(\epsilon c)}{\partial t}=D \frac{\partial^{2}(\epsilon c)}{\partial x^{2}}-\phi\left(c, c_{a}\right)-\lambda \epsilon c \\
& \frac{\partial\left[1-\epsilon c_{a}\right]}{\partial t}=+\phi\left(c, c_{a}\right)-\lambda[1-\epsilon] c_{a}
\end{aligned}
$$

where $\phi\left(c, c_{a}\right)$ is the interphase reaction rate.

By adding (2.6.3) and (2.6.4) we get

$$
\frac{\partial}{\partial t}\left[\epsilon c+(1-\epsilon) c_{a}\right]=D \frac{\partial^{2}(\epsilon c)}{\partial x^{2}}-\lambda\left[\epsilon c+(1-\epsilon) c_{a}\right]
$$

If the approximate Langmuir isotherm is valid, then for $c>c^{*}, \quad c_{a}=\mathcal{F}=$ constant and (2.6.5) reduces to

$$
\frac{\partial(\epsilon \mathfrak{c})}{\partial t}=D \frac{\partial^{2}(\mathrm{cc})}{\partial x^{2}}-\lambda \epsilon c-\lambda(1-\epsilon) c_{a}, \quad c>c^{*}
$$

and for $c<c^{*}(2.6 .1)$ applies and (2.6.5) reduces to

$$
\frac{\partial(K \epsilon c)}{\partial t}=D \frac{\partial^{2}(\epsilon c)}{\partial x^{2}}-K \lambda \in c
$$

Figure 2.15(b) shows a backfill divided into parts, according to (2.6.7), (a) an inner saturated region inside which the liquid concentration is greater than $c^{*}$, and (b) an outer unsaturated region of lower concentration. Saturation will begin at the inner surface $(x=0)$, and the interface between saturated and unsaturated regions will move outward along the trajectory $\mathcal{G}=\mathcal{G}(t)$. To find the position of this saturation front or $\mathcal{G}(t)$ we solve the following equation set.

In the saturated region, the mass balance is

$$
\frac{\partial(\epsilon c)}{\partial t}=D \frac{\partial^{2}(\epsilon c)}{\partial x^{2}}-\lambda \epsilon c-\lambda\left(\frac{1-\epsilon}{\epsilon}\right) \mathcal{F}, \quad 0<x \leq \mathcal{G}(t), t>0
$$

In the unsaturated region

$$
\frac{\partial \bar{c}}{\partial t}=\frac{D}{K} \frac{\partial^{2} \bar{c}}{\partial x^{2}}-\lambda \bar{c}, \quad x \geq \mathcal{G}(t), \quad t>0
$$

where $\bar{c}$ is the concentration in the unsaturated zone. The initial condition are

$$
\bar{c}(x, 0)=0, x>0 \quad c(x, 0) \quad \text { unknown }
$$




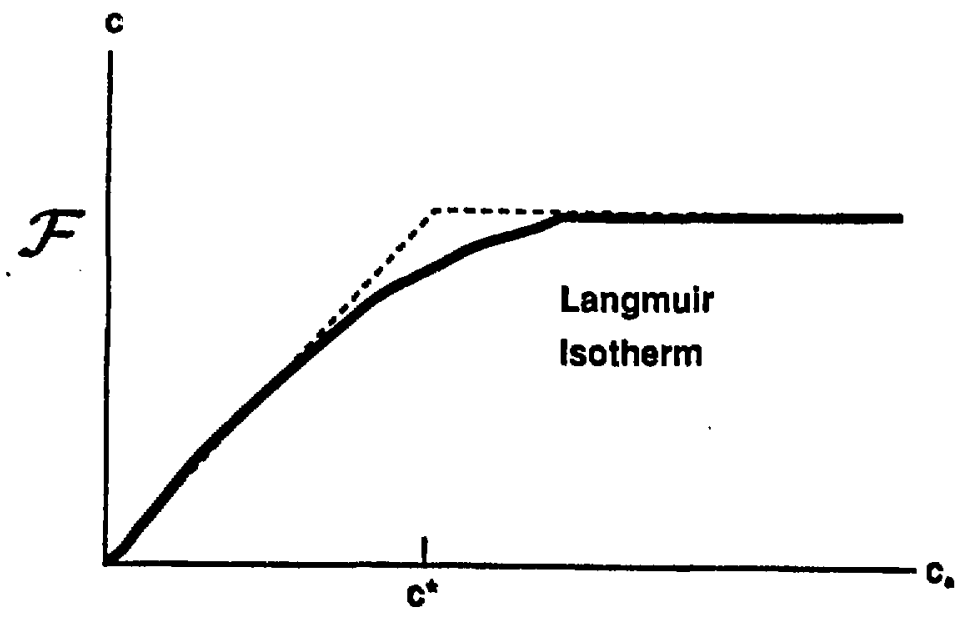

Figure 2.15a Approximate Langmuir Isotherm

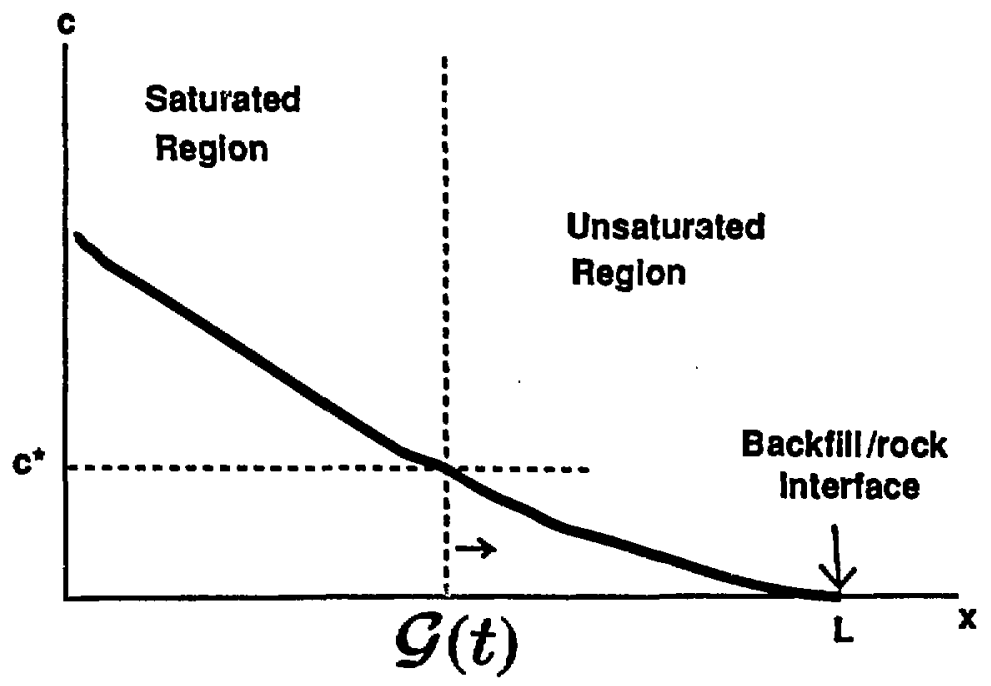

Figure 2.15b Movement of a Saturation Front in Backell 
and the following bcundary conditions

$$
\begin{aligned}
c(0, t) & =c,>c^{*}, \quad t>0 \\
c(\mathcal{G}(t), t) & =\bar{c}(\mathcal{G}(t), t)=c^{*}, \quad t>0 \\
-\epsilon D \frac{\partial c}{\partial x} & =-\epsilon D \frac{\partial \bar{c}}{\partial \bar{x}}, \quad x=\mathcal{G}(t), \quad t>0 \\
\tilde{c}(\infty, t) & =0, \quad t>0
\end{aligned}
$$

The solution is

$$
G(t)=h \sqrt{t}
$$

and for the time period that is shorter than the half-life of the nuclide, the solution can be obtained by solving for $h$ from the transcendental equation

$$
\frac{\exp \left\{(K-1) \frac{h^{2}}{d D}\right\} \operatorname{erfc}\left(\frac{h}{2 \sqrt{D / K}}\right)}{\operatorname{erf}\left[\frac{h}{2 \sqrt{D}}\right]}-\frac{\frac{c^{*}}{c_{0}} \sqrt{K}}{1-\frac{a^{*}}{c_{0}}}=0
$$

In Fig. $2.16 \hbar$ is plotted as a function of the dimensionless interface concentration $c^{*} / c$, with the retardation coefficient $K$ as the parameter. $D$ is fixed in these computations at $10^{-5} \mathrm{~cm}^{2} / \mathrm{s} . A_{s} c^{*} / c_{*} \rightarrow$ $1, \hbar \rightarrow 0$, because the salurated region becomes very narrow. In this case there is almost no unsaturated region in the backfill and hence the interface position will move very rapidly towards infinity. Five different $I$ values are shown in Figure 2.16 which shows that for an inczeajing $K$ the interface position moves more slowly, since a large $K$ implies strong retardation and hence a slowdown of the approach to saturation in the backfill.

The interface position $\mathcal{G}(t)$ is an indicator of the backfill performance because it shows how quickly saturation takes place with a resulting loss of nuclide retardation. If the backfill thicknew is $b$ then retardation by the backfill disappears when the saturation interface penetrates a distance equal to $b$. The breakthrough time $T_{b}$ for such penetration is given by

$$
T_{b}=\left(\frac{b}{h}\right)^{2}
$$

Figure 2.16 also shows the breakthrough time as a function of $c^{*} / c$, with the same parameter $K$. The backfill thickness is taken to be $30 \mathrm{~cm}$. Because $T_{b}$ is inversely proportional to $\hbar^{2}$, as $c^{*} / c$, decreases, $T_{b}$ decreases. As $K$ increased, $T$ increases also. 'The importance of saturation in the backfill can be seen by comparing these results with those in which saturation is assumed absent. Assuming a linear isotherm with slope $K=$ 4000 , and for the diffusion coefficient $D=10^{-5} \mathrm{~cm}^{2} / \mathrm{s}$, Nowak [1979] showed that it would take 1000 years to raise the concentration at $x=30 \mathrm{~cm}$ to $1 \%$ of $c_{0}$. However, if saturation can occur, with $c^{*}=0.01 c_{s}$, the breakthrough time is reduced to 60 years as seen in Figure 2.16, i.e. only $\delta$ percent of the breakthrough time in absence of saturation.

To apply the solution for semi-infinite geometry to a backfill of finite thickness, one can use the region of Figure 2.16 that spans a concentration ratio $c^{*} / c_{*}=0.1$ at the backfill/rock interface. Because $T_{b}$ is less than 2000 years for $\hbar<10^{4}$ and $c^{*} / c_{\alpha}<0.1$, species with half lives greater than 5000 years can be treated as nondecaying for this analysis. 


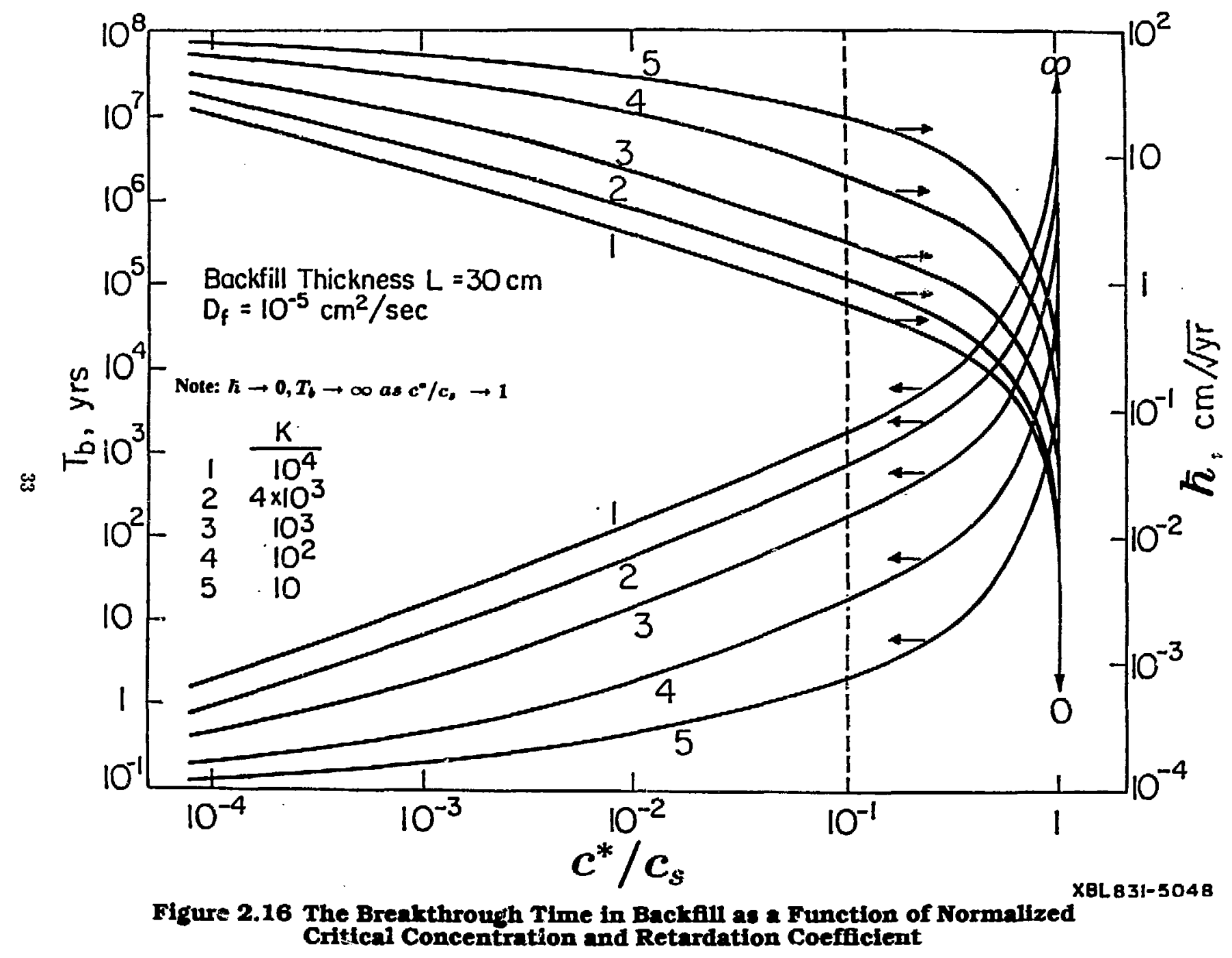


The purpose of this analysis is to illustrate the effect of nonlinear sorption on mass transport and to point out that the results can be quite different from results when a constant distribution coefficiert can be assumed. A similar approach can be taken if an actual nonlinear sorption isotherm is known.

\subsection{Effect of a Stationary Precipitation Front on Diseol ution and Transport}

In this section we deal with a single cor:caminant species and analyze the effect of a preci ${ }_{\text {. }}$ itation froint caused by a discontinuity in the solubility of the contaminant at some distance from the waste package [Light et al. 1988]. The precipitation front may ba due to local geochemical chi.nges such as changes in temperature, $\mathrm{pH}$ or redox potential, caused by nearby geologic features or the waste itself.

A spherical wiste solid of radius $R$ is embedded in an infizite water-saturated porous medium. There is no contaminant in the porors medium when dissolution begins at time $t=0$ and direct contact is assumed between the waste and the porous medium (no conlainer or other barricis). The solubility discontinuity, or so-called prexipit ation front, is assumed to be a concentric spherical shell of radius $R_{p}$ surrounding the waste package ( $\bar{r}$ 'igure $2.17 \mathrm{a}$ ). The lissolution rate at the waste surfoce is governed by a solid-liquid reaction-rate law with the maximum rate sccuring when there is no coniaminant in the pore water and the minimum rate, zero, approached only as the contaminant concentration in the pore waler approaches the solubility at the waste surface. In the limit that the reaction rate goes to infinity, this law reduces to a corstant-concentration boundary condition.

Transport in the porous medium is by fluid-phase diffusicn only, with no advection. Fueisrdation of the contaminant in the porous mediu:n is lreated by equilibrium sorion.

The precipitation front is assumec to be at a known, fixed location. Inside the spherical front and near the waste package, the solubility $c_{x}$ of the contaminant is high. Outside the front and furtser away from the waste, the reduced solubility $c_{r}$ is lower. This creates the possibility that some of ihe conlaminant being released from the waste will precipitate at the front and becomr immobilized At early times, when the concentration is below the solubility limits at the front location, the front is transparent to the transport process. The domain from the waste surface to infinity is then treated as a single homogenenus region and we have

$$
\frac{\partial c_{1}}{\partial t}=\frac{D}{K} \nabla^{2} c_{1}, \quad \begin{aligned}
& R<r<\infty \\
& 0<\iota<t_{p}
\end{aligned}
$$

where $c_{1}(r, t)$ is the fluid-phase contaminant concentration for $0<t<t_{p}, D$ is the contaminant diffusion ccefficient in the pore fluid, and $t_{p}$ is the time at which the solubility limit is reached and precipitation begins. The initial concentration and the concentration at infinity are both asaumed to be zero

$$
\begin{array}{ll}
c_{1}(r, 0)=0, & r_{0}<r<\infty \\
c_{1}(\infty, t)=0, & 0<t<t_{p}
\end{array}
$$

The assumed reaction-rate controlled dissolution rate at the waste surface as a function of cuncentration is

$$
-\left.\epsilon D \frac{\partial c_{1}}{\partial r}\right|_{r=R}=\left.j_{0}\left(1-\frac{c_{1}}{c_{0}}\right)\right|_{r=R}, \quad 0<t<t_{p}
$$

where $j_{o}$ is the forward dissolution reaction rate (assumed constant). To determine the precipitation time, $t_{p}$, we first solve eq. (2.7.1)-(2.7.4). The contaminant concentration predictad by eq. (2.7.1)-(2.7.4) increases steadily with time and monotonically decreases with distance from the waste. The concentration may not 


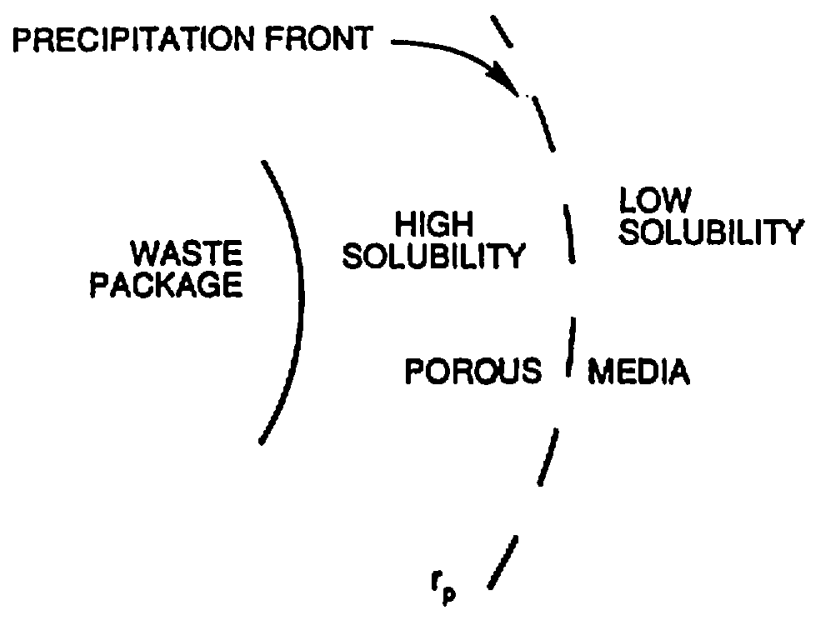

Figure 2.17a The Stationary Precipitation Front

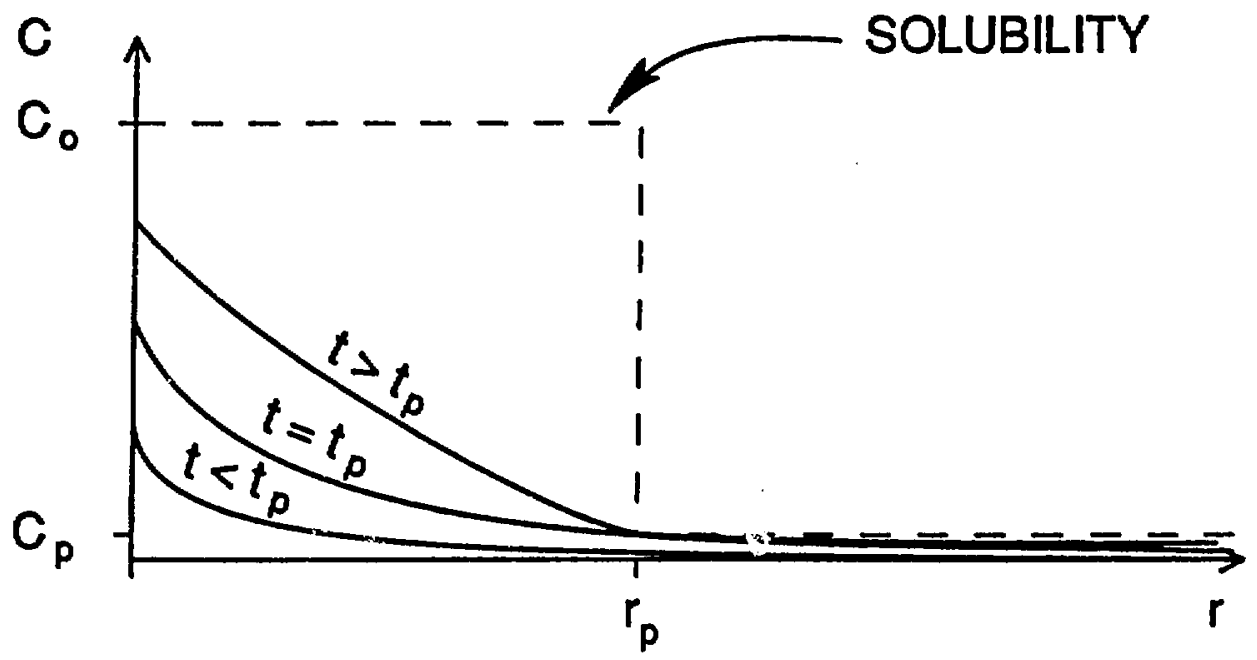

Figure 2.17b Schematic of Concentration Profiles 
reach the solubility limit anywhere, but if it does it will occur first at the front location, $r_{p}$, and we can then determine $t_{p}$ implicitly from the equation

$$
c_{1}\left(r_{p}, t_{p}\right)=c_{r}
$$

At time $t=t_{p}$, when precipitation begins, the governing equation (2.7.1) is no longer valid at the front so we divide the domain into two regions, one inside the front and the other outside the front. For the inner region

$$
\frac{\partial c_{4}}{\partial t}=\frac{D}{K} \nabla^{2} c_{4}, \quad \begin{aligned}
& R<r<r_{p} \\
& t_{p}<t<\infty
\end{aligned}
$$

where $c_{4}(r, t)$ is the contaminant concentration for $R<r<r_{p}$ and $t_{p}<t<\infty$. The initial condition for this problem is given by $c_{1}$ evaluated at $t=t_{p}$

$$
c_{4}\left(r, t_{p}\right)=c_{1}\left(r, t_{p}\right), \quad R<r<r_{p}
$$

The boundary condition at the wasce surface is the reaction-tate law as before with $c_{4}$ replacing $c_{1}$

$$
-\left.c D \frac{\partial c_{4}}{\partial r}\right|_{r=R}=\left.j_{0}\left(1-\frac{c_{4}}{c_{0}}\right)\right|_{r=R}, \quad t_{p}<t<\infty
$$

At the new boundary, $r=r_{p}$, we set the concentration to the reduced solubility limit $c_{r}$

$$
c_{4}\left(r_{p}, t\right)=c_{r}, \quad t_{p}<t<\infty
$$

This is a result of the physical requirement that the concentration be continuous across the front and that we are (somewhat artificially) limiting the concentration to the $c_{r}$ limit in the region $r_{p}<r<\infty$. In reality, the front would extend over some non-zero transition thickness without well-defined boundaries. We assume instead an abrupt discontinuity and also neglect the effect which the accumulating precipitate might have on the transport process such as by filling the pores or by moving as a colloid.

The region outside the precipitation front is treated similarly with the governing equation given by

$$
\frac{\partial c_{b}}{\partial t}=\frac{D}{K} \nabla^{2} c_{B}, \quad \begin{aligned}
& r_{p}<r<\infty \\
& t_{p}<t<\infty
\end{aligned}
$$

and the side conditions

$$
\begin{aligned}
& c_{5}\left(r, t_{p}\right)=c_{1}\left(r, t_{p}\right), \quad r_{p}<r<\infty \\
& c_{5}\left(r_{p}, t\right)=c_{p}, \quad t_{p}<t<\infty \\
& c_{s}(\infty, t)=0, \quad t_{p}<t<\infty
\end{aligned}
$$

The solution to eq. $(2.7 .1)-(2.7 .4)$ is

$$
c_{1}(\rho, \tau)=\frac{c_{o}}{\sigma \rho} \operatorname{erfc}\left(\frac{\rho-1}{2 \sqrt{\tau}}\right)-\frac{c_{\phi}}{\sigma \rho} \exp \left(\sigma \alpha(\rho-1)+\sigma^{2} \alpha^{2} \tau\right) \operatorname{erfc}\left(\frac{\rho-1}{2 \sqrt{\tau}}+\sigma \alpha \sqrt{\tau}\right), \begin{aligned}
& 1<\rho<\infty \\
& 0<\tau<\tau_{p}
\end{aligned}
$$

with these dimensionless parameters $\sigma=1+1 / \alpha, \alpha=j_{0} R / \epsilon D c_{s}, \rho=r / R, \tau=1 D / K R^{2}$. Using this result, eq. (2.7.5) is solved implicitly to obtain a nu. .erical value for $\tau_{p}=t_{p} D / K R^{2}$. Assuming a known value for $\tau_{p}$, which is dependent on $\alpha$ and $c_{v} / c_{r}$, eq. (2.7.6)-(2.7.9) are solved by the Fourier method with the result in infinite-series form

$$
c_{4}(\rho, \tau)=c_{1}\left[a+\frac{b}{\rho}+\frac{1}{\rho} \sum_{n=1}^{\infty} A_{n} \Phi_{n}(\rho) e^{-\lambda_{n}\left(\tau-\tau_{p}\right)}\right], \begin{aligned}
& 1<\rho<\rho_{p} \\
& \tau_{p}<\tau<\infty
\end{aligned}
$$


where

$$
\begin{aligned}
a & =\frac{\sigma \rho_{p} c_{r} / c_{s}-1}{\sigma \rho_{p}-1} \\
b & =\frac{\rho_{p}\left(1-c_{r} / c_{s}\right)}{\sigma \rho_{p}-1}
\end{aligned}
$$

The series coefficients $A_{n}$ are given by

$$
A_{n}=\frac{1}{\left\|\Phi_{n}\right\|^{2}} \int_{1}^{\rho_{y}} \Phi_{n}(\rho)\left[\rho c_{l}\left(\rho, \tau_{p}\right) / c_{1}-(a \rho+b)\right] d \rho
$$

where

$$
\left\|\Phi_{n}\right\|^{2}=\int_{1}^{p} \Phi_{n}^{2}(\rho) d \rho
$$

the eigenfunctions $\Phi_{n}$ are defined

$$
\Phi_{n}(\rho)=\sin \left[\sqrt{\lambda_{n}}\left(p_{p}-p\right)\right], \quad 1<\rho<p_{p}
$$

and the eigenvalues $\lambda_{n}$ are determined implicitly from

$$
\tan \left[\sqrt{\lambda_{n}}\left(\rho_{p}-1\right)\right]=\frac{-\sqrt{\lambda_{n}}}{1+\alpha}
$$

Equations (2.7.10)-(2.7.13) are solved by Green's-function method to yield the solution

$$
c_{5}(\rho, \tau)=\frac{\rho_{p}}{\rho} c_{r}+\frac{1}{\rho} \int_{\rho_{p}}^{\infty}\left[\eta c_{1}\left(\eta, \tau_{p}\right)-\rho_{p} c_{\tau}\right]\left(\frac{\exp \left[\frac{-(\rho-\eta)^{2}}{\pi\left(\tau-\tau_{p}\right)}\right]-\exp \left[\frac{-\left(\rho+\eta-2 \rho_{p}\right)^{2}}{4\left(\tau-\tau_{p}\right)}\right]}{\sqrt{4 \pi\left(\tau-\tau_{p}\right)}}\right) d \eta, \begin{aligned}
& \rho_{p}<\rho<\infty \\
& \tau_{p}<\tau<\infty
\end{aligned}
$$

The mass-transfer rate $\dot{M}$, representing the flow rate of contaminant species through a concentric sphere of radius $r$ at time $t$, is proportional to the concentration gradient, in this case

$$
\dot{M}(r, t)=-4 \pi r^{2} c D \frac{\partial c}{\partial r}
$$

where $c_{1}(r, t), c_{4}(r, t)$, or $c_{5}(r, t)$ is inserted for $c(r, t)$ depending on the place and time of interest.

Figure 2.18 summarizes the principal results of the numerical illustration. The normalized masstrarsfer rates at two locations are plotted against dimensionless time, with the location of the precipitation front as a parameter. The mass-transfer rate $\dot{M}[\mathrm{M} / \mathrm{t}]$ is normalized by the constant $4 \pi \epsilon R D c_{0}[\mathrm{M} / \mathrm{t}]$. The dimensioniess time $\tau$ is obtained by dividing actual time by $K R^{2} / D[t]$. As indicated on the caption for Figure 2.18, the solubility $c_{r}$ in the outer region is set at $10^{-3}$ of the solubility of the inner, higher-solubility region. The calculations have been done for $\alpha=500$, to ensure that dissolution is controlled primarily by diffusion.

The upper set of curves in Figure 2.18 shows the mass-transfer rates at the surface of the waste sphere, $R$, for four locations of the precipitation front $r_{p}$. The start of precipitation is indicated by the vertical 


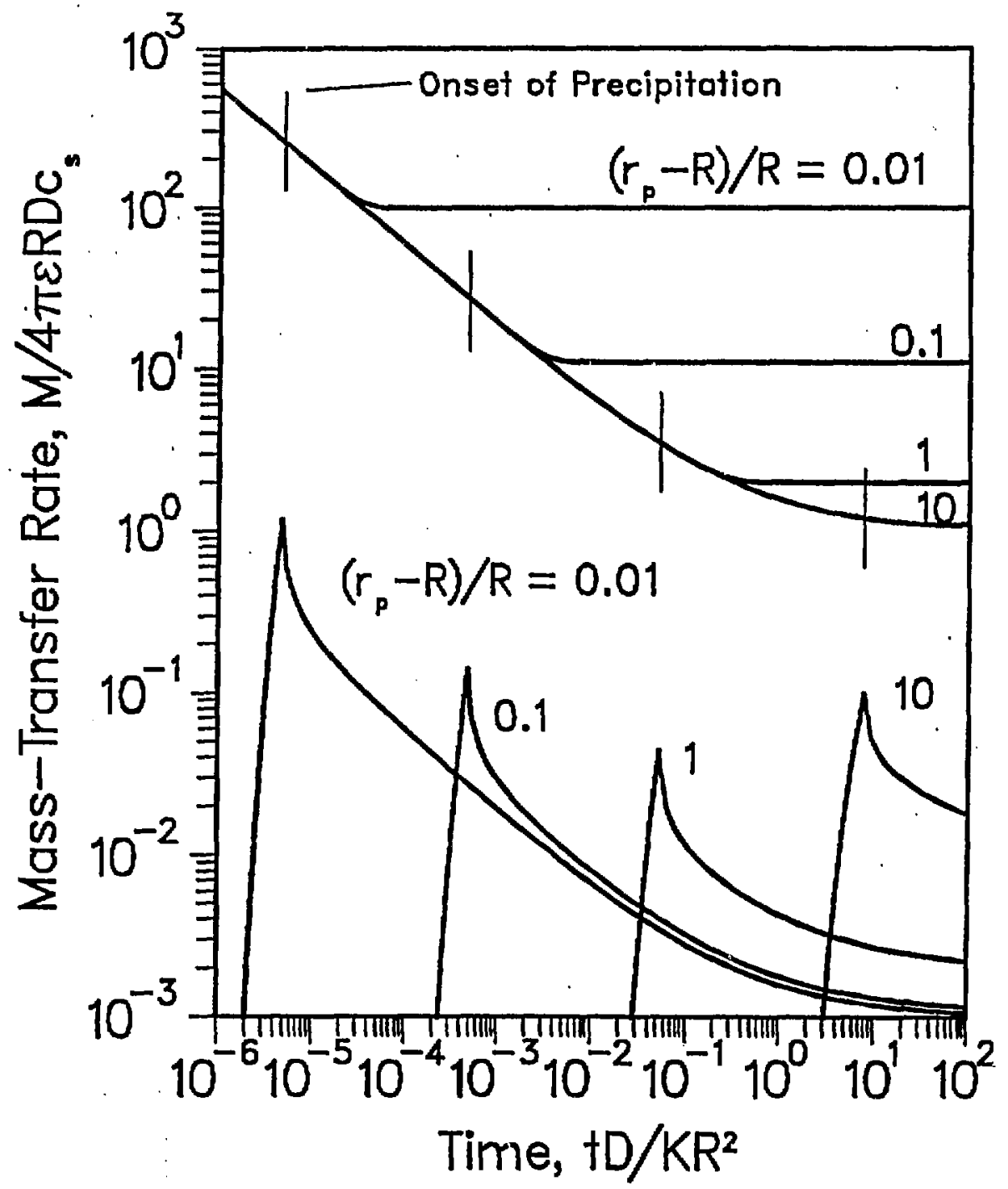

Figure 2.18 Dimensionless Mass Transfer Rate Out of a Waste Sphere and the Precipitation Front 
bars. If the precipitation front is close to the waste surface, precipitation starts soon and steady state is reached in early times. The mass-transfer rate at steady-state is about 100 times higher for the precipitation front at $\left(r_{p}-R\right) / R=0.01$ than for the precipitation front at infinity. The precipitation front is essentially an additional sink for dissolving contaminants, and putting it closer to the waste surface magnifies its effect by increasing the concentration gradient at the waste surface.

The lower set of curves shows the mass-transfer rates at the location of the precipitation front. The contaminant takes some time to arrive at this location. When concentration reachs the local solubility precipitation begins. Once precipitation starts, the mass-transfer rate out of the precipitation front decreases dramatically. The location of the precipitation front affects the time when precipitation begins. It also affects the steady-state mass-transfer rate out of the precipitation front, but only slightly.

At early times, the release rate is controlled by the solid-liquid renction rate represented by the dimensionless quantity $\alpha$. At later times extending to steady state, the relesse rate depends on the location of the precipitation front and on the solubility ratio $c_{J} / c_{r}$.

The result of fixing the front concentration at $c_{r}$ is to stcepen the concentration gradient on the waste package side of the front and to flatten the gradient in the region outside the front. 'The rate of contaminant transport from the waste to the front location is thereby maintained at a higher than normal rate while the rate of transport away from the front is held to lower levels. The difference in the transport rates at the front is the rate of precipitation. Nearly all of the species released at $c_{r}$ from the waste form is immobilized. Whether this scenario is more or lese desirable than other predictions without precipitation depends on the goals - whether we care about the waste dissolution rate or far-field transport rates, and whether the assumed uniform solubility is nearer to $c$, or $c_{r}$.

If a near-field region of high solubility is viewcd as a perturbation to the normal low solubility case, then we may conclude that the effect of the perturbation is to increase the release rate at the waste surface as well as at the precipitation front. The release rate at the waste surface may be greally affected if the front is very close to the waste surface and the ratio $c_{*} / c_{r}$ is very large. The release rate from the front location will increase with increasing radius of the high-solubility region due to the larger surface area at which the concentration $c_{r}$ is maintained.

The effect at the waste surface has the greatest potential for dramatic influence [Garisto 1986; Garisto and Garisto 1986a,b; 1988; Garisto et al. 1986]. If we apply our model to a controlling matrix species, the dissolution of which releases other waste components, we see that if these components are not solubility limited, their release toward the far-field could be greatly accelerated by a local high-solubility region for the controlling matrix species.

\subsection{Isatople Effects on Solubility-Limited Dlesolution}

In the previous theoretical analyses, solubility-limited mass transfer from waste solids applies if a species in liquid at the waste surface is at constant concentration given by the element al solubility. However, if there are other isotopes present, the species concentration must be less than the solubility. For an element with isotopes that decay appreciably during the time of interest, a solubility boundary condition results in a time-dependent boundary concentration of each isotope.

Let there be $\mathcal{M}$ isotopes of the element, and $\gamma_{i}$ the respective isotopic fraction in the waste solid so that $\sum_{i=1}^{M} \gamma_{i}=1$. Because the $\mathcal{M}$ isotopes decay at different rates, $\gamma_{i}=\gamma_{i}(t)$. However, for simplicity we 
assume that [U.S. Department of Energy 1986; Yung et al. 1987]

$$
\gamma_{i}(t)=\gamma_{i}, \quad \forall t
$$

With this assumption, the fractional release rate $f(t)$ for an isotope of elemental solubility $c_{\text {ae }}$, released from the surface of a waste sphere of radius $k$ by diffusive mass transfer into surrounding saturated porous rock of porosity $\epsilon$, based on the initial inventory $M_{i}^{0}$, is

$$
f_{i}(t)=\frac{4 \pi R c_{, e} \gamma_{i} D c}{M_{i}^{0}}\left\{1+\sqrt{\frac{K_{i} \lambda_{i} R^{2}}{D}} \operatorname{erf} \sqrt{\lambda_{i} t}+\sqrt{\frac{K_{i} R^{2}}{\pi D t}} c^{-\lambda_{,} t}\right\}, \quad \ell>0
$$

Eq. (2.8.2) is a suitable approximation for most radionuclides important in high-level waste. It can be used conservatively for species that decay in the time of interest by adopting $\gamma_{i}$ as the maximum value for that isotope during the interval.

A more accurate approach is to solve the mass-transfor equations for time-dependent $\gamma_{i}(t)$. For an elenent with two isotopes, the time-dependent inventories $M_{i}(t)$ and $M_{*}(t)$ for the radioactive and stable isotopes in the waste solid are [lsayama et al. 1989]

$$
\frac{d M_{i}(t)}{d t}=-\lambda_{i} M_{i}(t)-4 \pi R^{2}\left(-\epsilon D \frac{\partial c_{i}(R, t)}{\partial r}\right), \quad t>0
$$

and

$$
\frac{d M_{0}(t)}{d t}=-4 \pi R^{2}\left(-\epsilon D \frac{\partial c_{0}(R, t)}{\partial r}\right), \quad t>0
$$

where $c(r, t)$ is the nuclide concentration in pore liquid. For short-half-life nuclides the assumption can be made that

$$
4 \pi R^{2}\left(-c D \frac{\partial c_{i}(R, t)}{\partial r}\right) \ll \lambda_{i} M_{i}(t)
$$

and there is considerable simplification of the system of equations to be solved. $(2.8 .3)$ reduces to

$$
\frac{d M_{i}(t)}{d l}=-\lambda_{i} M_{i}(t), \quad t>0
$$

and $(2.8 .4)$ to

$$
\frac{d M_{0}(t)}{d t}=0, \quad t>0
$$

and the fractional release rate is

$$
\begin{aligned}
f_{i}(t)=4 \pi R c_{s e} D \epsilon & \left(\frac{e^{-\lambda_{i} t}}{M_{i}^{0} e^{-\lambda_{i} t}+M_{i}^{0}}+\sqrt{\frac{K_{i} R^{2}}{\pi D}} \frac{e^{-\lambda_{1} t}}{M_{i}^{0}+M_{i}^{0}} \frac{1}{\sqrt{t}}\right. \\
& \left.+\sqrt{\frac{K_{i} \lambda_{i} R^{2}}{D}} \frac{2}{\sqrt{\pi}} \int_{0}^{\sqrt{\lambda_{1} t}} \frac{M_{i}^{i} e^{-2 \lambda_{i} t-\eta^{2}}}{\left(M_{i}^{0} e^{-\lambda_{1} t-\eta^{2}}+M_{i}^{o}\right)^{2}} d \eta\right), \quad r>R, \quad t>0
\end{aligned}
$$


Table 2.1. Date ueed for Inotople Efrect Illuntration

\begin{tabular}{|l|c|c|c|l|}
\hline \multicolumn{1}{|c|}{ Property } & Units & ${ }^{88} \mathrm{Sr}$ & ${ }^{90} \mathrm{Sr}$ & \multicolumn{1}{|c|}{ Ref. } \\
\hline Decay Constant $(\lambda)$ & per year & 0 & 0.024 & Browne and Firestone 1980 \\
\hline Isotopic Fraction $(\gamma)$ & & 0.4 & 0.6 & Browne and Firestone 1986 \\
\hline Initial Inventory $\left(M^{\circ}\right)$ & $\mathrm{g} / \mathrm{MTHM}$ & 349 & 519 & Roddy et al. 1986 \\
\hline Retardation Coefficient $(K)$ & & 200 & Pigford et al. 1983 \\
\hline Diffusion Coefficient $(D)$ & $\mathrm{m}^{2} / \mathrm{a}$ & $3 \times 10^{-3}$ & Pigford et al. 1983 \\
\hline Elcmental Solubility $\left(c_{\mathrm{se}}\right)$ & $\mathrm{g} / \mathrm{m}^{3}$ & 0.01 & Pigford et al. 1983 \\
\hline
\end{tabular}

'To illustrate, we consider the release of solubility-limited strontium, consisting of radionctive ${ }^{90} \mathrm{Sr}$ and

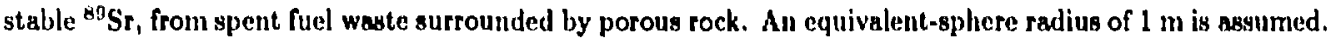
The waste container and fuel cladding are assumed not to be present, and the waste is assumed to contact ground water shortly after emplacement. Using assumed properties listed in 'Table I, calculated fractional release rates of ${ }^{90} \mathrm{Sr}$ for constant and time-dependent boundary concentrations are shown in Figure 2.19. Because ${ }^{90} \mathrm{Sr}$ is the only decaying species, the fractional release rate considering decay is much less than the more conservative value that neglects decay. Fractional release rates based on the 1000-year inventory, as required by federal regulations, can be obtained by multiplying the values in Figure 2.19 by $e^{1000 \lambda}$.

\subsection{SOLUBLE SPLCIES}

In a spent-fuel waste package the soluble cesium and iodine accunulated in fuel-cladding gaps, voids, and grain boundaries of spent fuel rods are expected to dissolve rapidly when groundwater penetrates the fuel cladding [Garisto et al. 1989]. Even though dissolution may be rapid, the rate of release of these readily soluble species from the waste package will be limited by the rate of mass transfer of the dissolved species into the surrounding porous media. Chambre has developed the analytic solution for the fractional release rate of a soluble radioactive species, assuming instantaneous dissolution of the soluble species into a volume $V$ of ground water that has penetrated in the waste package voids at $t=0$, and assuming that the groundwater flow rate is small enough that mass-transfer into surrounding porous rock is controlled by molecular diffusion,

\subsection{Mase Truncfer from Waste into Porous Rock}

We assume that the surrounding porous rock is in direct contact with the well-mixed void liquid (Figure 3.1a), that contains initially a specified quantity of these readily soluble species. Linear geometry is used in analyzing the dissolution of readily soluble species. The species migrate into the porous material under a concentration gradient. Assuming that advective transport in the near-field is small compared with diffusive transport, the space-time-dependent concentration $c(x, t)$ in pore water is given by

$$
K \frac{\partial c(x, t)}{\partial t}=D \frac{\partial^{2} c(x, t)}{\partial x^{2}}-\lambda K c(x, t), \quad x>a, \quad t>0
$$

The initial and boundary conditions are

$$
\begin{aligned}
& c(x, 0)=0, \quad x>a \\
& c(a, t)=c^{\prime}(t), \quad t \geq 0
\end{aligned}
$$




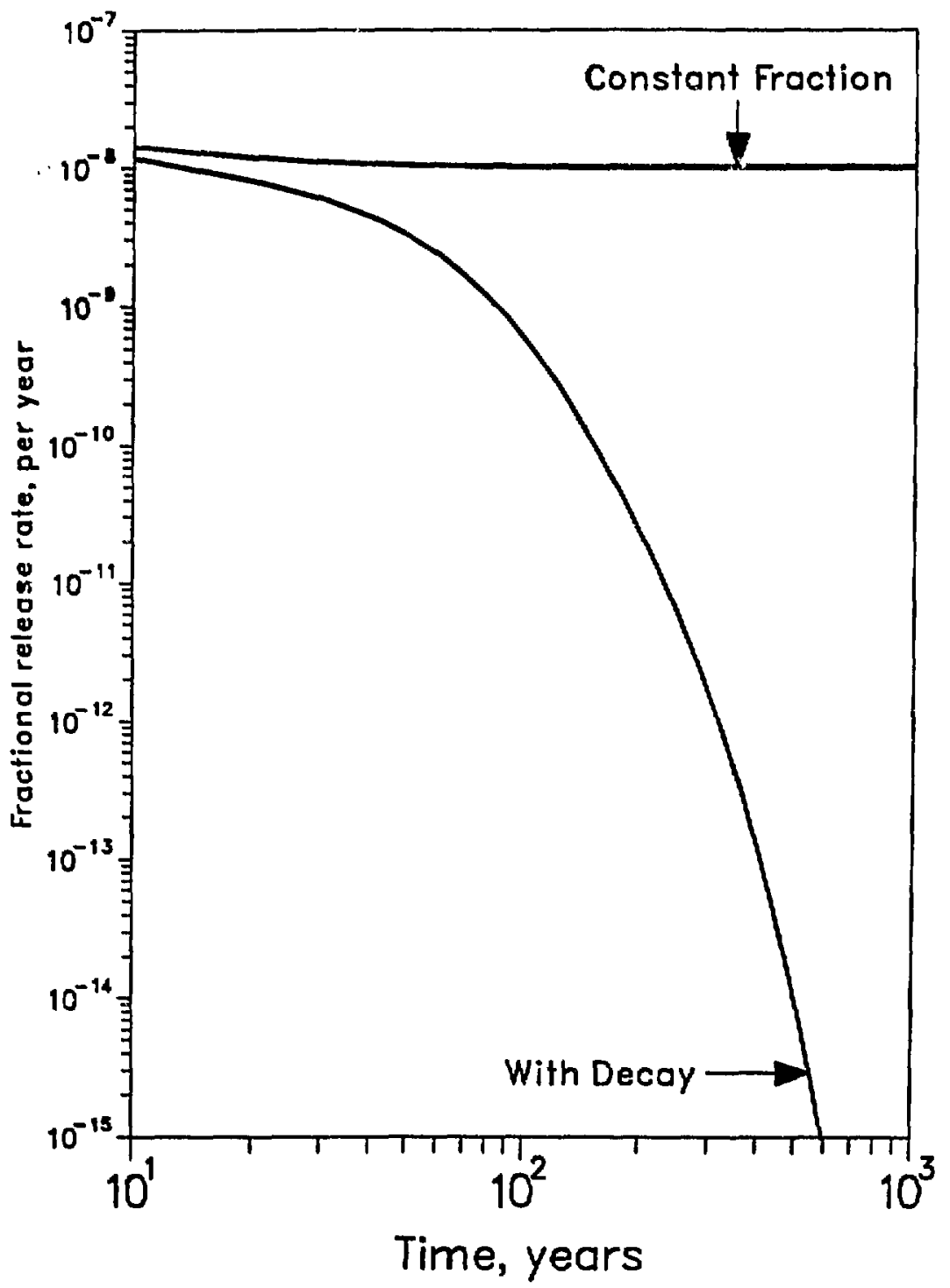

Figure 2.19 Fractional Release Rate of Sr-90 Assuming Constant Fraction and Accounting for Decay 


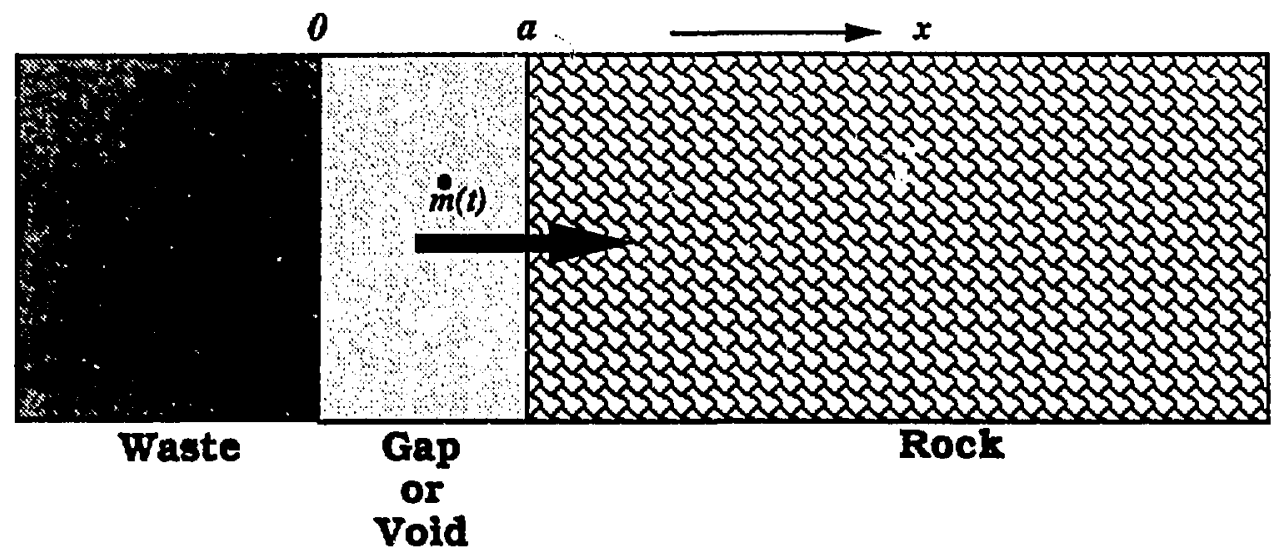

Figure 3.1a. Release of Soluble Species into Rock

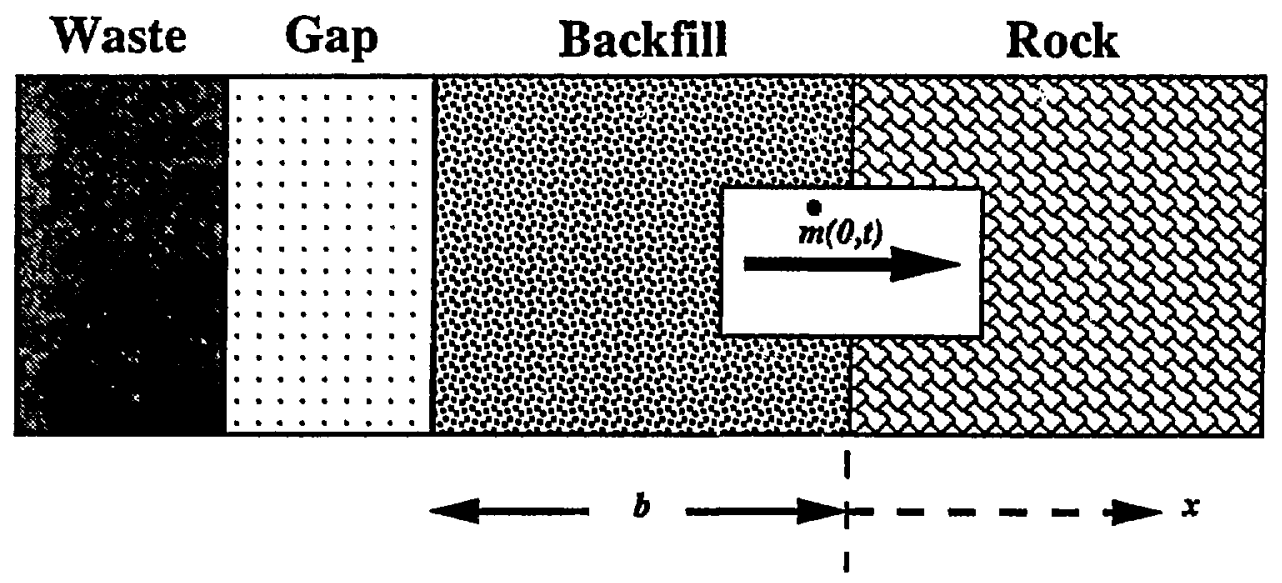

Figure 3.1b. Release of Soluble Species into Backfill and Rock 


$$
\begin{aligned}
& \text { Neantield Mane Tranofor } \\
& c(\infty, t)=0, \quad t \geq 0
\end{aligned}
$$

where $a$ is the thickness of the "gap" filled with void water. Here $c^{\prime}(t)$ is the time-dependent well-mixed concentration of the soluble species in the water in the void. To solve for $c^{\prime}(t)$, the mass balance in the void is

$$
V \frac{d c^{\prime}(t)}{d t}=\dot{m}_{f}(t)-\dot{m}(t)-\lambda V c^{\prime}(t), \quad t>0
$$

where $\dot{m}_{f}(t)$ is the rate of dissolution of the species from the waste matrix into the void volume $V$, and $\dot{m}(t)$ is the rate of species migration into the rock. To solve Eq. (3.1.5), we use the initial condition

$$
c^{\prime}(0)=c^{0}
$$

where $c^{\circ}$ is the concentration of the species in the void water, resulting frosii the assumed instantancous dissolution of the readily soluble form of the opecies. Chambre has obtained the solution to Eq. (3.1.5)

$$
c^{\prime}(l)=c^{0} e^{-\lambda l} \mathrm{~F}\left(\beta^{2} l\right)+\frac{1}{V} \int_{0}^{l} \dot{m}_{J}(\ell-r) e^{-\lambda \tau} \mathrm{F}\left(\beta^{2} r\right) d r, \quad t>0
$$

where

$$
F\left(\beta^{2} t\right) \equiv e^{\beta^{2}} \operatorname{erfc} \sqrt{\beta^{2} t}
$$

and

$$
\beta \equiv \sqrt{D h^{2} / a^{2}}
$$

The rate of mass transfer of the species into the rock is

$$
\dot{m}(t)=-S D c \frac{\partial c(a, t)}{\partial x}, \quad t>0
$$

where $S$ is the surface area of the interface between the void space and the rock $(S \equiv V / a)$. Using (3.1.6) the solution to (3.1.7) is

$$
\dot{m}(t)=c^{0} \beta V e^{-\lambda t}\left\{\frac{1}{\sqrt{\pi t}}-\beta \mathrm{F}\left(\beta^{2} t\right)\right\}+\beta \int_{0}^{t} \dot{m}_{j}(t-\tau) e^{-\lambda r}\left\{\frac{1}{\sqrt{\pi \tau}}-\beta \mathrm{F}\left(\beta^{2} \tau\right)\right\} d \tau, \quad t>0
$$

To obtain an expression for $\dot{m}_{f}$ use (2.1.2.2.1) to estimate a dissolution rate of the controller species, and the congruent dissolution assumption to get the species' matrix dissolution rate. The matrix of nuclear waste is likely to be either $\mathrm{UO}_{2}$ in spent fuel or silicn in glass waste. The matrix species have low decay rates, thus the assumption of a stable species is justified. In the planar geometry used in this section, we let $R \rightarrow \infty$ to obtain

$$
\dot{m}_{c}=S c, c \sqrt{\frac{K_{c} D}{\digamma}}
$$

where $\dot{m}_{c}$ is the mass transfer rate of the controller or don. ,nt species.

Using the congruent dissolution assumption

$$
\frac{\dot{m}_{f}(t)}{\dot{m}_{c}(t)}=\frac{M(t)}{M_{c}(t)}
$$

where $M(t)$ is the species inventory at $t$ and $M_{c}(t)$ is the controller's inventory at $t$ we obtain

$$
\dot{m}_{f}=S c_{0} c \sqrt{\frac{K_{c} D}{\pi t}} \frac{M^{\circ}}{M_{e}^{\circ}} e^{-\lambda t}
$$




\section{Near-fold Maes Tranetor}

where $M^{\circ}$ is the initial inventory of the species in the waste package, and $M_{c}^{\circ}$ is the initial inventory of the contrcller species in the waste package. We have the final results

$$
c(x, t)=c^{0} e^{-\lambda t} e^{\beta \sqrt{K / D}(x-a)} e^{\beta^{2} \tau} \operatorname{erfc}\left(\beta \sqrt{t}+\frac{\sqrt{K / D}(x-a)}{2 \sqrt{\tau}}\right)+c, \frac{M^{0}}{M_{c}^{0}} \sqrt{K_{c} / K} \beta \mathrm{F}\left(\beta^{2} t\right) e^{-\lambda t}, \quad t>0
$$

and

$$
\left.\dot{m}(t)=e^{0} \beta V e^{-\lambda t}\left\{\frac{1}{\sqrt{\pi t}}-\cdots \cdot \beta^{2} t\right)\right\}+\beta \int_{0}^{t} e^{-\lambda r}\left\{-\frac{1}{\sqrt{\pi \tau}}-\beta \mathrm{F}\left(\beta^{2} \tau\right)\right\} d \tau
$$

from which the fractional release rate can be calculated [Kim, Chambré and Pigford 1986].

A computer program, UCB-NE-107 [Lee 1989b] implements eq. (3.1.15) and is available from the National Energy Software Center.

Figure 3.2 shows the fractional release rates of ${ }^{138} \mathrm{Cs},{ }^{137} \mathrm{Cs}$ and ${ }^{129} \mathrm{I}$ based on Eq. (3.1.10). In this illustration we consider the release from a bare waste form exposed to ground water shorly after emplacement, conservatively neglecting the mass-transfer resiatance due to containers and cladding. The lower curves show the solubility-limited dissolution rate from the waste matrix, assuming congruent dissolution and a uranium solubility of $10^{-3} \mathrm{~g} / \mathrm{m}^{3}$. A conservatively high diffusion coefficient of $0.12 \mathrm{~m}^{2} / \mathrm{a}$ is used throughout the analysis, and a porosity of 0.01 is assumed. The fractional release rates in Figure 3.2 are normalized to initial inventories. At $t=0$, one percent of these epecies is assumed to disoolve into the water-filled void space of $0.45 \mathrm{~m}^{3}$. The calculaled USNRC fractional release rate limits on these species, based on initial inventories, are

$$
\begin{aligned}
{ }^{135} \mathrm{Cs} & =4.5 \times 10^{-5} \text { per year } \\
{ }^{137} \mathrm{Cs} & =1.8 \times 10^{-10} \text { per year } \\
{ }^{129} \mathrm{I} & =5.4 \times 10^{-4} \text { per year }
\end{aligned}
$$

With these parameters, the early contribution from gap inventory is more than $10^{7}$-fold greater than the contribution from the waste matrix. For early times, the fractional release rates of ${ }^{135} \mathrm{Cs}$ and ${ }^{137} \mathrm{Cs}$ are almost equal, but the ${ }^{137} \mathrm{Cs}$ release rate decreases rapidly because of radiouctive decay, whereas the release rate of $3 \times 10^{6}$-year ${ }^{135} \mathrm{Cs}$ is characteristic of a stable species. Because of the assumed negligible sorplion of jodine in the rock, the early fractional release rate of $1.7 \times 10^{7}$-year ${ }^{129} I$ is lower than the rates of strongly sorbing cesium, but the less rapid early depletion of iodine in the void water results in greater fractional release rate of iodine after about 20 years.

The fractional release rate of ${ }^{137} \mathrm{Cs}$ exceeds the USNRC release rate limit for several hundred years. The presence of metallic containers, and the time-distributed nature of container failure will likely help meet the requirement.

\subsection{Mace Tranafer of soluble 8pecles Into Backnll and Porous Rock}

The situation studied and the notation is similar to Section 2.3.1, except that linear geometry of Figure $3.1 \mathrm{~b}$ is used here. Here we define the origin at the interface of the gap and the backfill. The backfill is of thickness $b$, and the surrounding rock is infinitely thick. Water flow is small enough that near-field mass transfer is principally by diffusion. 


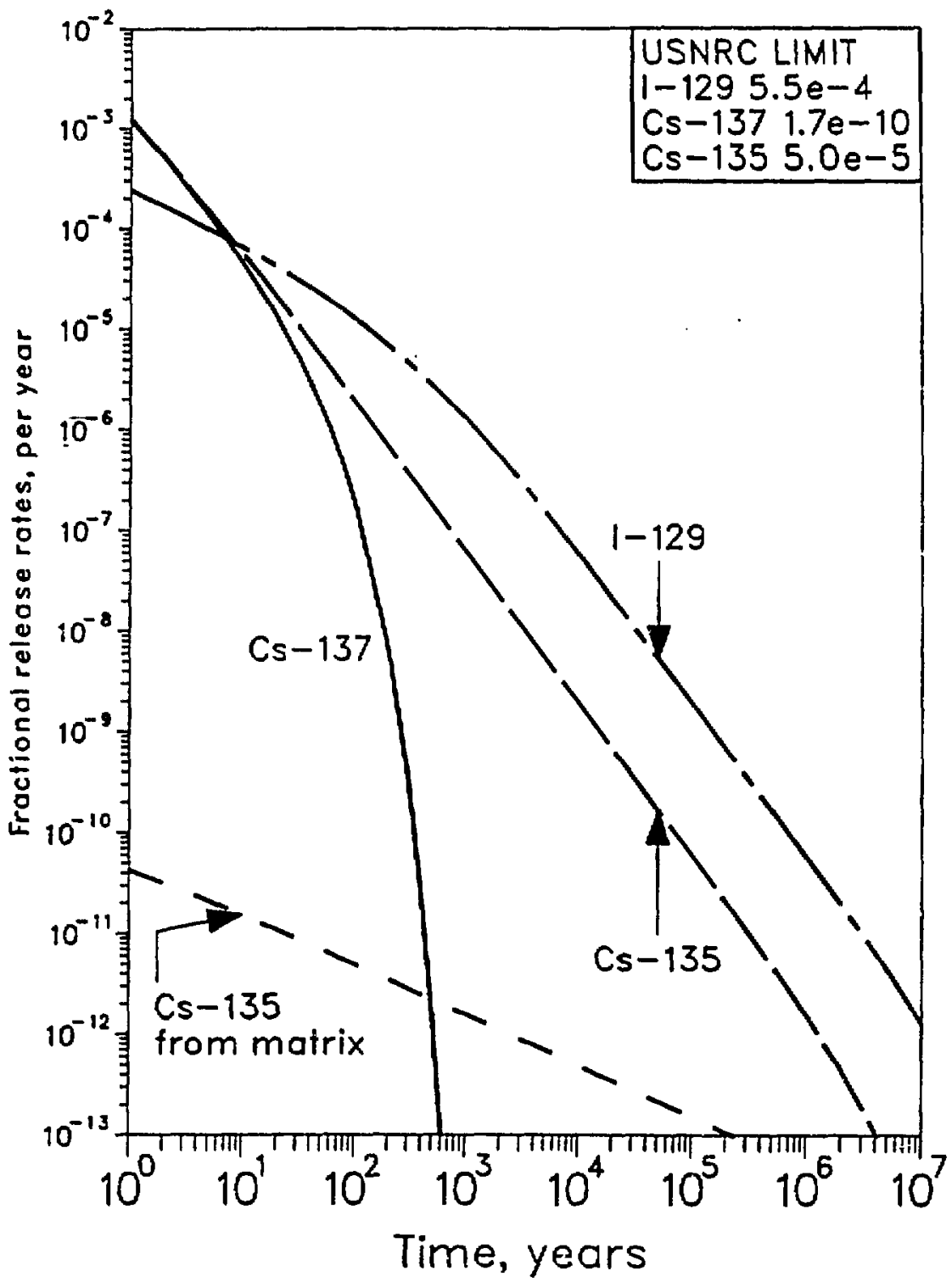

Figure 3.2 Fractional Release Rates of Some Soluble Species 
The governing equations are

$$
\begin{array}{cc}
\frac{\partial c_{1}}{\partial t}=D_{1} \frac{\partial^{2} c_{1}}{\partial x^{2}}-\lambda c_{1}, & -b<x<0, t>0, D_{1} \equiv \frac{D_{f} \sigma_{1}}{K_{1}} \\
\frac{\partial c_{2}}{\partial t}=D_{2} \frac{\partial^{2} c_{2}}{\partial x^{2}}-\lambda c_{2}, & x>0 . t>0, D_{2} \equiv \frac{D_{f} \sigma_{2}}{K_{2}}
\end{array}
$$

The side conditions are

$$
\begin{array}{rlrl}
c_{1}(x, 0) & =0, & & -b<x<0, \\
c_{2}(x, 0) & =0, & x>0 & \\
c_{1}(0, t) & =c_{2}(0, t), \quad \quad t \geq 0 \\
-\epsilon_{1} D_{1} \sigma_{1} \frac{\partial c_{1}}{\partial x} & =-\epsilon_{2} D_{j} \sigma_{2} \frac{\partial c_{2}}{\partial x} \quad \text { at } \quad x=0, \quad t \geq 0 \\
c_{2}(\infty, t) & =0, \quad t \geq 0
\end{array}
$$

We assume that the readil: soluble speciss are readily at $t=0$ into water that has filled the waste-package void volume $V$ which has a surface area $S$. Here we do not include the slower releare of the same species from the waste matrix. The mass balance of the readily soluble species in the void volume is

$$
-V \frac{\partial c_{1}(-b, t)}{\partial t}=-\partial_{f} \sigma_{1} \epsilon_{1} S \frac{\partial c_{1}(-b, t)}{\partial x}+\lambda V c_{1}(-b, t), \quad t \geq 0
$$

The initial concentration of the readily soluble species is taken to be

$$
c_{1}(-b, 0)=c^{0}
$$

We will write the solution in terms of the rate of mass transfer across the backfill/rock interface

$$
\begin{gathered}
\dot{m}(0, t)=2 K_{1} \epsilon_{1} c^{0} S \frac{e^{-\lambda t}}{(\delta+1)} \sum_{n=0}^{\infty}\left[\sqrt{\frac{D_{1}}{x t}} \operatorname{exf}\left\{\frac{(-2 n+1)^{2} b^{2}}{4 D_{1} t}\right\}-\omega D_{1} \exp \left\{(2 n+1) b \omega+D_{1} \omega^{2} t\right\}\right. \\
\left.\quad \times \operatorname{erfc}\left\{\frac{(2 n+1) b}{2 \sqrt{D_{1} t}}+\omega \sqrt{D_{1} t}\right\}\right]\left(\frac{\delta-1}{\delta+1}\right)^{n}, \quad n=0,1,2, \ldots, \infty
\end{gathered}
$$

where

$$
\delta=\sqrt{\frac{K_{1}}{K_{2}}} \frac{\epsilon_{1} \sigma_{1}}{\epsilon_{2} \sigma_{2}} \quad \omega=K_{1} \epsilon_{1} S / V
$$

\section{Numerical Illustrations}

Figure 3.3 shows some example fractional release rates of ${ }^{135} \mathrm{Cs},{ }^{137} \mathrm{Cs}$ and ${ }^{129} \mathrm{I}$ based on (3.2.10) [Chambré et al. 1986]. In this illustra ion we consider the release from a bare waste form exposed to ground water shortly after emplacement We assume that fuel cladding and a container are not present, water contacts the interior of spent-fuel rods shortly after emplacement, and 1 percent of the total inventory of cesium and iodine is rapidly dissolved into the "yoid water" that fills voids in the waste package. The void water is equivalent in volume to a $7.4-\mathrm{cm}$ thick layer of water between the waste solid and backfill. Ground-water flow is assumed to be small enough that mass transfer through backfill and into the rock is controlled by molecular diffusion. Time-dependent fractional release rates at the backfill/rock interface, 


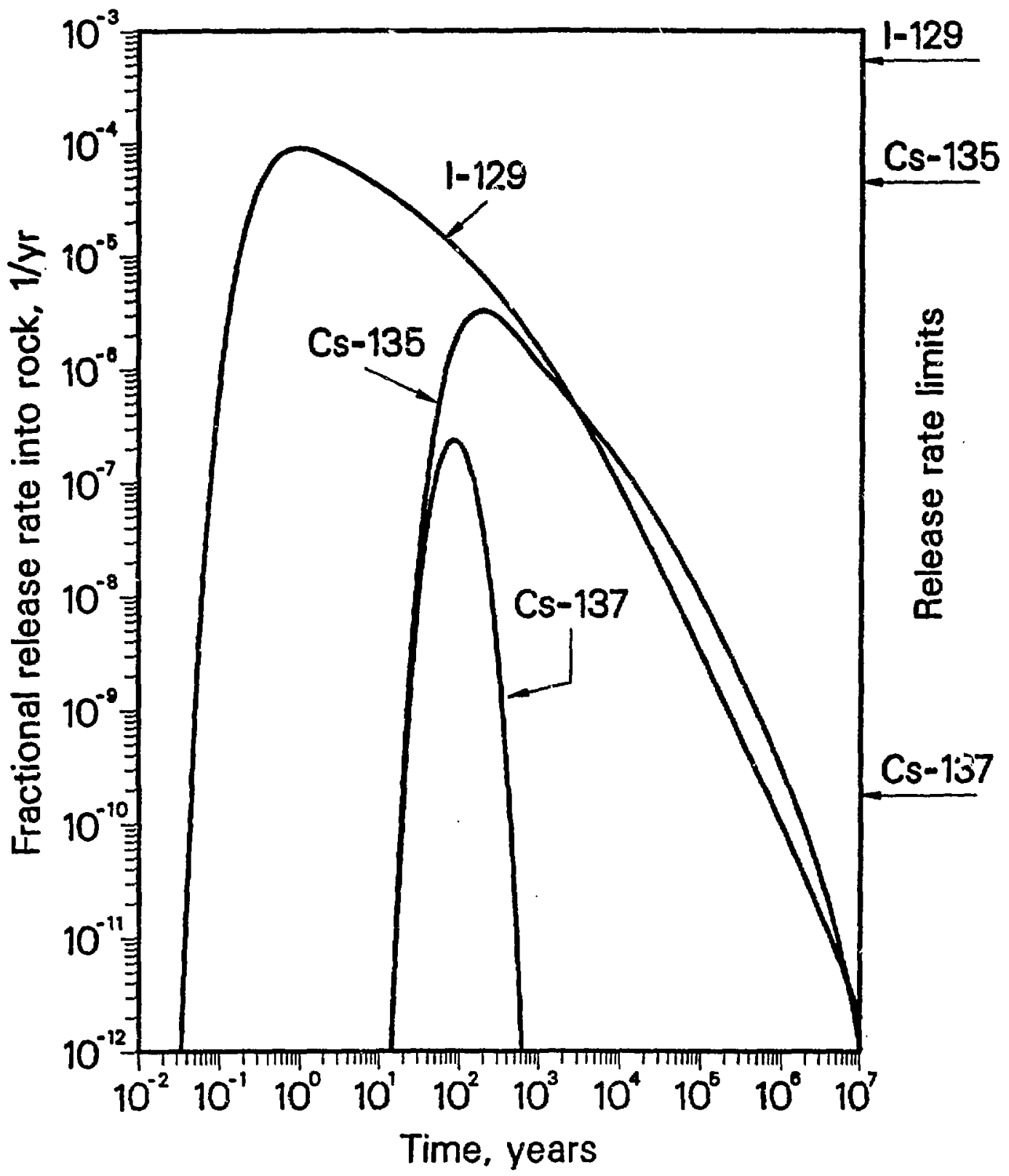

Figure 3.3 Fractional Release Rates of Some Soluble Species Through 30 cm of Backfll 
normalized to initial inventories, are shown in Figure 3.3 for a diffusion coefficient of $10^{-5} \mathrm{~cm}^{2} / \mathrm{s}$, backfill porosity of 0.2 , rock porosity of 0.01 , a concentration-based distribution coefficient of 100 for cesium, and for a backfill thickness of $30 \mathrm{~cm}$. Nonsorbing ${ }^{129} 1$ arrives at the backfill/rock interface in less than a year, with a pexk release rate about tenfold less than the equivalent fractional release rate limit calculated from the NRC criterion [USNRC 1983]. ${ }^{135} \mathrm{Cs}$ and ${ }^{137} \mathrm{Cs}$ arrive later simultaneously, but the normalized peak release rate of ${ }^{137} \mathrm{Cs}$ is less because of more rapid decay. The peak release rate of ${ }^{135} \mathrm{Cs}$ is about tenfold less than its release rate linitit, but the peak release rate of cesiuın- 137 exceeds its limit by several orders of magnitude for several hundred years.

A computer program, UCB-NE-108 [Kang and Lee 1989] implements eq. (3.2.10) and is available from the National Energy Software Center.

\subsection{Temperature Infecto}

Calculation of the effect of repository heating on the rate of diffusive mass transfer of soluble species into the rock is sinipler because the only parameter affected by temperalure is the diffusion coefficient, if the retardation coefficient can be asuned constant. Chambre obtained the solution of equation system (3.1.1) through (3.1.5) for a constant diffusion coefficient [Section 2.5], and Kim modified the solution for application to the problem with a time-dependent diffu.ion coefficient [Kim et al. 1988], adapting the transformations given in Chambré et al. [1985].

The solution gives the species concentration in the void as

$$
c(t)=c^{0} e^{-\lambda t} \exp \left\{\beta^{2} \int_{0}^{t} g\left(t^{\prime}\right) d t^{\prime}\right\} \operatorname{erf} \sqrt{\beta^{2} \int_{0}^{t} g\left(t^{\prime}\right) d t^{\prime}}, \quad t>0
$$

where

$$
\beta \equiv \sqrt{D_{0} K \epsilon^{2} / a^{2}}
$$

The concentration of the species in the rock is

$$
\begin{aligned}
c(x, t)=c^{0} e^{-\lambda t} e^{K(t x-a) / a} & \exp \left\{\beta^{2} \int_{0}^{t} g\left(t^{\prime}\right) d t^{\prime}\right\} \\
& \quad x \operatorname{erfc}\left\{\sqrt{\beta^{2} \int_{0}^{t} g\left(t^{\prime}\right) d !^{\prime \prime}}+\frac{K c(x-a)}{2 a} \frac{1}{\sqrt{\beta^{2} \int_{0}^{\prime} g\left(t^{\prime}\right) d t^{\prime}}}\right\}, x \geq a, t>0
\end{aligned}
$$

The mass flux of the species into the rock is

$$
\dot{m}(t)=-S D(t) \epsilon \frac{\partial c(a, t)}{\partial x}, \quad t>0
$$

Using (3.3.2) the solution to (3.3.3) is

$$
\dot{m}(t)=c^{0} \beta V g(t) e^{-\lambda t}\left\{\frac{1}{\sqrt{\beta^{2} \int_{0}^{t} g\left(t^{\prime}\right) d t^{\prime}}}-\beta e^{\beta^{2} \int_{0}^{t} g\left(t^{\prime}\right) d t^{\prime}} \operatorname{erfc} \sqrt{\beta^{2} \int_{0}^{t} g\left(t^{\prime}\right) d t^{\prime}}\right\}, t>0
$$

The results are illustrated for ${ }^{135} \mathrm{Cs}$ in Figures 3.4 and 3.5. For the time intervals of Figure 3.4, the ${ }^{135} \mathrm{Cs}$ concentration in the water filling the waste package is always lower than that predicted on the basis of 


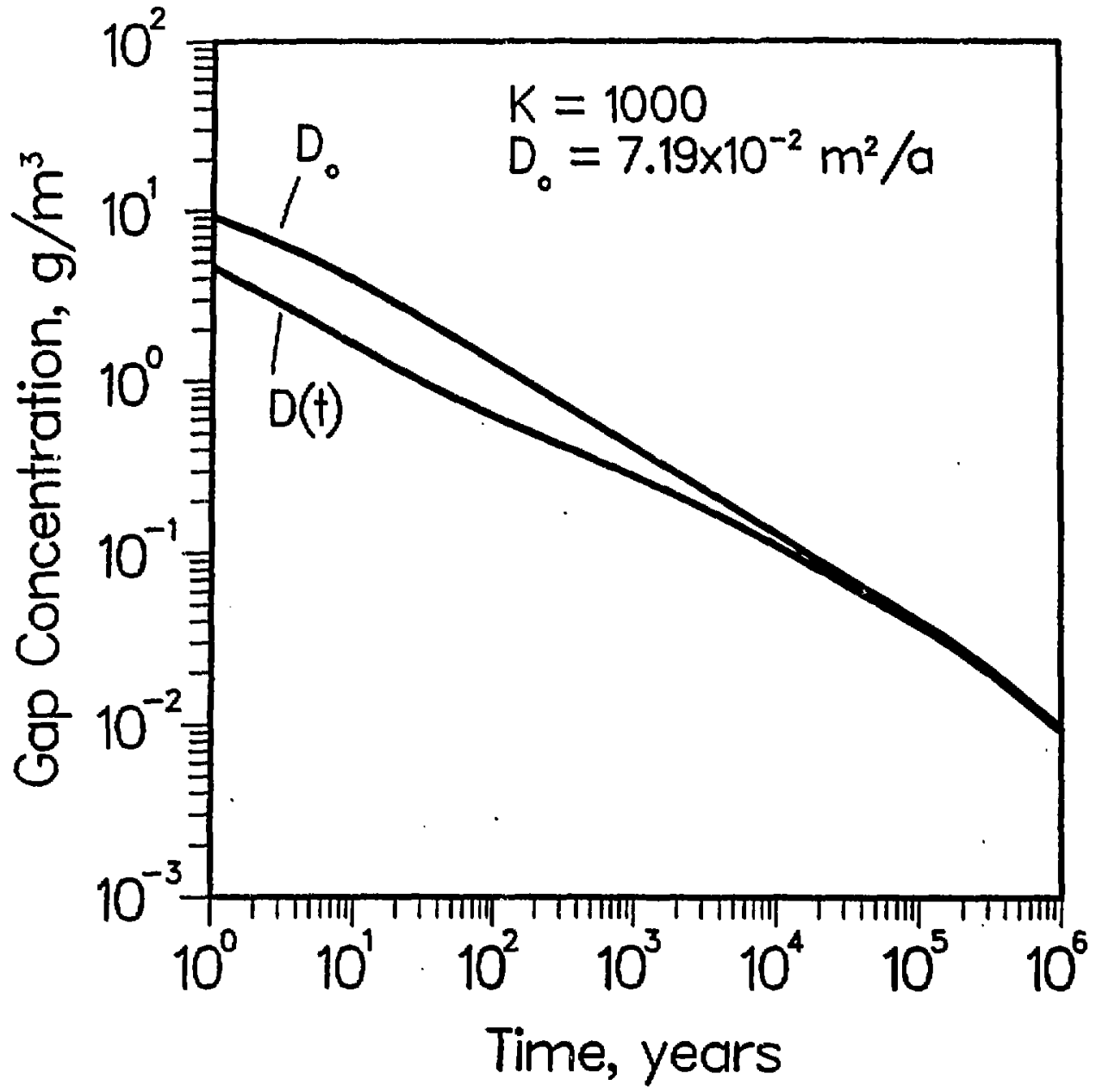

Figure 3.4 Time-Temperature-Dependent Concentration of Cs-135 in the Vold 
Fractional Release Rate, $a^{-1}$

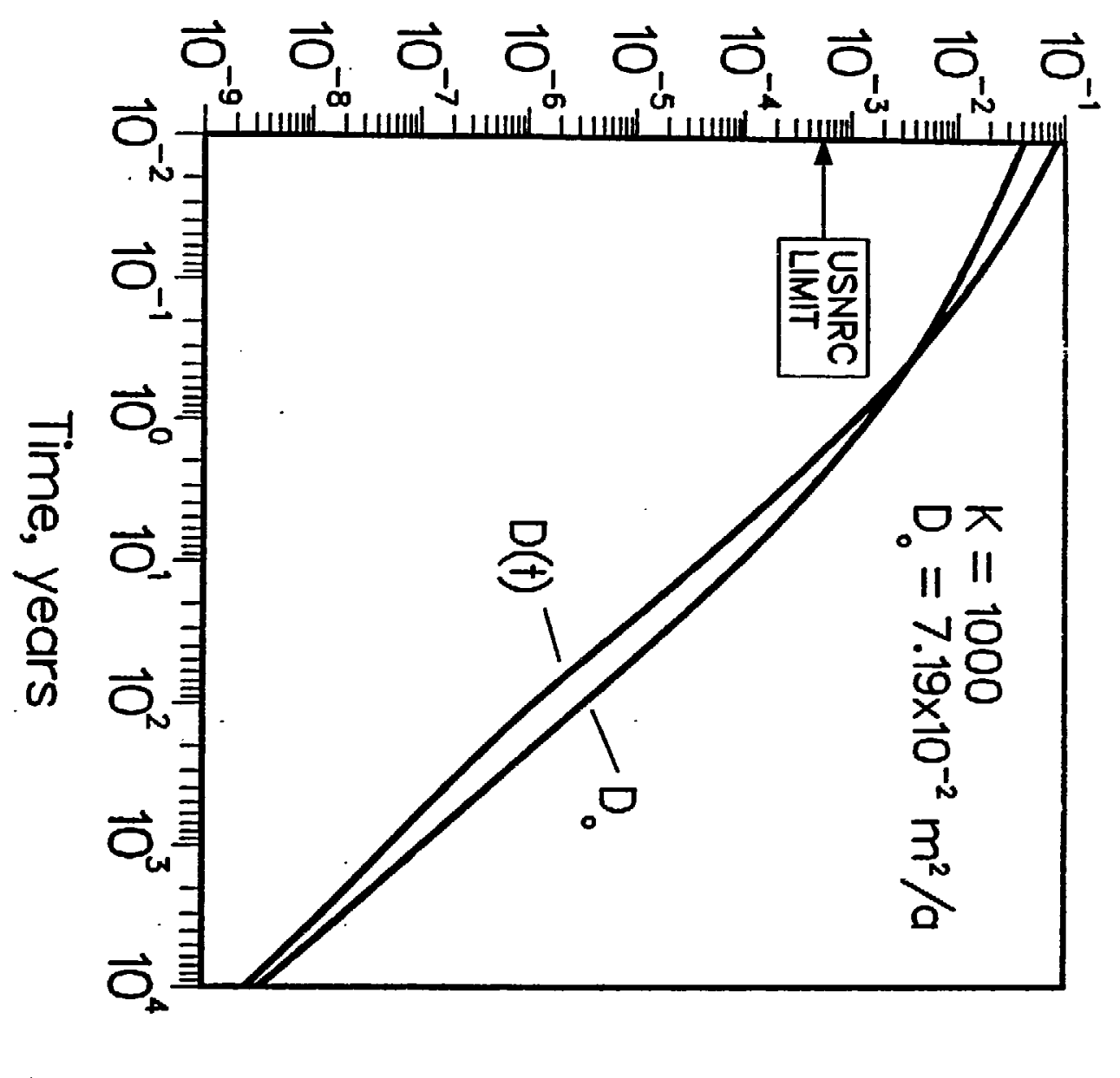


a constant ambient temperature. At very early times, as shown in Figure 3.5, the higher diffusion coefficient causes greater mass transfer rate from the waste-package water into the surrounding rock, depleting the concentration in the waste-package water. This early depletion results in a later mass-transfer rate that is lower than would occur if the temperature were always at the ambient temperature. Thus, for most times of interest, the release rate predicted by using a diffusion coefficient evaluated at ambient temperature is conservatively higher than the release rates corrected for repository heating.

\subsection{DIscussion OF THLORT AND LnITATIONS}

\subsection{Effect of a Lquid-Filled Annulus Between wate and Rock}

The mass-transfer equations described above assume that the waste solid is in contact with porous rock containing ground water. The ansumption of a constant solubility-linut boundary concentration for low-solubility species has been discussed above. The theory assumes conservatively that the corrosionresistant container of the waste package has failed and that its corrosion products offer no resiatance to mass transfer. If there ia a liquid-filled annulus between the waste package and the rock, or between the waste solid and the rock, the mase-tranefer equations are still applicable, provided there is no appreciable convective flow through the annulus. It is ressonable to assume that the liquid between the waste solid and rock is well mixed, so the dimensions of the borehole should be used for the geometrical parameters in the mass-transfer equations. The effects of convective transport in the annulus and convective flow through the waste solid have not been analyzed, in the present report.

\subsection{Iffect of Mow Direction and Geometry}

The analyses described above have assumed that ground water flows normal to the cylindrical axis of a waste package. Other flow directions are possible in a repository. Chambré has considered flow parallel to the axis, as well as other waste-form geometries, and has shown that predicted dissolution rates are not significantly different.

\subsection{Hydrodynamic Dieperalon}

It has been suggested by some [Ross 1967] that because of hydrodynamic dispersion the effective diffusion coefficient that appears in the analytical solutions should be a value greater than that for molecular diffusion. However, experimental data [Sherwood, Pigford and Wilke 1975; Pfankuch 1963] for effective diffusion coefficients in packed columns, show that for the ground water velocities and dimensions typical for individual waste packages the value for molecular diffusion should be used. At locations far enough removed from the waste surface for hydrodynamic dispersion to become important, the concentration gradients are too small to affect the mass transfer from the waste surface. However, if the same governing equations were to be applied to mass transfer over greater distances, the effect of hydrodynamic dispersion should be considered. As Pfannkuch [1963] shows, the effective diffusion coefficient will increase with distance, requiring equations for diffusive-advective transport with a space-dependent diffusion coefficient, such as that developed by Chambré [Kang, Chambré and Pigford 1985].

\subsection{Effect of Radlonctive Decay}

The equations described above were developed for radionuclides with no radioactive-decay precursors. 
Some of the radionuclides important in repository performance assessment are continuously generated by decay of precursors, e.g., Ra-226 from U-234 and Th-230, and Th-229/Ra-229 from Np-237 and U-233. It is not necessarily conservative to apply the mass-transfer equations for a species with no precursor separately to each member of the decay chain, assuming that each species is at its solubility limit in ground water near the waste surface [USDOE 1986]. Decay of a precursor in the transport field can cause penetration of its daughters into the field further from the waste surface, resulting in greater rates of mass-lransfer into the rock. This is particularly important when mass-transfer theory is used to predict the rate of transport through backfill, or through other intervening diffusing media, into surrounding rock. The greater penetration of a long-lived precursor through the backfill is a means for a shorter-lived daughter to appear at appreciable distances from the waste surface. A near-field man-transfer analysis applicable to the simultaneous diffusive transport of a radionuclide chain has been developed and is described later.

\subsection{Local Borptlon Equitbrium}

These equations assume local sorption equilibrium, with an assumed constant retardation coefficient. Mass transport without local chemical equilibrium between liquid and solid phases has been analyzed in a previous report [Zavoshy el al. 1985]. Mass transfer with local sorption equilibrium but with a concentrationdependent sorption distribution coefficient is discussed in Section 2.6 of this report.

\subsection{Surface Diffundon}

The analyses and equations above asaume no diffusion of sorbed species on or in the solid phase. However, some experiments with selected species and solids have demonatrated appreciable surface diffusion of sorbed species. For accurate predictions of mass transfer an experimentally determined diffusion coefficient is desirable, rather than using the upper-limit value usually adopted in our numerical illustrations. In making such measurements, it is important to check also the posaibility of surface diffusion. The mas-tranafer equations can be reformulated if such measurements indicate that surface diffusion need be considered.

\subsection{Interference from Other Wante Packages}

These equations for the rate of mass transfer from individual waste packages conservatively neglect the overlapping concentration fields resulting from species dissolved from nearby waste packages. For high-level waste packages separated by several meters the concentration fields are not expected to overlap enough in the near field to significantly reduce the mas transfer from an individual package.

Although nearby waste packages do not appreciably affect the dissolution and release rates, the overlapping concentration fields do affect the calculation of far-field transport from arrays of waste packages [Pigford et al. 1980; Kim et al. 1987; Ahn et al. 1987]. Array effects are illustrated in Figure 4.1, where the local steady-state concentration of a contaminant along the flow path, normalized to the steady-state concentration at that position for an infinite plane source of the same areal source strength, is plotted against a dimensionless quantity that increases with distance along the flow path. Near the waste package the threedimensional contaminant plumes from irradiated packages must be considered. At greater distances the concentration fields from individual packages mer, se, the concentration is reduced by transverse dispersion from the outer edges of the coalesced plumes, and the concentration field is characteristic of that from a single finite planar source of the same areal source strength as the array. 


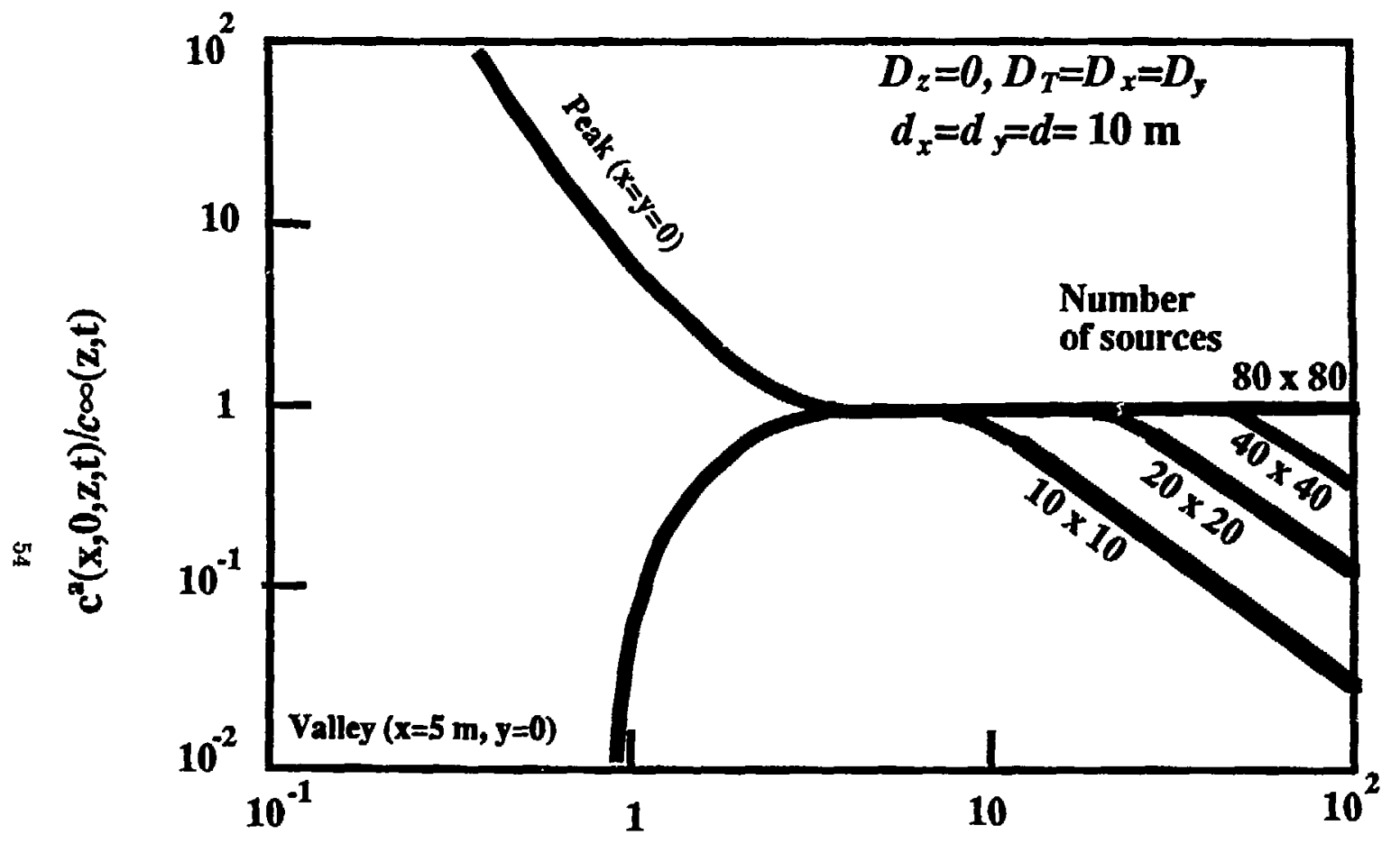

Distance Parameter, $q=\left(z D_{T} / u\right)^{1 / 2}$

Figure 4.1 Effect of an Array of Sources 


\subsection{Porous or Fractured Rock}

The mass-transfer equations described above, and extensions of these equations described in some of the following sections, assume that the surrounding the waste solid can be reasonably characterized as a porous solid. A steady-state equation for mass transfer into ground water in discrete fractures has been derived from boundary-layer theory by Neretnieks [1978]. Chambre's analytical equations for time-dependent mass transfer from a waste solid through porous backfill and into discrete fractures have been discussed above.

\subsection{Constant Temperature}

The equations described above assume that the waste solid and surrounding rock are at a constant and spatially uniform temperature. Extensions to account for time-dependent temperatures expected if the waste solid is exposed to ground water when the repository is heated by radioactive decay have been described in Sections 2.5 and 3.3 .

\subsection{Conatant and Uniform Chemlcal Invironment}

In predicting the dissolution rate of low-solubility species, it is important to examine the possibility of solubility changing with time, due to changes in the local chemical environment. For example, dissolution of borosilicate glass waste causes local changes in $\mathrm{pH}$, thereby affecting solubility of several species. Also, the oxidizing environment due to air during construction and waste emplacement can revert to a more reducing environment after repository sealing and, for saturated-rock repositories, after resaturation. As a result, the solubility of species with several oxidation states, such as uranium, neptunium, and other actinides, can decrease with time. If the chemical environment stabilizes within a few hundred years, while the protective container is still effective, the solubility corresponding to the stabilized environment would be the appropriate value to use in predicting release rates.

A longer-term mechanism for changing the chemical environment is the radiolysis of ground water by alpha particles from transuranics in the dissolving waste. If radiolytically produced hydrogen can escape, hydrogen peroxide can create a locally oxidizing environment and greater solubilities. Radiolysis can be particularly important in affecting the long-term release from spent fuel, becsuse there uranium is the matrix and because of the greater quantity of alpha emitters than usually found in borosilicate glass waste. Andersson, Rasmuson and Neretnieks [1982] have analyzed the progress of such a redox front for a spent-fucl repository in granite, determined by the rate of peroxide generation, mass transfer of peroxide from the waste surface, and reaction of peroxide with ferrous compounds in the water and rock. The result is a moving and expanding redox front, a transition from the oxidizing region of high uranium solubiity near the waste surface to the low-solubility reducing region. To predict the net rate of release of uranium across this front, the equations for mass-transfer of low-solubility species can be applied, using the radius of the redox front as the geometrical parameter.

\subsection{Release of Other Specles From a Low-Solubllity Wante Matrix}

If there is no preferential leaching of other chemical elements contained in the low-solubility waste matrix, all constituents in the matrix can be released congruently as the matrix dissolves or restructures. Upon release from the matrix, a constituent can all dissolve and transport into the surrounding media, or it can form a local precipitate and dissolve at a rate controlled by the precipitate solubility. 
Restructuring, also referred to as alteration, is the reaction of the waste solid with water or with oxidizing constituents in the water to form a solid of different lattice structure, thereby exposing other constituents in the original matrix to reaction with water. The restructuring process may involve local dissolving of the matrix and precipitation of a new solid phase of the matrix components. In the present report this will be referred to as alteration. Dissolution here refers to net dissolution, so that the released species remains locally in solution and undergoes diffusive-convective transport through ground water in the surrounding media.

For example, the rate of dissolution of uranium from spent fuel can be predicted by mass-transfer analyses of solubility-limited transport of uranium through the surrounding media. 'The appropriate solubility is that of the stable solid phase of uranium in the local chenical environinent at the waste surface. Assuming that dissolution of the uranium is the rate-limiting process for other constituents in the spent fucl, the rate of congruent dissolution of another constituent can be calculated by specifying that the instantancous fractional dissolution rate of that constituent be identical with instantaneous fractional dissolution rate of the uranium. For rigor, the fractional dissolution rate must be interpreted here as the instantancous mass rate of dissolution of a species divided by the instantaneous inventory of that species in the waste. Thus, for congruent dissolution the equations for solubility-limited dissolution of a single-component waste solid can be applied to the waste matrix, thereby yielding the fractional dissolution rates of the constituents.

Restructuring alteration of the matrix can also release waste constituents for dissolution or for precipitation. For example, uranium dioxide can be locally oxidized to $\mathrm{U}_{3} \mathrm{O}_{7}$ without structural changes. If the local environment is sufficiently oxidizing, non-isomorphous $\mathrm{U}_{3} \mathrm{O}_{8} \mathrm{can}$ form, releasing other matrix constituents to react with ground water. If dissolution of a matrix constituent is not rate limited by any other process, its fractional dissolution rate can be assumed to be congruent with the fractional alteration rate of the uranium matrix. Given experimental data for the fractional alteration rate, the fractional dissolution rate of a constituent can be specified as a boundary condition for mass-transfer analysis.

Also, as has been discussed earlier, a waste constituent released by matrix dissolution or by alteration does not necessarily dissolve. The solubility of that constituent can be sufficiently low that a stable precipitate of that constituent will form at the waste surface. The dissolution rate of that constituent can then be analyzed from the equations for solubility-limited dissolution and mass transfer, using the constituent solubility as a boundary condition.

One can calculate the fractional dissolution rate of a waste constituent for each of these three processes: (a) dissolution congruent with dissolution of the waste matrix, (b) dissolution congruent with matrix alteration, and $(c)$ dissolution at a rate controlled by the elemental solubility of that constituent. The rate-limiting dissolution process will be that with the lowest predicted dissolution rate of the constituent. Radioactive decay within the waste solids can cause the relative inventories of the waste matrix and of another waste constituent to change with time. As a result, the rate-limiting dissolution process for a constituent can change with time. For example, a low-solubility radioactive species initially present in sufficient concentration to be dissolution-rate-limited by its own solubility can eventuaily decay to a concentration in the waste low enough to be dissolution-rate-limited by matrix dissolution or alteration.

Borosilicate glass waste and its constituents can undergo the release and dissolution mechanisms described above. Silica in the glass matrix can dissolve. Likewise, the amorphous structure of glass can restructure to a thermodynamically stable solid phase. 
Leaching experiments, on borosilicate glass containing waste actinides confirms some of our predictions of controlling modes of dissolution. Some of the contained actinides dissolve less rapidly than would be predicted by congruence with release silica from the matrix, and saturation concentrations of neptunium and plutonium in leach solutions are found to equal the solubilities of the stable compounds formed when these actinides react with the aqueous leachant [Rai and Strickert 1980]. This suggests that actinides released congruently with silica release form precipitates at the waste surface. For any such constituent whose dissolution rate is limited by its own solubility, the fractional dissolution rate can be predicted by applying the single-component mass-transfer equations described above, using the measured solubility of that species for its boundary concentration. The results will be valid if the instantaneous fractional dissolution rate of that species, limited hy its own solubility, is less than the instantaneous release rate of the waste matrix.

\subsection{TRANBPORT ON CHANNB, CONCENTRATION BOUNDART CONDITION}

Up to this point we have considered the dissolution and transport of apecies without precursors. It is, however, important to consider the transport of radioactive chains explicity because as members of long chains nove, they produce decay products which are sources in themselves. Failure to account for these daughter/sources may lead to underestimation of releases prescribed by regulation.

Here we summarize our analysis for the transport of long chains in porous media of finite or limited extent [Lung et al. 1987]. The solutions are applicable if there is a backfill layer or a damaged rock $20 n e$. Different solutions are required in this case because there may be very different fluid flow conditions in the two regions.

In water-saturated one-dimensional finite domain $\mathcal{D}_{f}$ with flow along the $z$ direction, the governing equation for the transport of a radioactive chain for $0<z<b$ and $t>0$ is

$$
\begin{gathered}
K_{1} \frac{\partial c_{1}}{\partial t}+v \frac{\partial c_{1}}{\partial z}+\lambda_{1} K_{1} c_{1}=D_{1} \frac{\partial^{2} c_{1}}{\partial z^{2}} \\
K_{2} \frac{\partial c_{2}}{\partial t}+v \frac{\partial c_{2}}{\partial z}+\lambda_{2} K_{2} c_{2}=D_{2} \frac{\partial^{2} c_{2}}{\partial z^{2}}+\lambda_{1} K_{1} c_{1} \\
\vdots \\
K_{i} \frac{\partial c_{i}}{\partial t}+v \frac{\partial c_{i}}{\partial z}+\lambda_{i} K_{i} c_{i}=D_{i} \frac{\partial^{2} c_{i}}{\partial z^{2}}+\lambda_{i-1} K_{i-1} c_{i-1}
\end{gathered}
$$

where

$c_{i}=c_{i}(z, t)$ is the concentration of the $i^{\text {th }}$ member, $\left[\mathrm{M} / \mathrm{L}^{3}\right]$

$D_{i}$ is the species dispersion coefficient, $\left[\mathrm{L}^{2} / \mathrm{t}\right]$

$b$ is the thickness of the backfill. [L]

$K_{i}$ is the species retardation coefficient, and

$\lambda_{i}$ the species decay constant, $\left[\mathrm{t}^{-1}\right]$.

Eq. (5.1) is subject to the initial condition

$$
c_{i}(z, 0)=0, \quad z>0
$$

and the Type-III boundary condition

$$
-D_{i} \epsilon \frac{\partial c_{i}}{\partial z}+v \epsilon c_{i}=v \epsilon c_{i}^{\circ} \phi_{i}(t), \text { for } z=0, \quad t>0
$$


where $\phi_{i}(t)$ is the source term. A Type-IIl boundary condition specifies both concentration and flux. At the other end of the finite region, the boundary condition is

$$
-D_{i} c \frac{\partial c_{i}}{\partial z}+v \epsilon c_{i}=h\left[c_{i}-c_{i}^{*}(t)\right], \quad \text { for } \quad z=b, \quad t>0
$$

where $c_{i}^{*}$ is the average concentration of the nuclide outside of the region and $h$ is an assumed constant mass-transfer coefficient describing the mase flux at $z=b$.

Eq. (5.1) can be re-written as

$$
\frac{K_{i}}{D_{i}} \frac{\partial c_{i}}{\partial t}+\frac{v}{D_{i}} \frac{\partial c_{i}}{\partial z}+\nu_{i} c_{i}=\frac{\partial^{2} c_{i}}{\partial z^{2}}+\nu_{i-1} c_{i-1}, \quad z>0, \quad t>0, i=1,2, \ldots
$$

where

$$
\nu_{0}=0, \quad \nu_{i}=\frac{K_{i} \lambda_{1}}{D_{i}}, \quad \nu_{i-1}=\frac{K_{i-1} \lambda_{i-1}}{D_{1}}
$$

The general analytic solution for $c_{i}(x, t)$ can be expresed as a sum of functions. For example, for the $i^{\text {th }}$ member of any chain

$$
c_{i}(z, t)=c_{i}^{(i)}(z, t)+\sum_{j=1}^{i-t} c_{i}^{(j)}(z, t), \quad z>0, t>0, i=1,2, \ldots
$$

If this decomposition is used, then the equation syatem (5.1) - (5.4) can be written as

$$
\begin{gathered}
\frac{K_{\ell}}{D_{\ell}} \frac{\partial c_{\ell}^{(j)}}{\partial t}+\frac{v}{D_{\ell}} \frac{\partial c_{l}^{(j)}}{\partial z}+\nu_{\ell} c_{\ell}^{(j)}=\frac{\partial^{2} c_{\ell}^{(j)}}{\partial z^{2}}+\nu_{\ell-1} c_{\ell-1}, \quad 0<z<\infty, t>0, \nu_{0}=0, \ell=1,2, \ldots, i, j \leq \ell \\
c_{\ell}^{(j)}(z, 0)=0, \quad z>0 \\
-D_{\ell} \frac{\partial c_{l}^{(j)}(0, t)}{\partial z}+v \epsilon c_{\ell}^{(j)}(0, t)=\delta_{\ell j} v \epsilon c_{\ell}^{(j} \phi_{j}(t), \quad j \leq \ell, \ell>0
\end{gathered}
$$

where $\delta_{\ell j}$ is the Kronecker delta that vanishes for $\ell \neq j$ and is unity for $\ell=j$.

$$
-D_{\ell} \epsilon \frac{\partial c_{\ell}^{(j)}(b, t)}{\partial z}+v \epsilon c_{\ell}^{(j)}(b, t)=h\left[c_{\ell}^{(j)}(b, t)-\delta_{\ell j} c_{\ell}^{*}(t)\right], \quad j \leq \ell, t>0
$$

We will illustrate the solution for a Bateman boundary condition, at $z=0$,

$$
c_{i}(0, t)=\sum_{j=1}^{i} B_{i j} e^{-\lambda_{j} t}
$$

in which the Bateman constant $B_{i j}$ is

$$
B_{i j}=\sum_{m=1}^{j} c_{m}^{i}\left(\frac{1}{\lambda_{j}} \prod_{r=m}^{i} \lambda_{r}\right) / \prod_{\substack{l=m \\ l \neq i j}}^{i}\left(\lambda_{l}-\lambda_{j}\right)
$$

where $c_{m}^{\circ}$ is the initial concentration of the $m^{\text {th }}$ nuclide and the product term in the denominator is defined as unity when $m=j=i$.

$c_{i}(z, t)=\exp \left\{\frac{v z}{2 D}\right\} \frac{D}{K_{i}}\left\{\sum_{k=1}^{i} B_{i k} \mathrm{e}^{-\lambda_{k} t} \sum_{m=1}^{\infty}\left(\frac{2}{b+\ell_{m}}\right) \frac{\beta_{m} \sin \beta_{m} z}{\Delta_{i k}}\left(1-e^{-\Delta_{i k} t}\right)+\right.$ 


$$
\left.+\sum_{j=1}^{i-1} C_{i}^{(j)} \sum_{k=1}^{i} B_{j k} e^{-\lambda_{m} l} \sum_{n=j}^{i} \sum_{m=1}^{\infty}\left(\frac{2}{b+\ell_{m}}\right) \frac{\beta_{m} \sin \beta_{m} z}{\prod_{r=k}^{i}\left[\Gamma_{n r} \beta_{m}^{2}+\gamma_{n r}\right] \Delta_{n k}}\left(1-e^{-\Delta_{m+l}}\right)\right\} \begin{gathered}
z>0 \\
t>0
\end{gathered}, i=1,2, \ldots
$$

where

$$
\begin{array}{cc}
\Delta_{n j}=\frac{D}{K_{n}}\left(\beta_{m}^{2}+q_{n j}^{2}\right), & q_{n j}^{2}=\left(\frac{v}{2 D}\right)^{2}+\frac{K_{n}}{D}\left(\lambda_{n}-\lambda_{j}\right), \quad C_{i}^{(j)}=\prod_{n=j}^{i-1} \lambda_{n} \\
\ell_{m}=\frac{\alpha_{2}}{\beta_{m}^{2}+\alpha_{2}^{2}}, \quad \alpha_{2}=\frac{h-v \epsilon / 2}{D \epsilon}, \quad \gamma_{n r}=\left[\left(\lambda_{r}-\lambda_{n}\right)+\left(\frac{v}{2 D}\right)^{2} r_{n r}\right]
\end{array}
$$

and the eigenvalues $\beta_{m}$ are determined from solving nunxerically

$$
\tan \beta_{m} b=-\frac{\beta_{m}}{\alpha_{2}}
$$

Figures 5.1 and 5.2 are illustrations for the ${ }^{234} \mathrm{U} \rightarrow{ }^{230} \mathrm{Th} \rightarrow{ }^{226} \mathrm{Ra}$ chain. In these figures the vertical scalc is logarithmic to show the very small amounts of the daughter nuclides. Figure 5.1 shows the concentration profile normalized to the initial concentration of the first member at the inner edge of the first layer, as a function of distance at 1000 years. Because initially there is no thorium, all ${ }^{230} \mathrm{Th}$ comes from the decay of ${ }^{234} \mathrm{U}$. This figure shows relatively little ${ }^{230} \mathrm{Th}$ in the field, because the ${ }^{230} \mathrm{Th}$ half life is so short relative to that of ${ }^{234} \mathrm{U}$. Similarly, the concentration of ${ }^{226} \mathrm{Ra}$ cannot be shown in this figure because its half life is even shorter.

At the time of Figure $5.1,{ }^{234} \mathrm{U}$ has reached its steady state while ${ }^{230} \mathrm{Th}$ and ${ }^{226} \mathrm{Ra}$ are still rising. ${ }^{226} \mathrm{Ra}$ shows a maximum inside the backfill.

Figure 5.2 show flux profiles, at both interfaces of the backfill, normalized to to the initial concentration of the first member at the inner edge of the first layer, as functions of time. In Figure 5.2 the solid curves represent the mass fluxes at $z=0$ and the dashed lines the fluxes at $z=b$. Also plotted are the mass fluxes of ${ }^{226} \mathrm{Ra}$ for high $h$ (the dotted curves) for comparison. For a low $h$ we show only ${ }^{234} \mathrm{U}$ and ${ }^{230} \mathrm{Th}$ since the ${ }^{226} \mathrm{Ra}$ flux is too low to be shown. One can see that after 1000 years the mass fluxes of ${ }^{234} \mathrm{U}$ at $z=0$ and at $z=b$ are almost equal, which means the backfill can no longer retard the migration of uranium. On the other hand, ${ }^{230}$ Th does not show the same phenomenon, and the barkfill still provides some retardation. This is also true for ${ }^{226} \mathrm{Rn}$, though not shown here. The decay effect is illustrated by the thorium flux at $z=0$, which is higher than that of its ${ }^{23} \mathrm{U}$ parent after one thousand years.

Strong water flow in region 2 can enhance the mass fluxes at the outer surface of backfill, as can be seen from the dotted curves. Note that the mass flux of ${ }^{226} \mathrm{Ra}$ at $z=b$ is higher than that at $z=0$ for both values of $h$.

A series of computer programs, known as UCB-NE-40,41,51,51,52, implements eq. (5.12) and other similar solutions in Lung [Lung et al. 1987]. These computer programs are available from the National Energy Software Center.

\subsection{NLAR-FINLD MASS TRANBTLR IN A SALT REPOSTTORT}

Salt is the proposed host rock for geologic repositories of nuclear waste in several nations because it is "dry" and probably "impermeable." Although experiments and experience at potential salt sites indicate 


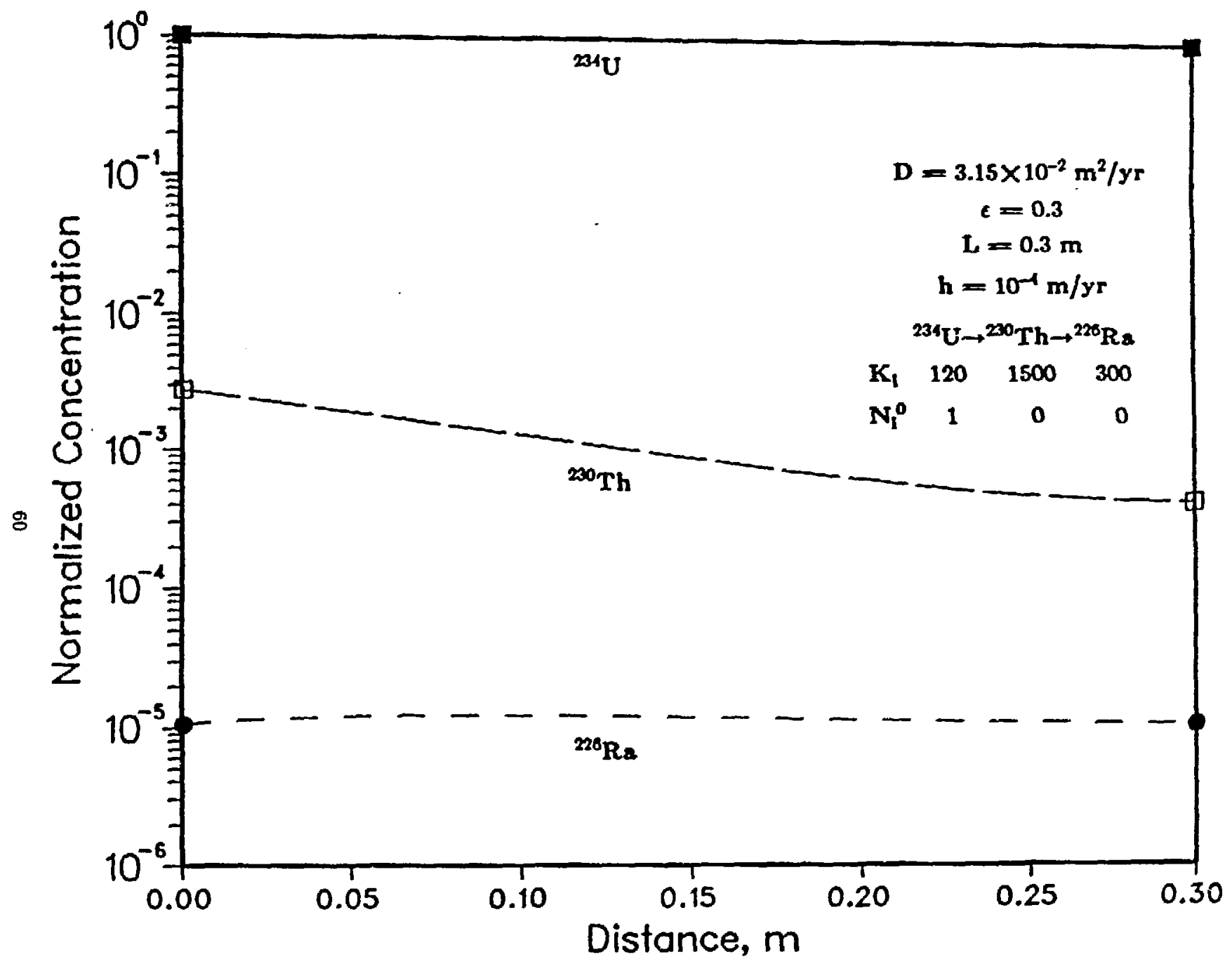

Figure 5.1 Normalized Concentration Profile for U-234 $\rightarrow$ Th-230 $\rightarrow$ Ra-226 in Backfill as Functions of Distance at 1000 years, Bateman-type boundary condition 


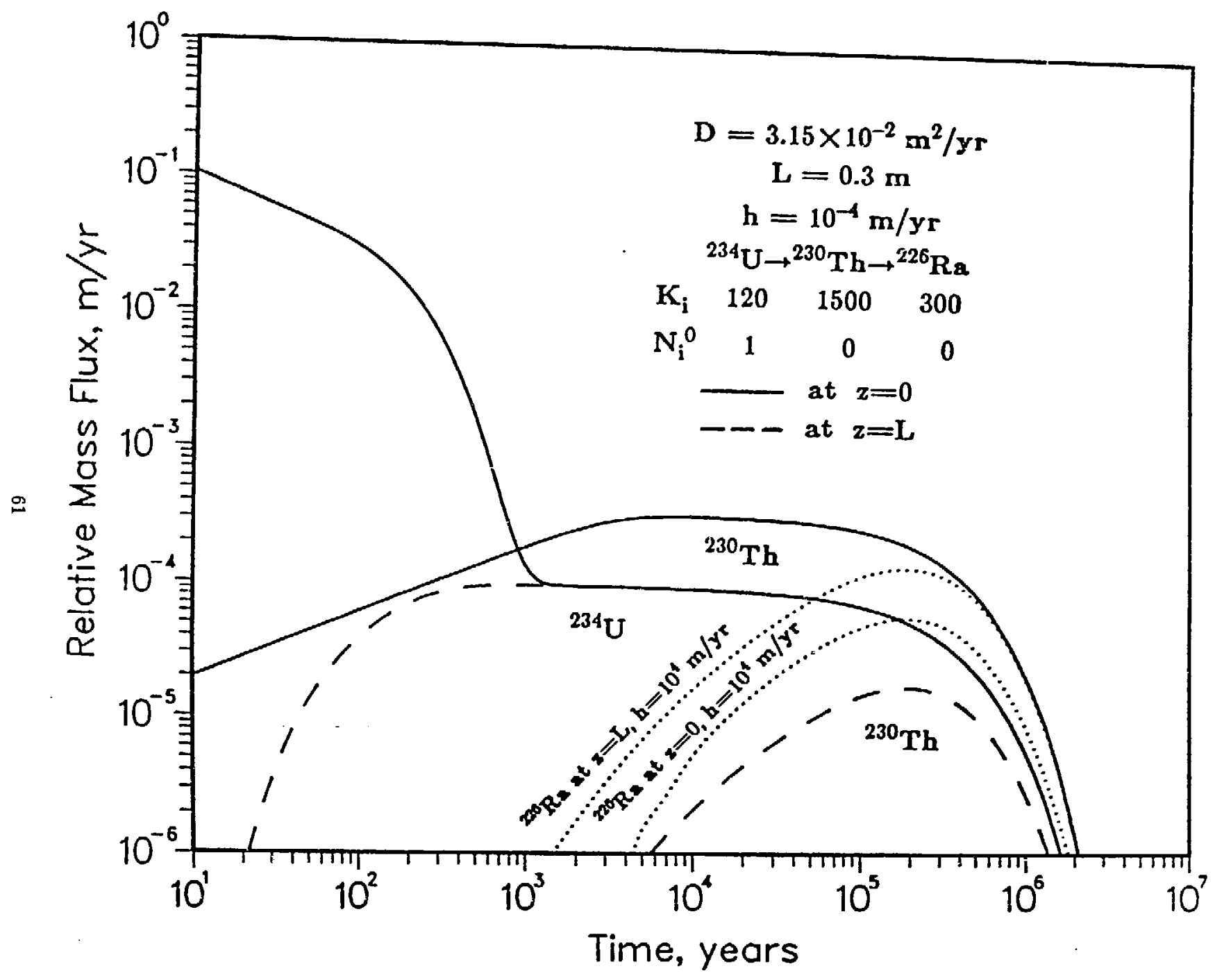

Figure 5.2 Normalized Mass Flures for U-234 $\rightarrow$ Th-230 $\rightarrow$ Ra-226 at both ends of the Backfill as Functions of Time, Bateman-type boundary condition 
that salt may contain brine, the low porosity and permeability of Jalt make :^ z:ill a good choice for geologic isolation. Here we summarize some analyses of near-field mass trans ${ }^{*}$ er in salt repositories [Pigford and Chambré 1985].

\subsection{Brine Migration}

Brine in grain boundarjes of natural salt can flow die to pressure differences within the salc. It is paramount to know the magnitude of such flow and its contribution to radionuclide transport.

When salt is mined to create a waste repository, brine from grain boundaries will inigrate into the rooms, tunnels and boreholes because these cavities are at atmospheric pressure. Heat-emitting waste packages will impose temperature gradients in tie surrounding salt. Hot salt near the wasce package expands against the waste package and surrounding salt, creating high compressive stresses near the waste package and resulting in pressure above the lithostatic pressure. Brine pressure further increases because grain-boundary brine expands more than does the salt. This increased pressure gradient causes brine to flow outward into the cooler salt. Outward flow of brine relieves the pressure gradient on the fluid, which finally relaxes to near-lithostatic pressure.

The Darcy velocity can be written as

$$
v(r, t)=-\frac{k}{\mu} \frac{\partial P}{\partial r}
$$

where $P$ is the relative pore pressure $\left[\mathrm{M} \mathrm{L}^{-1} \mathrm{t}^{-2}\right]$,

$r$ is tise distance variable $[L]$,

$k$ is the permeability [ $\left.\mathrm{L}^{2}\right]$,

$\mu$ is the fluid viscosity $\left[\mathrm{M} \mathrm{L}^{-1} \mathrm{t}^{-1}\right]$.

To obtain an expression for $\frac{\partial P}{\partial r}$, we treat the salt as a linear thermoelastic solid. McTigue [1986] derived the following expression, witten here for salt surrounding an assumed spherical waste solid,

$$
\frac{\partial P}{\partial t}=d \frac{1}{r^{2}} \frac{\partial}{\partial r}\left(r^{2} \frac{\partial P}{\partial r}\right)+b^{\prime} \frac{\partial \theta}{\partial t}, \quad t>0, r>R
$$

where $\theta(r, t)$ is the relative temperature, actual minus ambient [T],

$R$ is the radius of spherical-equivalent waste package $[L]$, and

$b^{\prime}, d$ are constants which are functions of material properties

$$
\begin{gathered}
b^{\prime}=\frac{4 G B\left(1+\nu_{u}\right)}{9\left(1-\nu_{u}\right)}\left[\alpha_{s}^{\prime}+\frac{B(1-\nu)\left(1+\nu_{u}\right)}{2\left(\nu_{u}-\nu\right)} \epsilon\left(\alpha_{f}-\alpha_{s}^{\prime \prime}\right)\right] \\
d=\frac{k}{\nu} \frac{2 G(1-\nu)}{1-2 \nu}\left[\frac{B^{2}(1-2 \nu)\left(1+\nu_{u}\right)^{2}}{9(1-\nu)\left(\nu_{u}-\nu\right)}\right]
\end{gathered}
$$

where $G$ is the shear modulus $\left[\mathrm{M} \mathrm{L}^{-1} \mathrm{t}^{-2}\right.$ ]

$\nu$ is Poisson's ratio for the solid phase

$\nu_{u}$ is the undrained Poisson's re' io

$\epsilon$ is the reference porosity

$\alpha$, is the fluid-phase thermal expansion coefficient $\left[\mathrm{T}^{-1}\right]$

$\alpha_{3}^{\prime \prime}$ is the second cubical thermal expansion coefficient of the solid $\left[\mathrm{T}^{-1}\right]$, and 
$B$ is the pore-pressure modulus, where

$$
\frac{1}{B}=1+\epsilon \frac{\mathcal{X}\left(1-\mathcal{K}_{f} / \mathcal{K}_{!}^{\prime \prime}\right)}{\mathcal{K}_{f}\left(1-\mathcal{K} / \mathcal{K}_{!}^{\prime}\right)}
$$

in which $\mathcal{X}$ is the bulk modulus $\left[\mathrm{M} \mathrm{L}^{-1} \mathrm{t}^{-2}\right]$, and

the subscripts $f$ and $s$ refer to the fluid phase and solid phase, respectively.

Eq. (6.1.2) states that the variation in pore pressure is due primarily to the change of relative temperature. The major assumptions in the equation are

- The system is linearized.

- Thermal convection is neglected.

- Material properties are constant with temperature. Thus (6.1.2) is only valid for omall temperature changes.

- The porous material is homogenous.

According to (6.1.2), the prewure field responce is due primarily to the change of temperature, on the right-hand-side of (6.1.2) so we muat obtain an analytic expreanion for the time derivative of temperature.

Neglecting heating effects from nearby waste packages, and asouming polar and aximuthal symmetry, the governing equation for the temperature profile is

$$
\frac{\partial \theta}{\partial t}-\frac{\kappa}{r^{2}} \frac{\partial}{\partial r}\left(r^{2} \frac{\partial \theta}{\partial r}\right)=0, \quad r>R, t>0
$$

where $x$ is the thermal diffusivity $\left[\mathrm{L}^{2} / \mathrm{t}\right]$.

We use a known thermal decay rate a boundary condition for solving (6.1.3)

$$
-\left.\lambda \frac{\partial \theta}{\partial r}\right|_{r=R}=Q_{0} f(t)
$$

where

$\Lambda$ is the thermal conductivity [M L t $\mathrm{t}^{-3} \mathrm{~T}^{-1}$ ],

$Q_{0}$ is the initial heat flux of the waste package $\left[\mathrm{M} / \mathrm{t}^{3}\right]$, and

$f(t)$ is a known time history of the normalized heat flux of the waste package.

The other side conditions are

$$
\begin{array}{cc}
\theta(\infty, t)=0, & t>0 \\
\theta(r, 0)=0, & r>R
\end{array}
$$

Then the relative temperature at the waste package aurface is

$$
\left.\theta\right|_{r=R}=\frac{\theta_{0} \kappa}{R^{2}} \int_{0}^{t} f(t-\tau)\left[\sqrt{\frac{R^{2}}{\pi \kappa \tau}}-\exp \left\{\frac{\kappa \tau}{R^{2}}\right\} \operatorname{erfc}\left\{\sqrt{\frac{\kappa \tau}{R^{2}}}\right\}\right] d \tau
$$

where

$$
\theta_{0}=\frac{Q . R}{\Lambda}
$$

The temperature profile in the salt is

$$
\theta=\frac{\theta_{0} \sqrt{\kappa}}{r} \int_{0}^{t} f(t-\tau)\left[\frac{1}{\sqrt{\pi \tau}} \exp \left\{\frac{-(r-R)^{2}}{4 \kappa \tau}\right\}-\sqrt{\frac{\kappa}{R^{2}}} \exp \left\{\frac{(r-R)}{R}+\frac{\kappa \tau}{R^{2}}\right\} \operatorname{erfc}\left\{\frac{1}{2} \frac{r-R}{\sqrt{\kappa \tau}}+\sqrt{\frac{\kappa \tau}{R^{2}}}\right\}\right] d \tau
$$


When given a time-history of heat flux from a waste package, (6.1.8) allows us to obtain the temperature at the waste package surface and the time derivative of (6.1.9) gives us the source term for (6.1.2).

We shall give the analytic solutions for a hot waste package in an emplacement hole backfilled with crushed salt [Hwang et al. 1987; 1989a]. Thermomechanical studies have shown that salt creep closes the air gap between the waste package and the rock salt in a matter of months to a few years after the emplacement of the waste package. The governing equation for brine flow is eq. $(6.1 .2)$ and the initial condition is

$$
P(r, 0)=0, \quad r>R
$$

The boundary conditions are

$$
\begin{array}{rl}
\lim _{r \rightarrow \infty} P(r, t)=0 & t>0 \\
\left.\frac{\partial P(R, t)}{\partial r}\right|_{r=R}=0, & t>0
\end{array}
$$

We will express the solution as the Darcian brine migration velocity

$$
v(\xi, t)=\frac{k b^{2} \sqrt{\kappa} \theta_{0}}{\mu R^{2}\left(1-\varphi^{2}\right)} \int_{0}^{t} f(t-\tau) \Psi(\xi, \tau) d \tau
$$

where the $\Psi$ function is

$$
\begin{gathered}
\Psi(\xi, t)=\left(1-\frac{1}{\xi}\right) \frac{1}{2 x \sqrt{\pi t^{3}}}\left[\exp \left\{\frac{-(\xi-1)^{2}}{4 \chi^{t}}\right\}-\frac{1}{\varphi} \exp \left\{\frac{-(\xi-1)^{2}}{4 \chi \varphi^{2} t}\right\}\right] \\
-\frac{1}{\sqrt{\pi t}} \frac{1}{\xi}\left(1-\frac{1}{\xi}\right)\left[\exp \left\{\frac{-(\xi-1)^{2}}{4 \chi t}\right\}-\varphi \exp \left\{\frac{-(\xi-1)^{2}}{4 \chi \varphi^{2} t}\right\}\right] \\
+\sqrt{x} \frac{1}{\xi}\left(1-\frac{1}{\xi}\right)\left[\exp \{(\xi-1)+\chi t\} \operatorname{erfc}\left\{\frac{\xi-1}{2 \sqrt{\chi^{t}}}+\sqrt{x^{t}}\right\}-\varphi^{2} \exp \left\{(\xi-1)+\chi \varphi^{2} t\right\} \operatorname{erfc}\left\{\frac{\xi-1}{2 \varphi \sqrt{\chi^{t}}}+\varphi \sqrt{\chi t}\right\}\right]
\end{gathered}
$$

and

$$
\varphi^{2}=d / \kappa, \quad \xi=r / R, \quad \chi=\kappa / R^{2}
$$

For illustration consider a spherical-equivalent spent-fuel waste package of 0.72 -meter radius in an infinite salt medium. The parameter values used in the calculations are from McTigue, and are shown in Table 6.2.1. The initial heat flux at the waste form surface was 928 watts per square meter. Calculaled timedependent profiles of temperature are shown in Figure 6.1 and calculated brine pressure after consolidation is shown in Figure 6.2.

Figure 6.3 shows the Darcy brinc velocity near a waste package as a function of time. Pressure-induced brine migration within consolidated salt is a transient phenomenon. After about ten years the velocity is nearly zero. Even the highest velocity is of the order of millimeters per year, and occurs on?: .. hin a meter or so of a waste package. At these Darcy velocities molecular diffusion may be the dom , a't transport process for radionuclides in salt. 


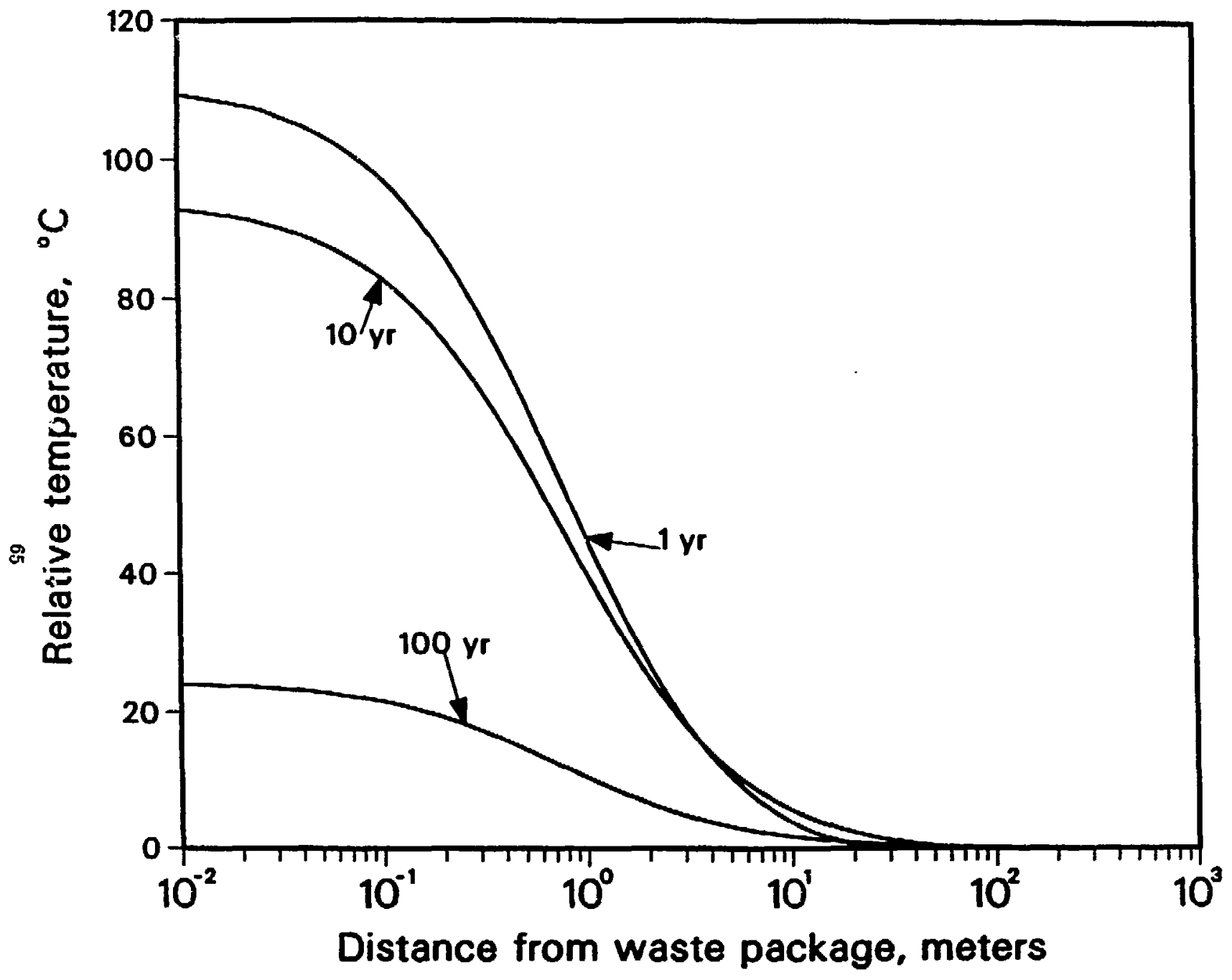

Figure 6.1 Relative Temperature in Salt After Emplacement 


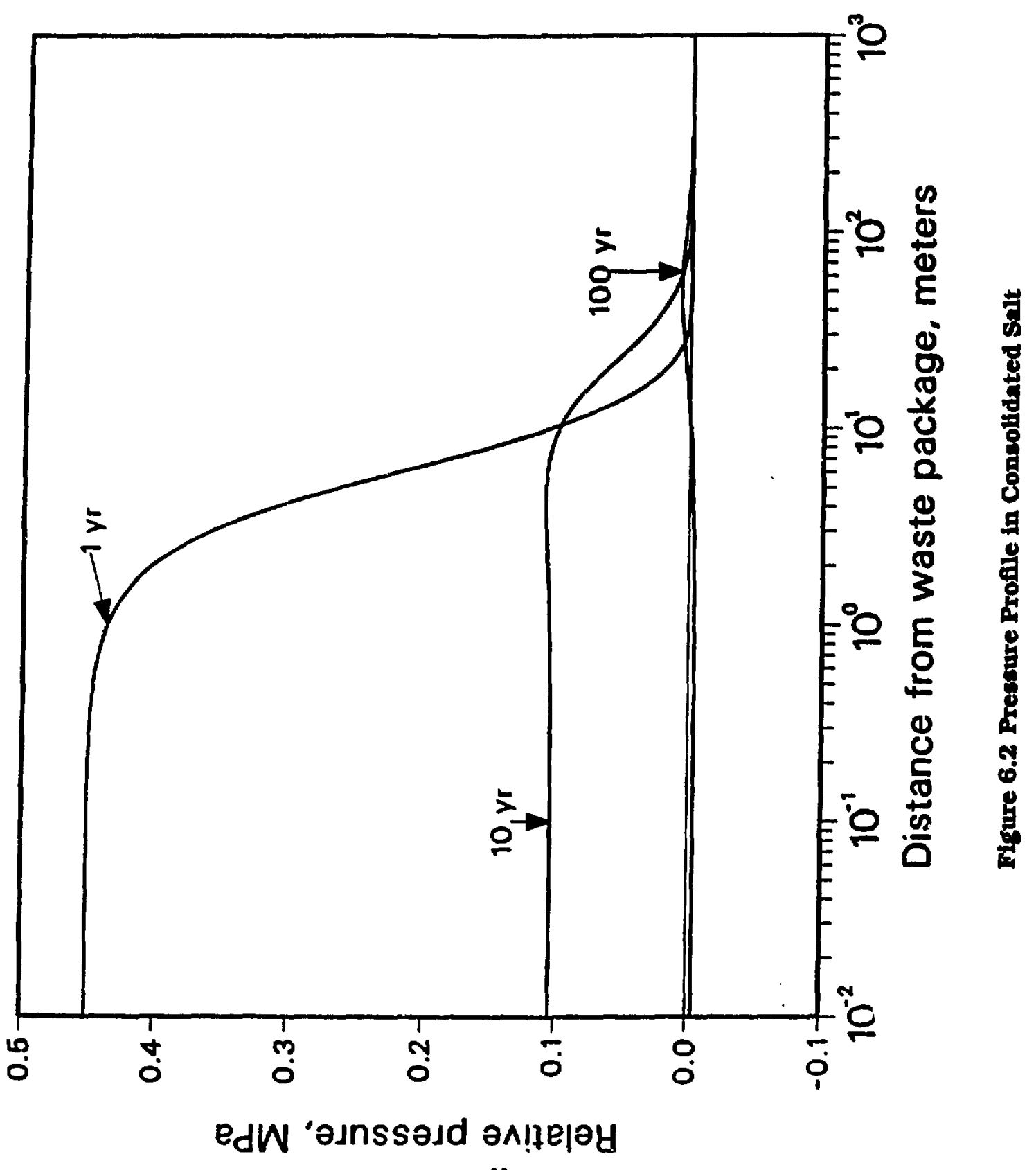




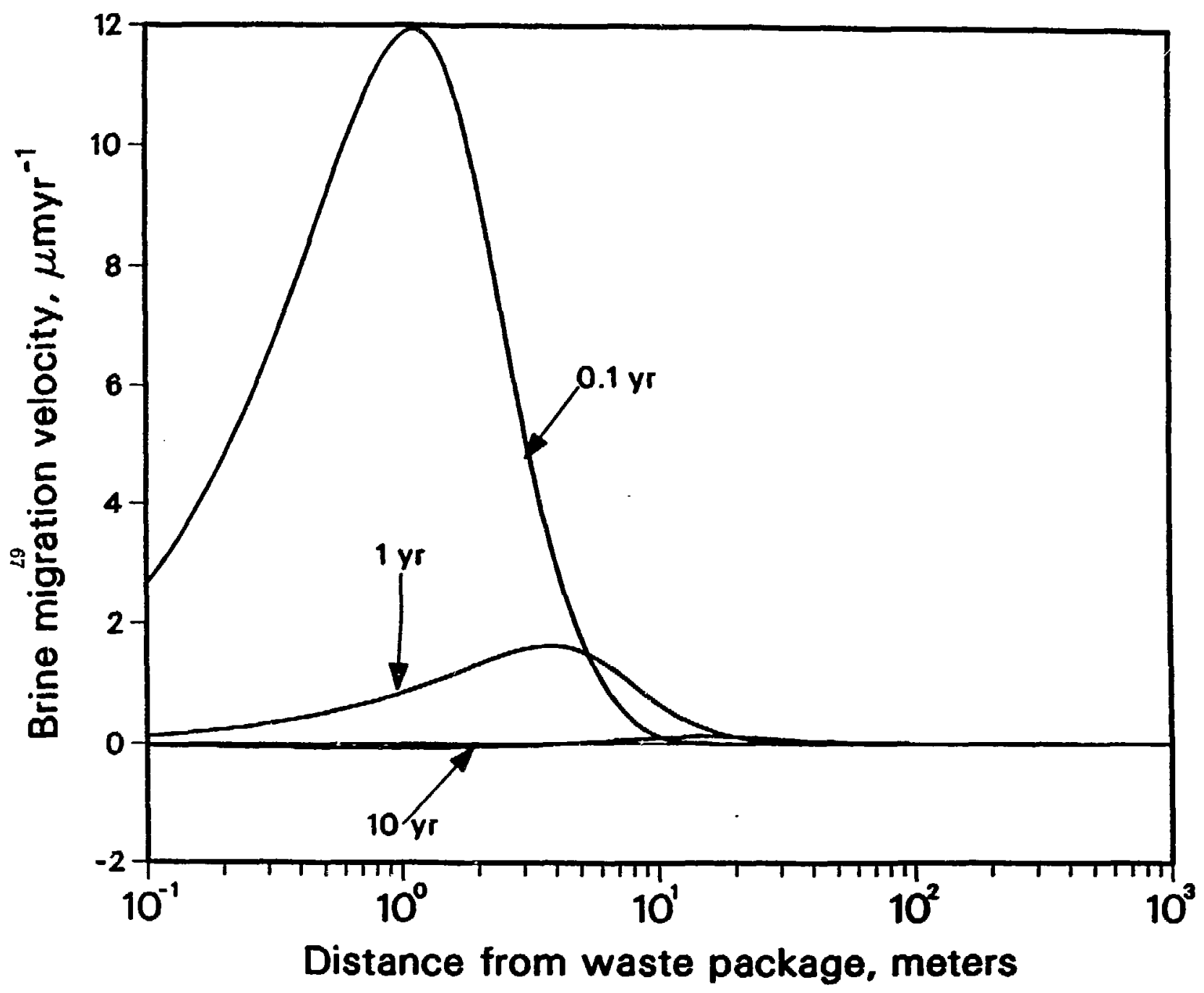

Figure 6.3 Darcian Brine Migration Velocity in Consolidated Salt 
Tuble 6.1. Farametor Valwos Ueod in salt Calculations

(After McTigue [1986], for the Salado Formation, Delaware Basin, New Mexico)

\begin{tabular}{|c|c|c|}
\hline Property & Value & Units \\
\hline $\begin{array}{l}\text { Conductivity }(\Lambda) \\
\text { Heat Capacily }\end{array}$ & $\begin{array}{c}6.60 \\
1.89 \times 10^{6}\end{array}$ & $\begin{array}{l}W \cdot m^{-1} \cdot K^{-1} \\
J \cdot m^{-8} \cdot K^{-1}\end{array}$ \\
\hline Drained Bulk Modulus $(\boldsymbol{K})$ & 20.7 & GPa \\
\hline Fluid Bulk Modulus $\left(\boldsymbol{N}_{J}\right)$ & 2.0 & GPa \\
\hline Solid Bulk Moduli $\left(\mathcal{K}_{\prime}^{\prime}, \mathcal{K}_{0}^{\prime \prime}\right)$ & 23.5 & GPa \\
\hline Shenr Modulus $(G)$ & 12.4 & GPa \\
\hline Porosity (c) & 0.001 & \\
\hline Permeability (k) & $10^{-21}$ & $m^{2}$ \\
\hline Fluid Expansivity $\left(\alpha_{f}\right)$ & $3.0 \times 10^{-1}$ & $K^{-1}$ \\
\hline Solid Expansivity $\left(\alpha_{0}^{\prime}, \alpha_{a}^{\prime \prime}\right)$ & $1.2 \times 10^{-4}$ & $\mathbf{K}^{-1}$ \\
\hline Fluid Viscosity $(\mu)$ & $1.0 \times 10^{-3}$ & $\mathrm{~Pa} \cdot \mathbf{s}$ \\
\hline 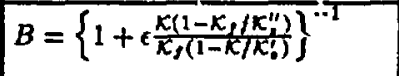 & 0.93 & \\
\hline Poisson's Ratio $(\nu)$ & 0.25 & \\
\hline Undrained Poisson's Ratio $\left(\nu_{u}\right)$ & 0.27 & \\
\hline$b^{\prime}$, Eq. (2a) & 29.0 & $\mathbf{k P a} \cdot \mathbf{K}^{-1}$ \\
\hline Fluid Diffusivity (d) & $0.16 \times 10^{-6}$ & $m^{2} \cdot g^{-1}$ \\
\hline Thermal Diffusivity $(\kappa)$ & $3.5 \times 10^{-6}$ & \\
\hline$\varphi=\sqrt{d / x}$ & 0.21 & \\
\hline
\end{tabular}

\subsection{Releace Rates In Salt by Diffualon}

Having predicted very low brine velocities due to pressure-driven brine migration, we applied the analysis of Sections 2 and 3 to predict release rates in salt repositories [Chambré et al. 1987; Hwang et al. $1989 \mathrm{~d}]$.

Figure 6.4 shows the release rates of some solubility-limited species, calculated using eq. (2.1.2.2.1). It can be seen that for the parameter values used, the release rates are well below the USNRC limits. For a $\mathrm{UO}_{2}$ matrix solubility under oxidizing conditions of $50 \mathrm{~g} / \mathrm{m}^{3}$, the release rates are proportionally higher, but still very much below USNRC limits.

Figure 6.5 shows the release rates of ${ }^{137} \mathrm{Cs},{ }^{135} \mathrm{Cs}$ and ${ }^{129} \mathrm{I}$ for conditions typical in a salt repository. The fractional release rates for soluble species, calculated from eq. (3.1.15), are normalized here to initial 


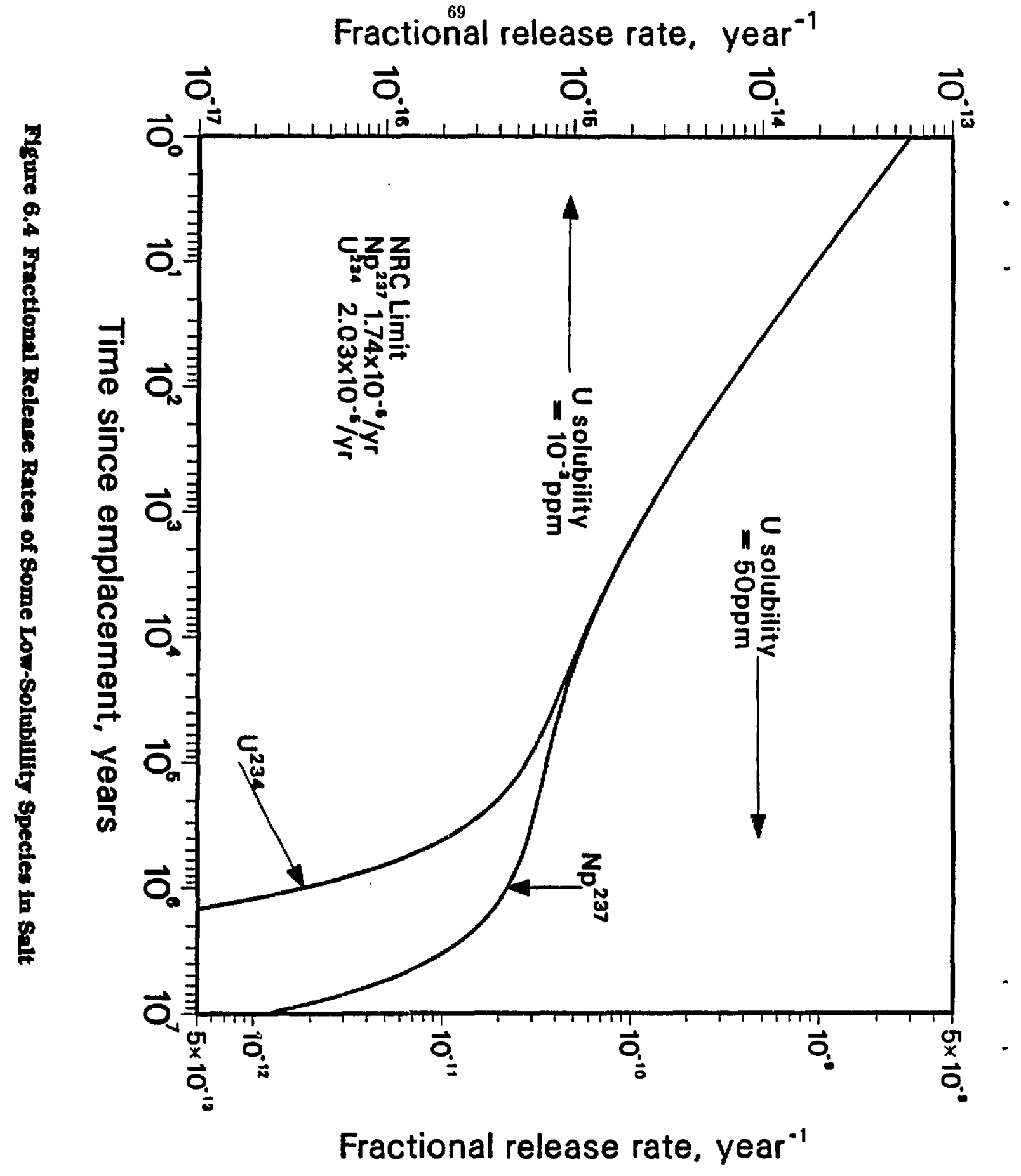




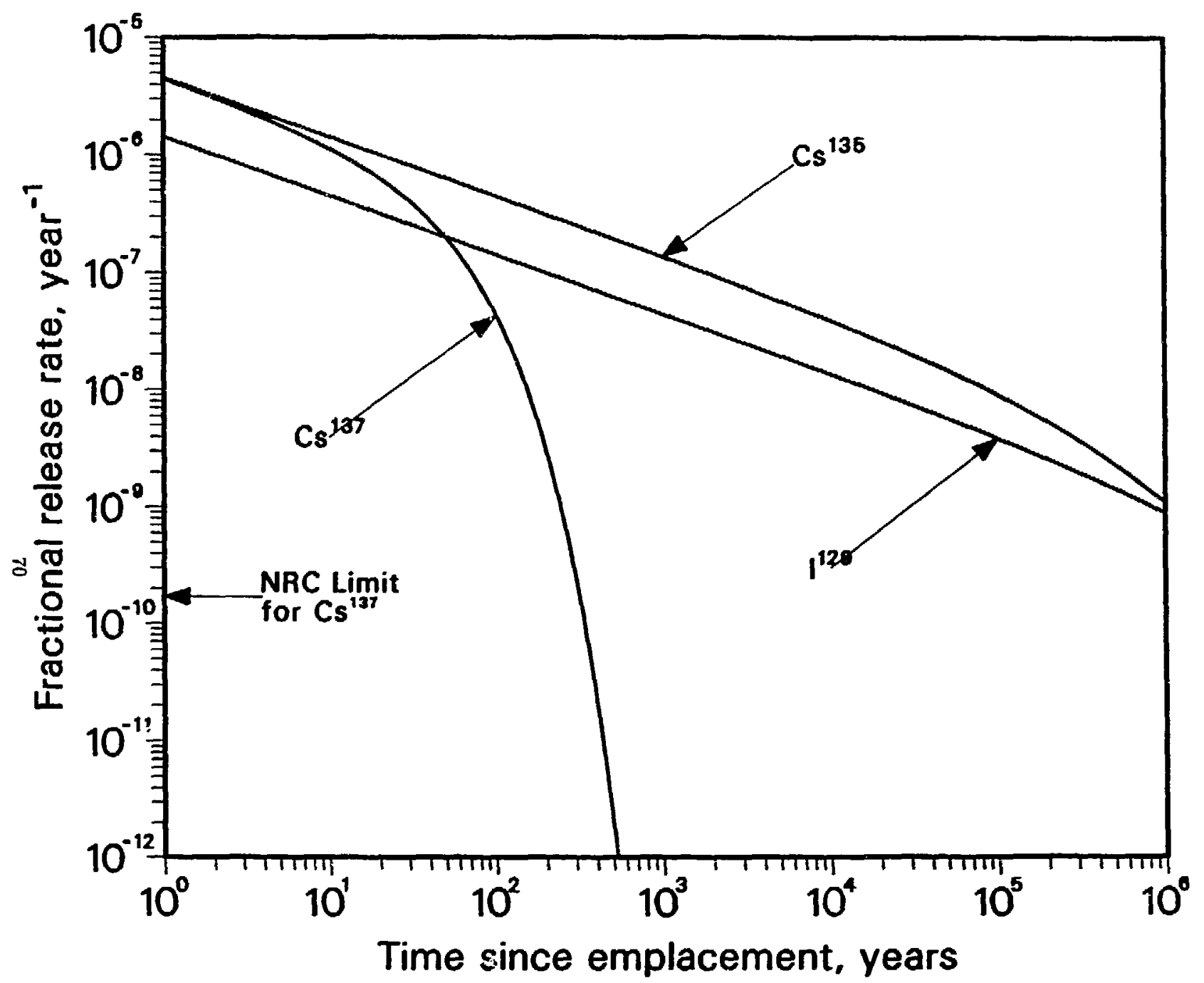

Figure 6.5 Fractional Release Rates of Some Soluble Species in Salt 
inventories and assuming that waste is exposed to brine shortly after emplacement. It is assumed that one percent of the total inventory of cesium and iodine is present as readily soluble species in the fuel. The dissolution of cesium and iodine species by congruent dissolution from the waste matrix (Section 3.1) is also calculated but is much smaller than the contribution from readily soluble material, and has been neglected in Figure 6.4.

The release rates of ${ }^{135} \mathrm{Cs}$ and ${ }^{129} \mathrm{I}$ are below the calculated release rate limits at all times shown in Figure 6.5. The calculated limit for ${ }^{137} \mathrm{Cs}$ is exceeded for some 300 ycars, if no waste container is present. $A$ container with a life of 300 years will allow sufficient decay time for the calculated limit for ${ }^{137} \mathrm{Cs}$ to be met.

\section{3 steady-8tate Mass Transport in salt Interbeds}

While the salt is known to be quite pure in salt domes, bedded salt is interlnced with beds of sediments. Traditionally rock salt has been considered almost incapable of conducting water, but sodirnent layers are classical porous media, capable of conducting water. Therefore, there is interest in decermining whether interbeds in bedded salt constitute a significant pathway for radionuclide migration.

In this Section we consider steady-state migration of radionuclides from a single waste cylindor into a single interbed. Two approaches are used. In 1982 Neretnieks [Andersson, Rasmuson and Neretnieks, 1982] proposed an approach for calculating the steady-stale transport of oxidants to a copper container. We have adapted that approach for calculating steady-state radionuclide migration away from the waste package.

The situation studied is shown in Figure 6.6. A wuste package is inserted into an emplacement hole in a salt repository and backfilled with crushed salt. The emplacement hole intersects an interbed. Given the large number of interbeds observed in cores near some prospective salt sites, an interbed intersection is probable. The following assumptions are used.

- The crushed salt has consolidated to the extent that there is no flow within the crushed-salt region.

- There is ground waler flow in the interbed and the velocity is constant.

- The interbeds are planar and and parallel and are perpendicular to the longitudinal axis of the waste cylinder.

- The interbeds are uniformly spaced.

- The waste cylinder is sufficiently long so that end effects can be ignored.

- In calculating temperature effects we use constant values of parameters such as diffusion coefficients, but for the highest temperatures expected.

- The surrounding salt is impervious to water flow and radionuclide transport.

- Steady-stale conditions prevail.

With these assumptions, the problem reduces to one of one-dimenional diffusion. For a nuclide to move from the waste cylinder where it is at a higher concentration to the flowing ground water in the interbed where it is at a lower concentration, the problem can be conceptualized as

$$
\dot{m}=\frac{w_{i} w_{c} A_{e} A_{i}}{w_{i} A_{i}+w_{c} A_{c}} c_{s}
$$

where $\dot{m}$ is the mass transport rate, $c$ is the species concentration, $A$ the area over which mass transport is taking place and $w$ a mass transfer coefficient, and the subscripts $c$ and $i$ refer to the crushed salt and interbeds respectively. $c$, is the solubility at the waste. 


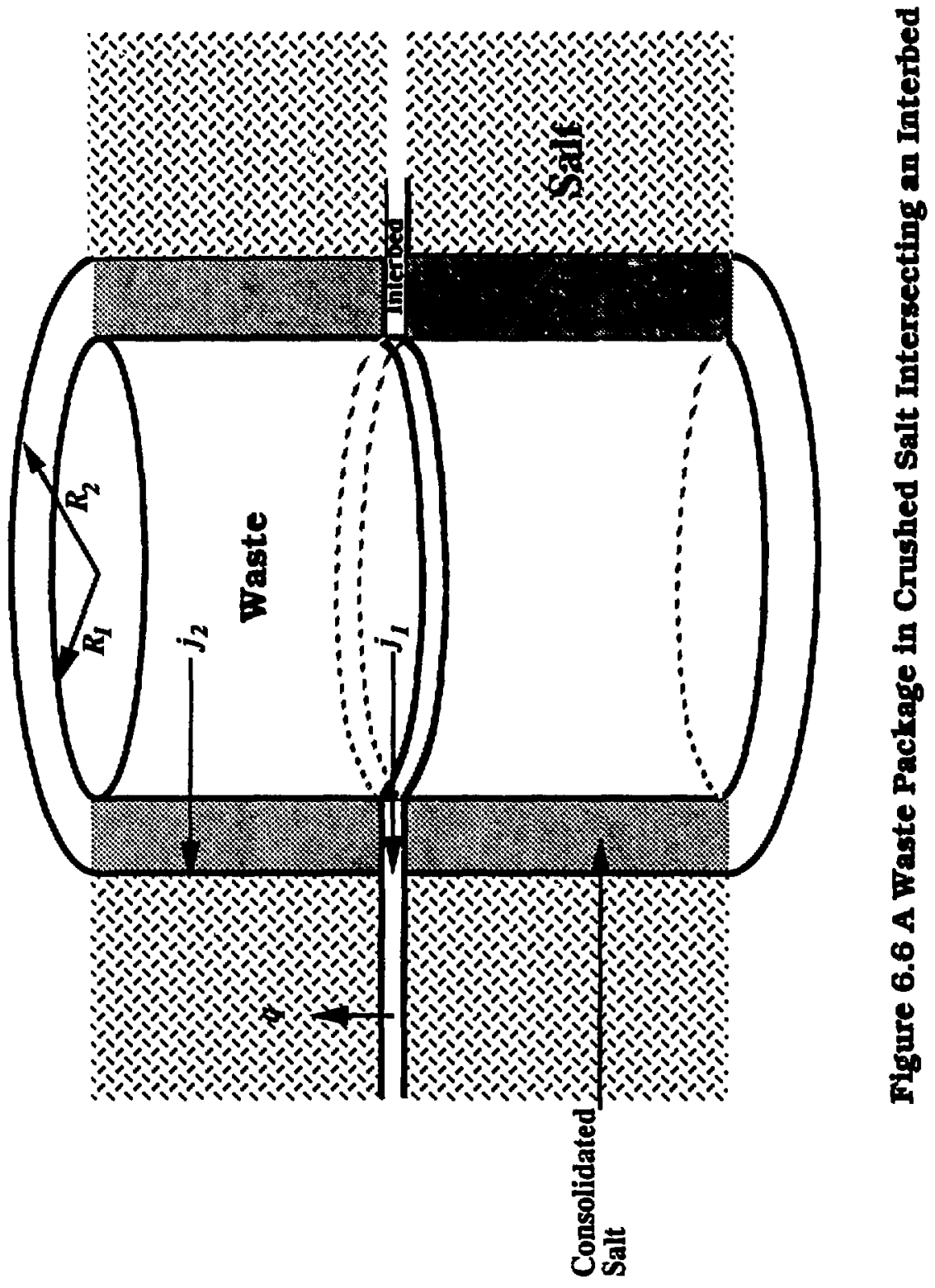


For transport in the crushed salt region,

$$
A_{c}=2 \pi \frac{R_{2}-R_{1}}{\ln \left(R_{2} / R_{1}\right)} \frac{S-2 b}{\ln (S / 2 b)} \quad \text { and } \quad w_{c}=\frac{\epsilon_{c} D}{R_{2}-R_{1}}
$$

where $\mathcal{S}$ is the spacing between interbeds, $2 b$ is the thickness of the interbed, $R_{1}$ is the waste-cylinder radius, and $R_{2}$ is the emplacement-hole radius.

Andersson, Rasmuson and Neretnieks [1982] suggest the following mass-transfer confficient in a planar fracture, which we adopt here for the interbed

$$
A_{i} w_{i}=8 b D \epsilon_{i} \sqrt{P e}
$$

where $\mathrm{Pe}$ is the Peclet number (cf. eq.(2.1.1.2.2)). Our analyses at Berkeley show that (6.3.3) is a good approximation if $\mathrm{Pe}>\mathbf{4}$.

Using eq. (6.3.1) we calculate the fractional release rate for ${ }^{238} \mathrm{U}$ from a single waste cylinder through an interbed [Hwang et al. 1989b]. Table 6.2 shows the values of parameters we use in numerical calculations. We use a waste cylinder diameter of $0.31 \mathrm{~m}$, a crushed salt region thickness of $3 \mathrm{~cm}$. Salt material properties are taken from studies by Brandschug [1987] and McTigue [1986].

Table 8.2. Input Date for Ealt Interbed Caloulations

\begin{tabular}{|l|c|}
\hline Radius of waste cylinder & $0.31 \mathrm{~m}$ \\
Length of waste cylinder & $3.65 \mathrm{~m}$ \\
U-238 1000-year inventory & $5.4 \times 10^{6} \mathrm{~g}$ \\
\hline Crushed salt thickness & $3 \mathrm{~cm}$ \\
Crushed salt porosity & 0.001 \\
\hline Interbed thickness & $0.1,1.0,5 \mathrm{~cm}$ \\
Interbed separation & $0.5,1.0,2.0 \mathrm{~m}$ \\
\hline Interbed porcosity & $0.005,0.01,0.1$ \\
\hline Diffusion coefficient & $10^{-7} \mathrm{~cm}^{2} / \mathrm{s}$ \\
\hline Uranium Solubility & $0.001,50 \mathrm{~g} / \mathrm{m}^{3}$ \\
\hline
\end{tabular}

The fractional release rates of ${ }^{233} \mathrm{U}$ from a waste cylinder through a single interbed and as a function of the parameters in Table 6.1 are shown in Figures 6.7 and 6.8 . As might be expected, the release rates are well below the allowable U.S. Nuclear Regulatory Commission (USNRC) limit of $10^{-5}$.

\subsection{Transient Difualon from a Waste Cylinder into an Interbed}

A more realistic situation is when there is no ground-water flow in ihe interbeds. Here we use some results previously given in Section 2.4 for transient diffusion of radioactive species from a waste cylinder intersecting a planar fracture to the problem of diffusion from a waste cylinder intersecting an interbed in a salt repository. 
Fractional release rate, per year

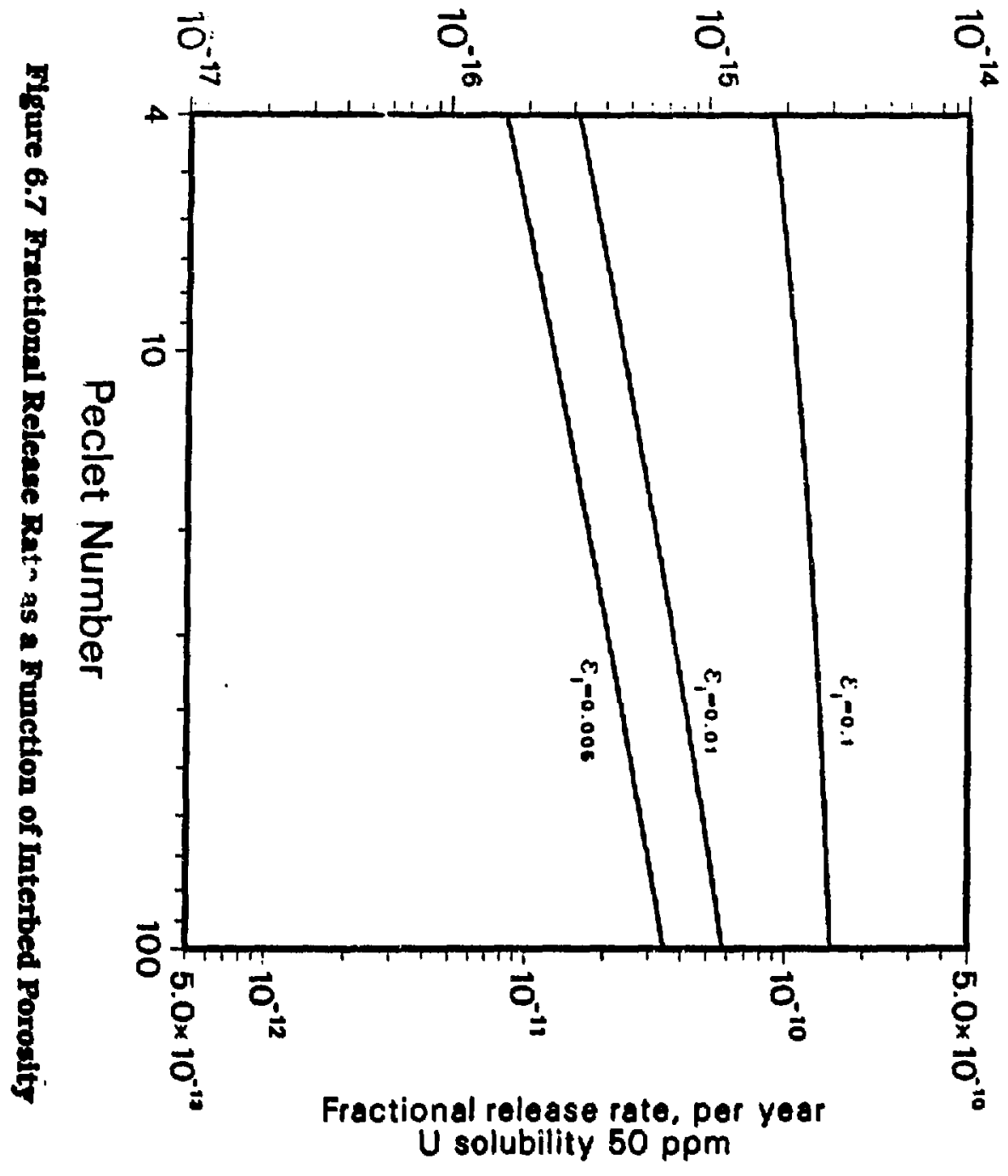




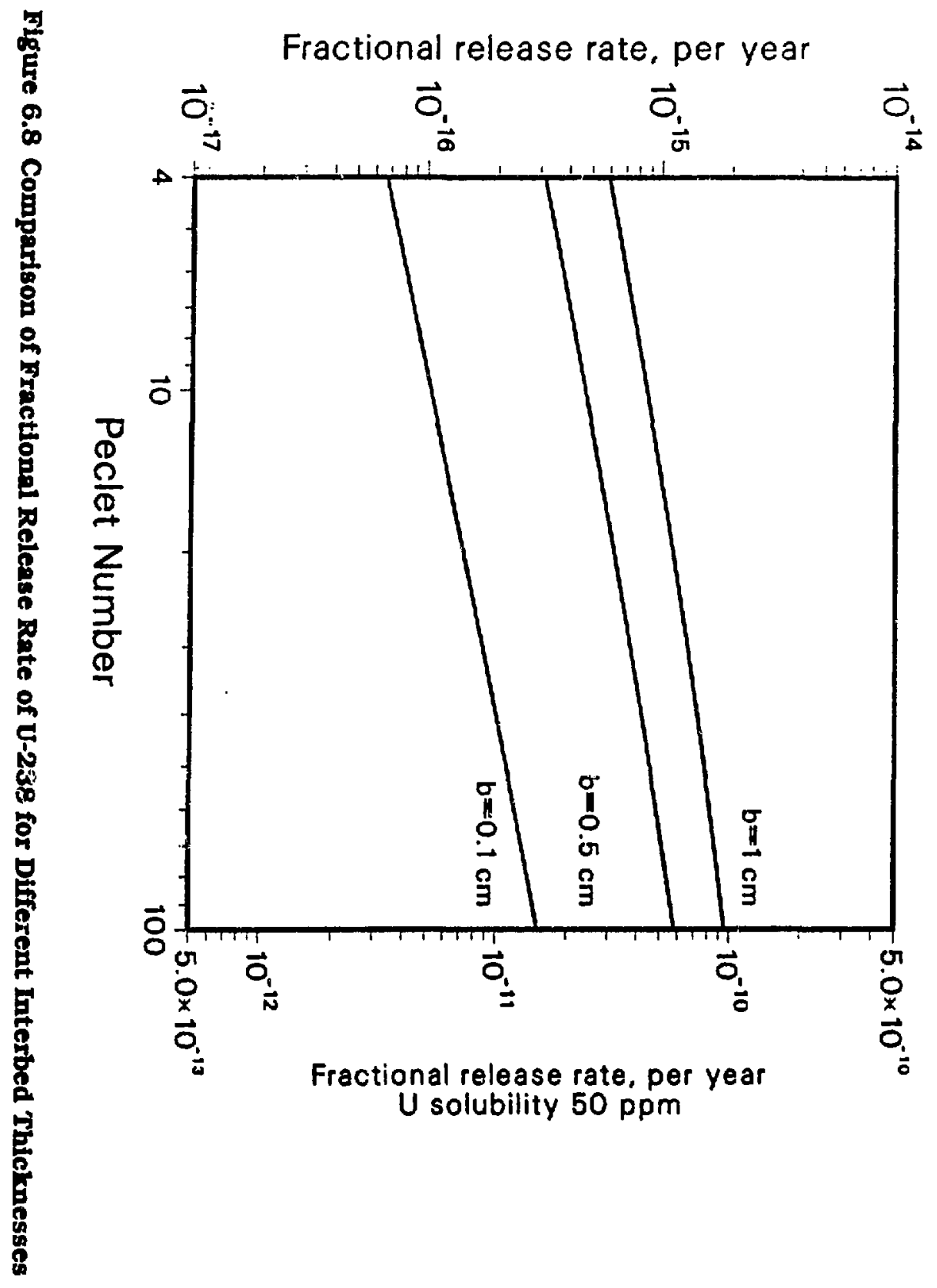


We will now illustrate eq. (2.4.23) and (2.4.24) for a salt repository of nuclear waste. These parameter values are used. The waste cylinder is $0.31 \mathrm{~m}$ in radius.

Table 6.3. Salt Propertios uned in Translent Diffualon muntration

\begin{tabular}{|l|c|c|c|}
\hline Parameter & Units & Salt & Interbed \\
\hline Diffusion coefficient & $\mathrm{cm}^{2} / \mathrm{s}$ & $10^{-7}$ & $10^{-7}$ \\
\hline Porosity & & 0.001 & $0.01^{5}$ \\
\hline Interbed half-width & $\mathrm{m}$ & & $1 \times 10^{-3}$ \\
\hline
\end{tabular}

Table 8.4. Nuclides atudied in Tranalent Difualon Ellustration

\begin{tabular}{|l|c|c|c|}
\hline Species & $\begin{array}{c}\text { Dece Constant } \\
\left(\mathrm{a}^{-1}\right)\end{array}$ & $\begin{array}{c}\text { Retardation Coefficient } \\
\text { in Salt }\end{array}$ & $\begin{array}{c}\text { Retardation Coefficient } \\
\text { in Interbed }\end{array}$ \\
\hline $\mathrm{U}-234$ & $2.81 \times 10^{-6}$ & 1 & 20 \\
\hline Np-237 & $3.24 \times 10^{-7}$ & 1 & 20 \\
\hline Pu-239 & $2.84 \times 10^{-5}$ & 1 & 20 \\
\hline
\end{tabular}

In terms of the dimensionless quantities, we have

$$
\Delta=\hat{D}_{1} \hat{K}_{2} / \hat{D}_{2} \hat{K}_{1}=20, \quad b_{2}=0.0161
$$

We calculate the mass flux into the interbed and directly into the salt [Hwang et al. 1989c]. Figures 6.9 shows thr dimensionless flux into the interbed as a function of the Thiele modulus, which is a dimensionless paramenter for radioactive decay, and at various values of the Fourier number, which is dimensionless time. In Figure 6.6, at early times such as $t=0.1$ or about 600 years on the real time scale, the flux into the interbed of all species is about the same, except for extremely short-lived ones. At larger $t$, such as $t=10$ or 100 , long-lived species show markedly lower dimensionless fluxes. This is because for shorter half-life species radioactive decay serves as an additional sink, increasing the gradient for dissolution.

Figure 6.10 shows the dimensionless flux into the salt as a function of distance into the salt for different Fourier numbers. At $t=0.1$, the dimensionless flux in the vicinity of salt/in $t:$ bed interface is smaller than that further away from the interface. This is due to the diffusion from the interbed to the rock matrix. Because the porosity in the interbed is higher than the porosity in the salt, whereas the diffusion coefficient has been held constant, there is more rapid diffusion of the species in the interbed. The diffusion of the species from the interbed into the salt reduces the gradient for diffusion from the waste cylinder directly into salt, hence the lower flux closer to the salt/interbed interface. As time increase: this region influenced by the interbed expands as shown in Figure 6.10.

Because this analysis was originally developed for transient diffusion from a waste cylinder into a rock fracture, there is some interest in comparing the overall releases from a waste cylinder facing an interbed 


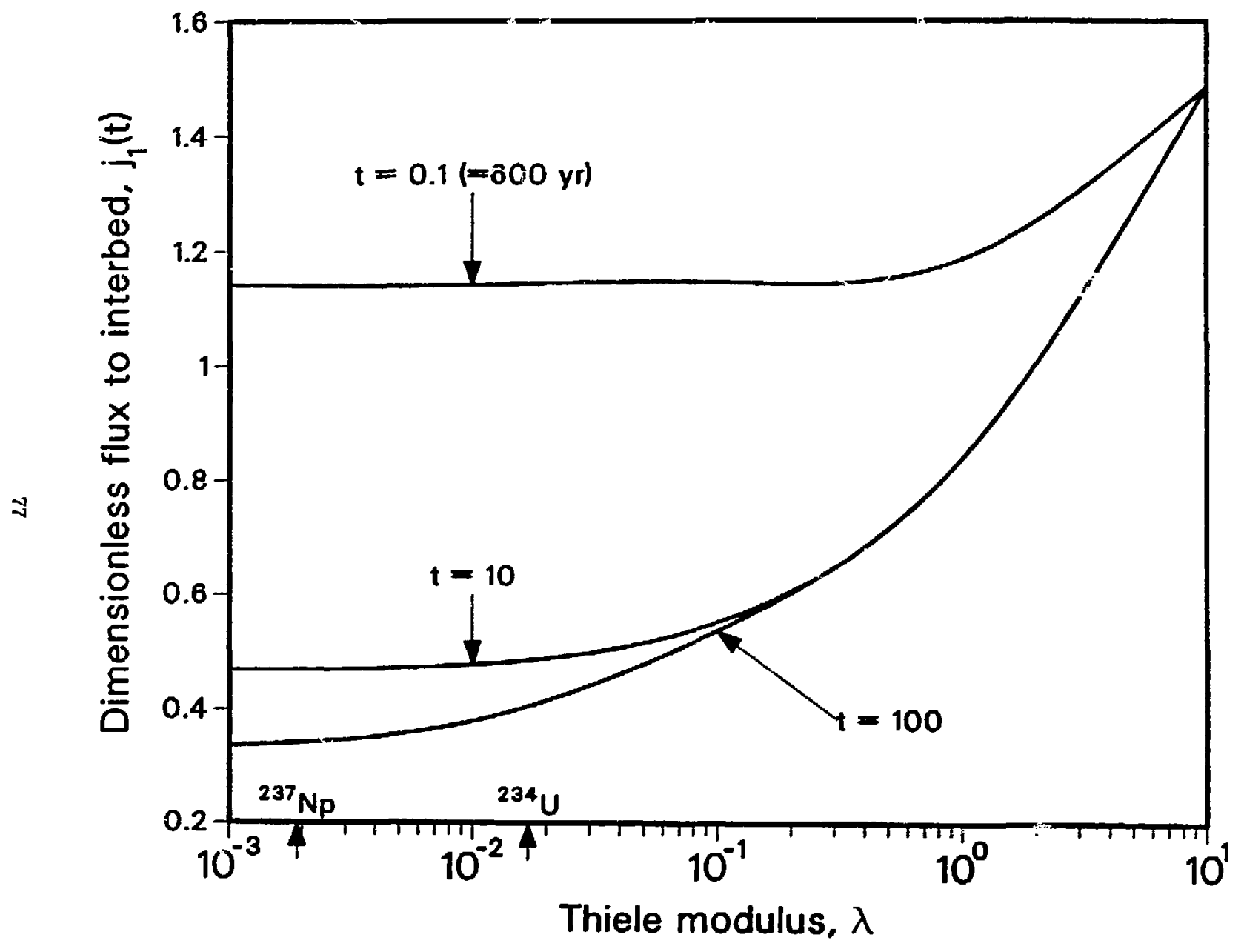

Figure 6.9 Effect of Decay and Time on Mass Flux to the Interbed 


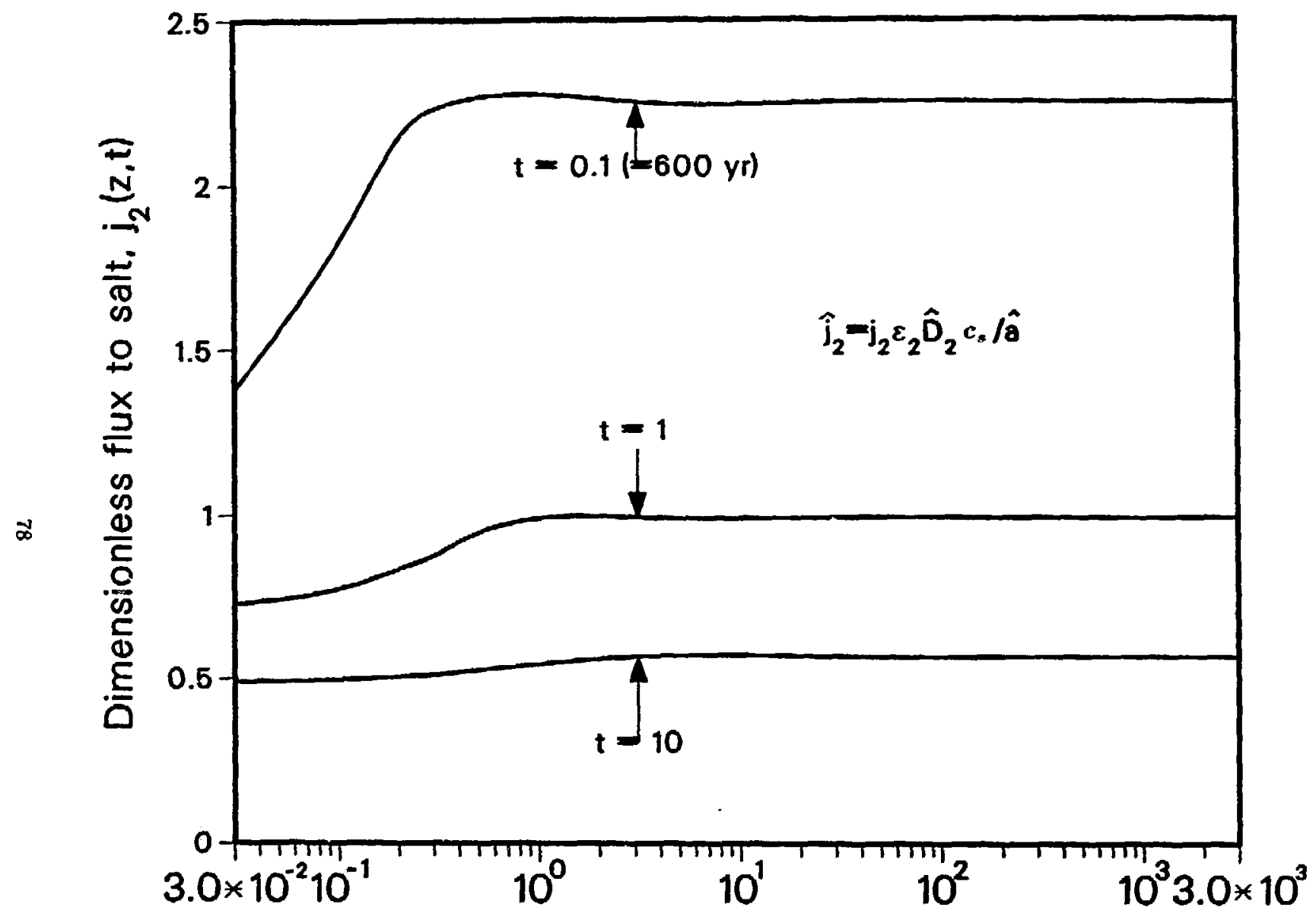

Distance from salt/interbed interface, meters

Figure 6.10 Diffusive Flux from the Waste Cylinder Directly into the Salt 
in salt and a waste cylinder facing a fracture in granite. In this section, we compare the integrated releases from a waste cylinder of length $L$.

The instantaneous mass flux into the interbed/fracture is

$$
\dot{m}_{3}(t)=2 \hat{b} 2 \pi \hat{a} \hat{j}_{3}(t)=4 \pi \hat{R}_{1} \hat{D}_{1} \hat{c}_{3}\left(\frac{c_{3} \hat{b} \hat{D}_{3}}{\dot{R}_{1} \hat{D}_{1}}\right) j_{3}(t)
$$

and the instantaneous mass flux into the salt/rock is

$$
\dot{m}_{1}(t)=2 \times 2 \pi \dot{R}_{1} \int_{0}^{L / 2-t} \dot{j}_{1}(\dot{z}, t) d \hat{z}=4 \pi \dot{R}_{1} \dot{D}_{1} \hat{c}_{0} \epsilon_{1} \int_{0}^{L / 2 \dot{R}_{1}-l / \dot{R}_{1}} j_{1}(z, t) d z
$$

Figure 6.11 shows the instantaneous mass fluxes, divided by $4 x \dot{R}_{1} \hat{c}_{4}$, fron a $3.65-\mathrm{m}$ long waste cylinder into salt and granite using the following data.

\begin{tabular}{|c|c|c|c|c|}
\hline & Porosity & $\begin{array}{l}\text { Diffusion coefficient } \\
\qquad \mathrm{cm}^{2} / \mathrm{s}\end{array}$ & Retardation coefficient & $\begin{array}{l}\text { Solubility } \\
\mathbf{g} / \mathbf{m}^{3}\end{array}$ \\
\hline Salt & 0.001 & $10^{-7}$ & 20 & $10^{-3}$ \\
\hline Salt Interbed & 0.01 & $10^{-7}$ & 1 & $10^{-3}$ \\
\hline Granite & 0.01 & $10^{-5}$ & 500 & $10^{-3}$ \\
\hline Granite Fracture & 1 & $10^{-5}$ & 1 & $10^{-3}$ \\
\hline
\end{tabular}

Tuble 6.E. Elit and Oranite Date unod in Comparicen

Because the product of asumed porosity and diffusion coefficient of salt is approximately $10^{-3}$ times less than that asourned for granite, the release rate to the surrounding salt is almost $10^{-3}$ times leas than that of granite. Figure 6.11 shows that for a bare waste cylinder, the mass fux directly into the waltrock is about 3 orders of magnitude higher than that into the interbed/fracture.

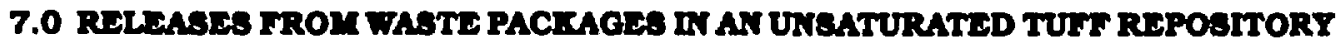

Through the Nuclear Waste Policy Amendments Act of 1987 (42 USC 10101 et seg), Congress directed that the Yucca Mountain site shall be the first to be characterized. The unsaturated rock and near-atmospheric pressure of the repository horizon at Yucca Mountain present new prot erms of predicting waste package performance. The major advantage of the Yucca Mountain site is that, with proper placement of waste, the repository will remain dry for many years. Here we review some methods to predict the performance of high-level waste packages in a repository in unsaturated rock.

Table 7.1 shows the posible release modes for the repository at Yucca Mountain. Results of detail calculations are in our reports [Sadeghi et al. 1989a,b].

As long as all waste packages remain surrounded by hot, dry rock, as is predicted for the first thousand or more years, only gaseous radionuclides can be released from failed waste packages. Only arter the surrounding rock has cooled sufficiently to allow moisture to exist in the rock matrix can ground water reach the waste packages and penetrate the failed containers. However, prior to moisture penetration air can 


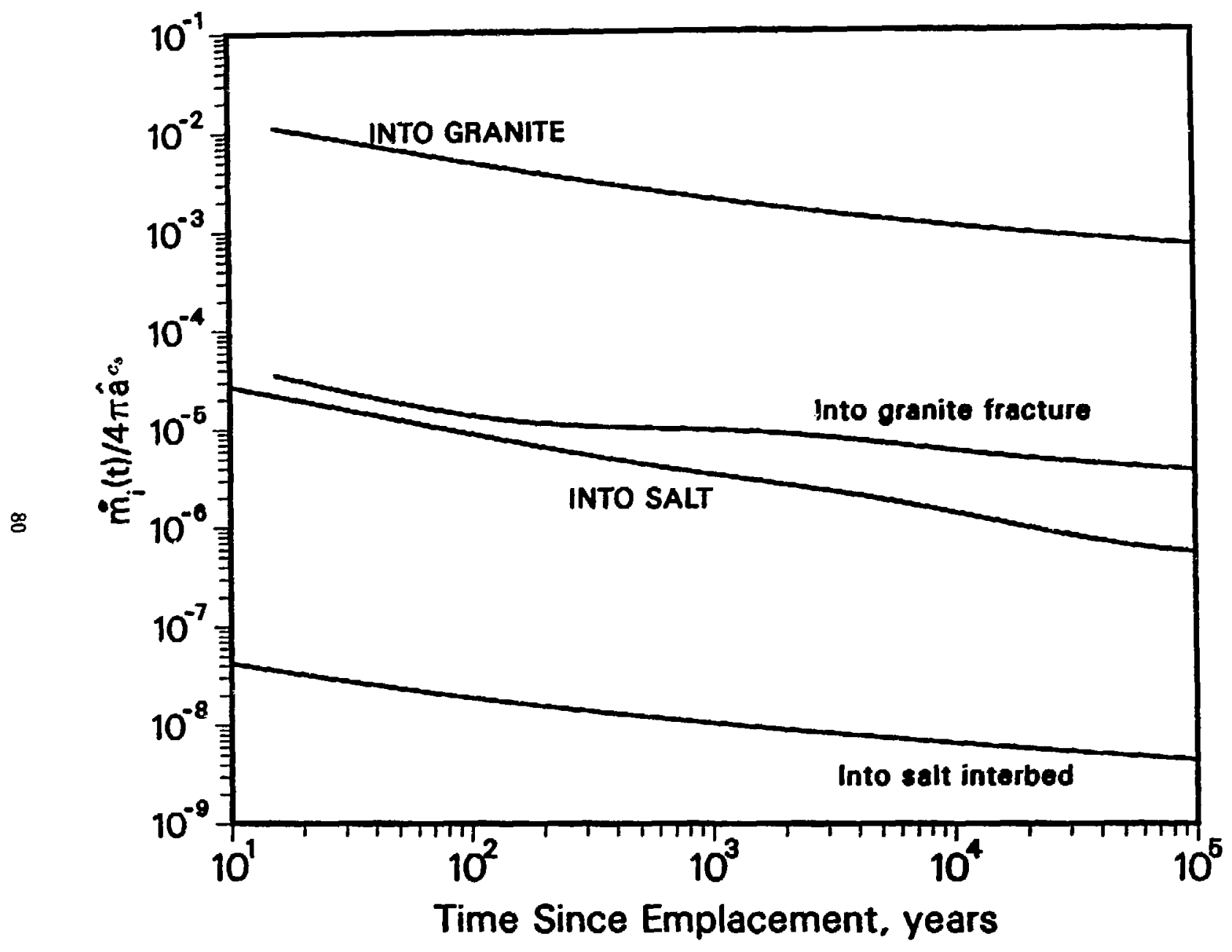

Figure 6.11 Totai Mass Flux of a Stable Nuclide from a 3.65-m Long Waste Cylinder in Salt and Granite 
enter failed containers. Air inleakage can oxidize Zircaloy cladding and mobilize more gaseous carbon-14. Oxidation of the uranium dioxide can cause additional cladding failures. The oxidized uranium will be more soluble, and contained radionuclides can be dissolved more readily if later exposed to ground water.

Table 7.1. Relene Modes at Yucea Mountain

\begin{tabular}{|c|c|c|c|c|}
\hline Environment & \multicolumn{4}{|c|}{ Species } \\
\hline & Gaseous & Low-Solubility & Instant-Relense & Alteration-Controlled \\
\hline Itot-Dry & $\sqrt{ }$ & No Release & No Release & No Release \\
\hline \multirow{2}{*}{ Ambient } & $\checkmark$ & Wet Drip & Wet Drip & Wet Drip \\
& or & or & or \\
& & Wet Continuous & Wet Continuous & Wet Continuous \\
\hline Saturated & No Release & Wet Continuous & Wet Continuous & Wet Continuous \\
\hline
\end{tabular}

\subsection{The Fot-Drip seenario}

At Yucca Mountain each waste package is to be emplaced in a borchole, with a $2-\mathrm{cm}$ air gap between the container surface and the surrounding rock [USDOE 1988]. The 0.2-m air gap between the container and the surrounding rock is designed to keep the container from contacting the rock. Water will contact the waste package only if there is some variation of the local environment away from the design condition, e.g., dripping from overhead rock or contact with moist rock [O'Connell 1990]. Possible variations in rock permeability may divert water into fractures that intersect the emplacement hole, possibly resulting in drips onto the package [O'Connell and Drach 1986]. However, even when the surrounding rock has reached an equilibrium moisture content, the repository is not expected to be saturated. The drips are assumed to cause local cracks in the container. We conservatively assume that all of the water dripping onto the container enters the cracks $8:$.d contacts spent fuel, and we neglect protection of the $\mathrm{UO}_{2}$ fucl by the Zircaloy cladding. For a scenario to predict the possible magnitude of radionuclide releases to ground water, the lawrence Livernore National Laboralory assumes that ground water drips from the rock above the waste package and penetrates through cracks and holes in failed containers. If there are no bottom-exit pathways, water can dissolve radionuclides as it slowly fills the container. Assuming that contaminated water can escape from other top penetrations and drip onto the rock below, the release rate after container overflow can be estimated for a low-solubility species by multiplying the volumetric flow rate by the elemental solubility and by the time-dependent atom fraction of the isotope in the element. The Zircaloy cladding is assumed to present no barrier to release of radionuclides to water within the container. Liquid within the container is expected to be well mixed at all times from diffusion and thermal convection. The water flow rate inio the failed container is assumed to be the product of the ambient Darcy velocity in the surrounding tuff and the cross-sectional area of the waste package. Smaller or larger flow rates may occur, depending on the extent. to which water is channeled iransversely in fractures above the waste packages.

The results of Sadeghi et al. [1989b] calculated for plutonium in spent fuel and horosilicate glass, are shown in Figure 7.1. The mass release rate of each isotope is normalized to the 1000-year inventory of that isotope. The solubilities are from Bruton's EQ3/6 calculations [Wilson and Bruton 1989; Bruton 1988]. The estimated void volume within the spent-fuel container is $1.5 \mathrm{~m}^{3}$. For an estimated Darcy velocity 
Fractional release rate, per year

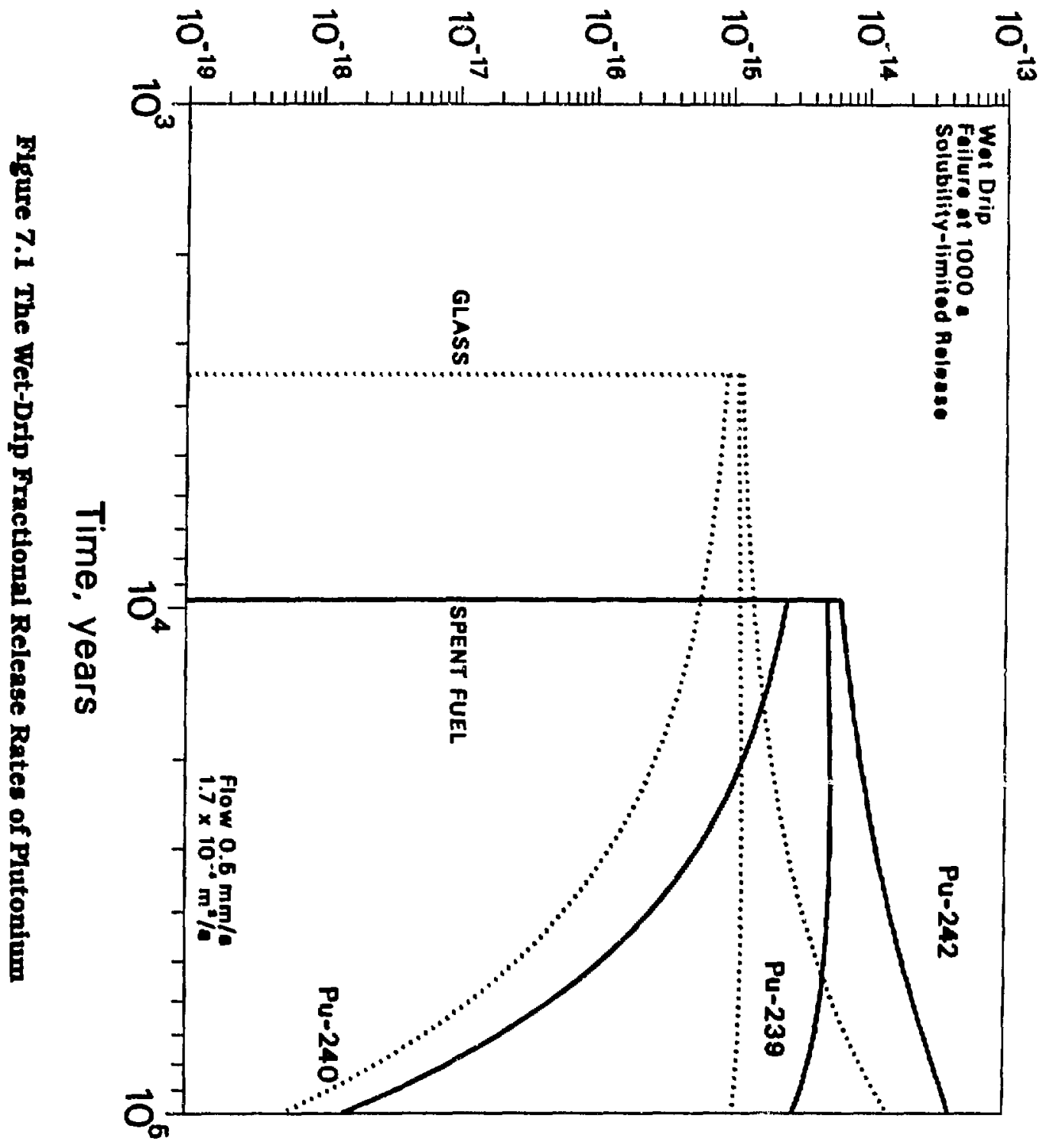


of $0.5 \mathrm{~mm} / \mathrm{a}$, [USDOE 1988] the spent-fuel-container fill time is about 8,000 years. Assuming first water penetration at 1,000 years, the first overflow release from the spent fuel container is at 9000 years. The release rate of 6,580-yr Pu-240 decreases rapidly with time because of decay, allowing greater concentrations of the longer-lived Pu-239 and Pu-242 within the constraints of elemental solubility. As 24,400-yr Pu-239 decays, greater solubility-limited concentrations of 379,000-yr Pu-242 are possible, and its release rate increases. The curves are calculated to 100,000 years to illustrate the effect of longer time periods that may be consitiered. For these parameters, the predicted fractional release rates for plutonium and other low-solubility actinides would fall below the USNRC fractional-release limits, even if those limits were conservatively assumed to apply to individual waste packages rather than to the repository-average release rates.

Results for plutonium released from glass defense waste are also shown in Figure 7.1. The release: begins earlier than for spent fuel because of the smaller void volume of $0.42 \mathrm{~m}^{3}$ within the defense wastr: package. The predicted fractional release rate of a species increases with solubility and decreases with increasing inventory. As compared with spent fuel, the lower solubility predicted for plutonium in defense waste overcomes the lower inventory, resulting in a three-fold lower release rate than for spent fuel.

Fractional release rates of readily soluble cesium and jodine that exist in fuel-cladding gap, fuel plenum, and grain boundaries are shown in Figure 7.2 [Sadeghi et al. 1989b]. The liquid in the failed container is assumed to be well mixed at all times, from diffusion and thermal convection, so the release rate falls off exponentially after the first overflow.

Some of the highly soluble species in the waste matrix may not be release-limited by their solubilities. Lahoratory studies suggest that their release may be congruent with the alteration of the waste matrix when it reacts with water, such as conversion of $\mathrm{UO}_{2}$ in spent fuel to $\mathrm{U}_{3} \mathrm{O}_{7}$ and the conversion of silica in borosilicate glass to a crystalline mineral phase. Present data are not sufficient to estimate siteration rates, but for illustration we assume a constant mass rate of alteration equivalent to a fractional rate of $0.001 / \mathrm{a}$ of the initial inventory of uranium in spent fuel or of silica in defense waste.

The predicted fractional rates [Sadeghi et al. 1989b] of Tc-99 released by waste-matrix alteration are shown in Figure 7.3 for spent fuel and defense waste. The first liquid overflow is at an average concentration resulting from the slow rise of liquid level in the container. Only at the time of overflow will all of the waste matrix have been exposed to water for alteration and release. The average concentration of long-lived species in the filled container increases further with time, and their release rates increase, until all of the waste matrix has altered and all soluble constituents are dissolved. For the rate constant asumed here, the last waste-solid alteration will be complete 1,:00 years after first overflow. The release then decreases exponentially with time as fresh ground water mixes uniformly with the container liquid. These results are only for illustration. Better data are needed to estimate alteration rates appropriate for this calculation.

The release rates of cesium and technetium could be limited instead by solubility. Low-solubility pollucite $\left[(\mathrm{Cs}, \mathrm{Na})_{2} \mathrm{Al}_{2} \mathrm{Si}_{4} \mathrm{O}_{12} \cdot \mathrm{H}_{2} \mathrm{O}\right]$ can be formed by cesium and silica from borosilicate glase (Bennington, Beyer and Johnson, 1983]. Bruton's calculations show that waier-waste reactions can result in an increasingly seducing environment [Wilson and Bruton 1989; Bruton 1988] that can promote a lower solubility of technetium. Also, the iron container is expected not to fail by uniform corrosion but by local penetrations, so iron-water reactions within the container can contribute further to a reducing environment.

The aiteration-cuntiolled release rates for borosilicate-glans waste show greater peak values than tor spent fuel and decay more rapidly after the peak. This is a consequence of the smaller void volume within 


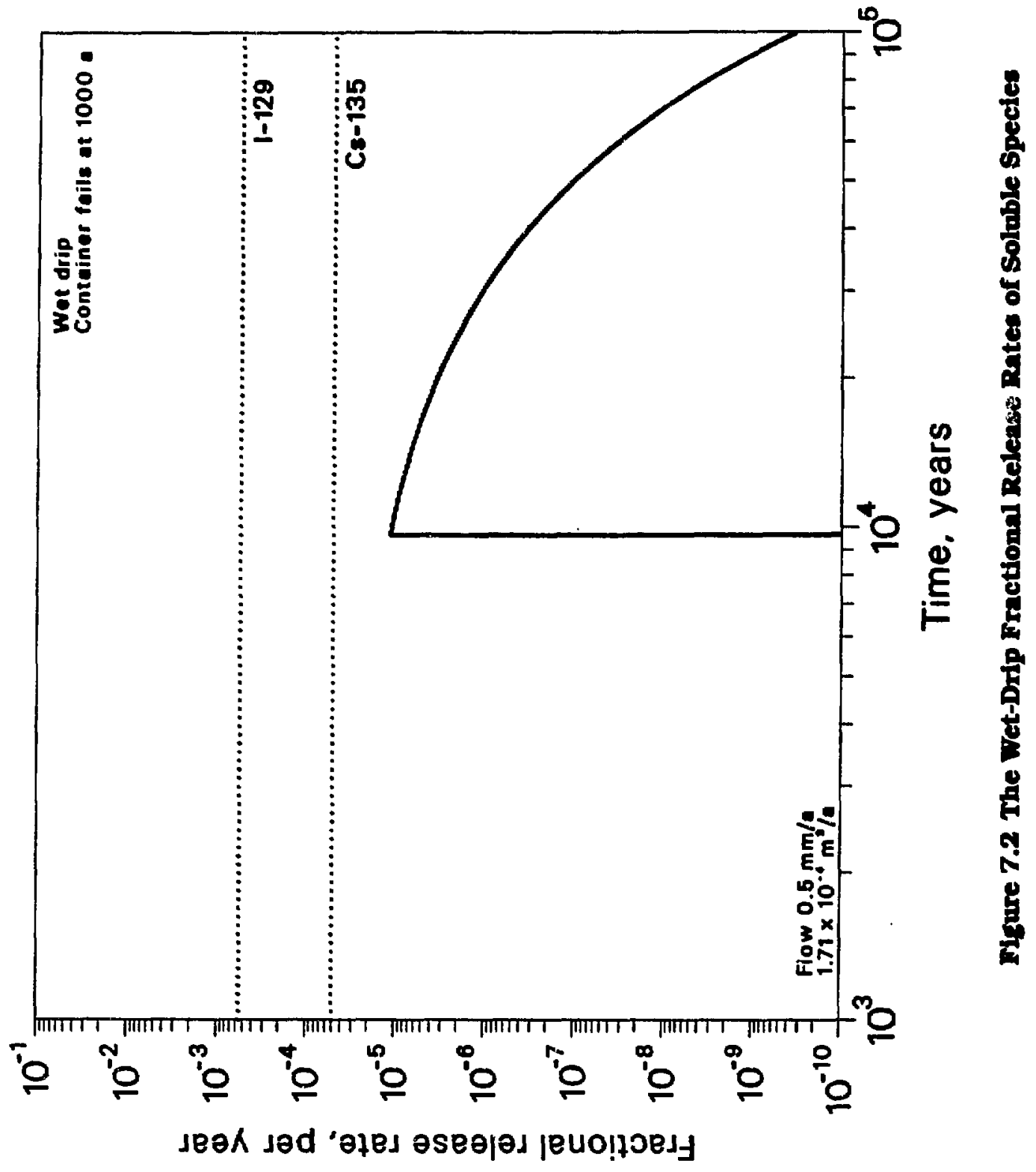




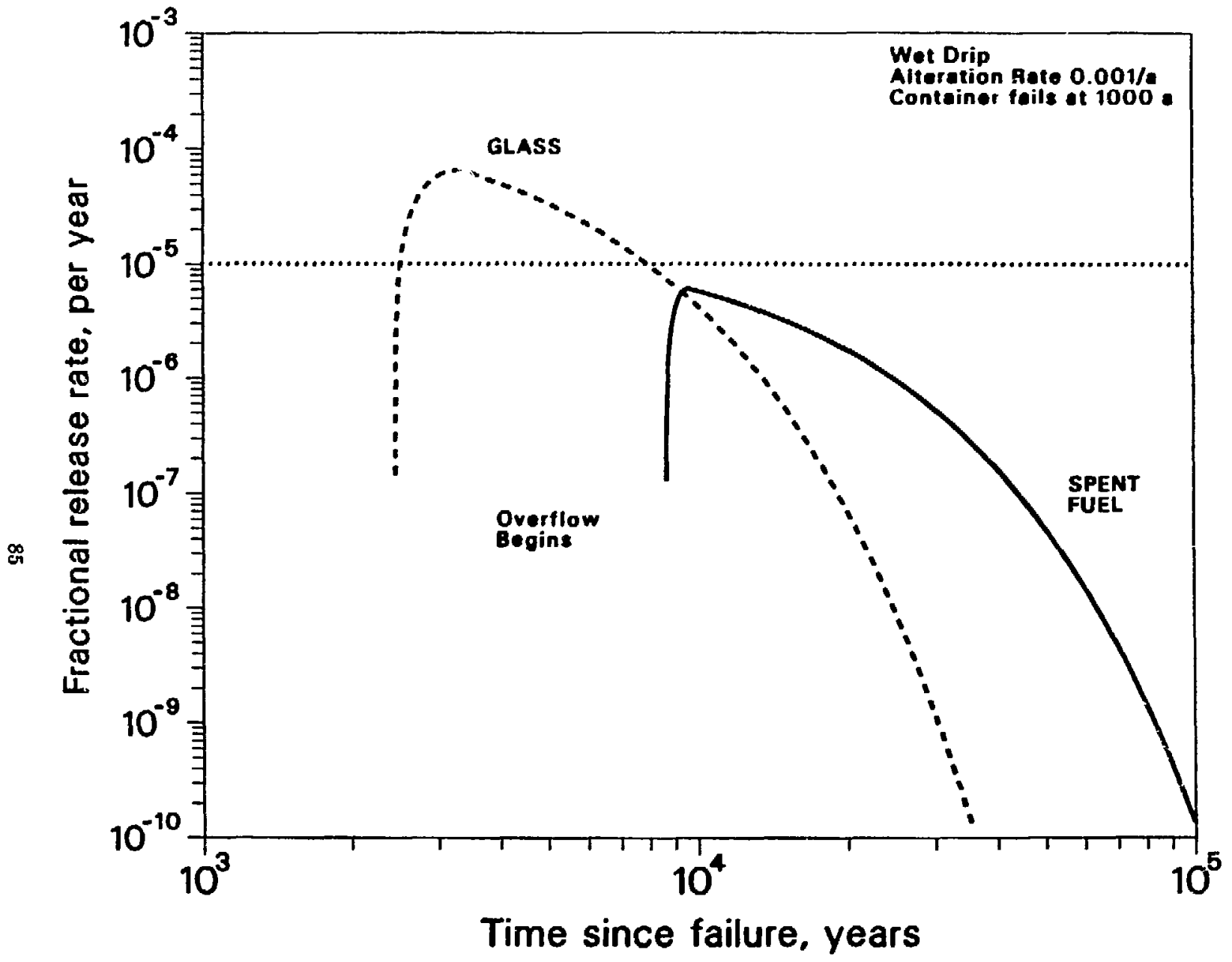

Figure 7.3 The Wet-Drip Fractional Release Rate of Tc-99 
the defense-waste container.

\subsection{The Wet-Continuous Scenarto}

The wet-drip scenario assumes that there are no pathways for diffusive release to the surrounding rock. However, part or all of the degraded container can make contact with surrounding rock or with exfoliated rock and rubble that may fill the annular space around the container. Diffusive pathways through the degraded container and into the surrounding rock are possible. If a diffusive pathway exists, then all of the lechniques reviewed in Sections 2 and 3 are applicable. We have shown [Sadeghi et al. 1990] that difiusive mass transfer through the porous media surrounding the waste can result in release rates grealer than those estimated for the wet-drip scenario, depending on the magnitude of the diffusion coefficient. Here we show the results of diffusive mass-transfer calculations, using analytic equations from Sections 2 and 3 [Sadeghi et al. 1989b], Conservatively, we neglect mea-transfer renistance from fuel cladding and failed metal containers.

\section{Solubillty-Limited Roloases}

The tine-dependent fractional releave rate of a low-solubility apecies from an equivalent spherical wayte can be calculated from the equations in Section 2.1.2. The fractional release rate is the mass release rate divided by the 1000-year inventory. Decay within the waste solid is neglected. For a saturated repository, or if a significant portion of the degraded container is in contact with surtounding intact rock, we obtain the results from plutonium isotopes from spent fuel shown in Figure 7.4. Long-term release is greater for the shorter-lived species becuuse decay steepens the concentration gradient at the white surface. For the parameter values used, [USDOE 1988; Wiloon and Bruton 1989] the predicted release rates are far below the regulatory limits but are greater than those predicted for a drip scenario.

If the annulus becomes filled with rubble and fines consolidated to the same consistency as intact rock, the consolidated annulus acts as a buffer. The resulting fractional relesse rate, calculated using eq. (2.3.1.9), across the original borehole surface is shown in Figure 7.5 for plutonium irotopes. The 2-cm buffer delays release of plutonium into the original rock, and it eliminates the early-time high release rate.

If the rubble and fines in the annulus do not consolidate, and if the repository is not saturated, diffusion through the rubble bed is inhibited by the small area of contact between individual rubble pieces [Sadeghi el al. 1990]. Assuming a 1,000-fold reduction in the effective mass transfer coefficient in the rubble compared to intact rock, we obtain the resulting time-dependent fractional releases of plutonium isotopes into the surrounding intact tuff are shown in Figure 7.6. The peak release rate is about 500 -fold below that calculated in Figure 7.5.

\section{Alteration-Controlled Relensed}

Soluble species in the spent-fuel matrix can be released directly to the rock by solid-phase alteration of spent-fuel matrix. If the release is congruent with alteration, the fractional release rate will equal the fractional alteration rate of the tranium. If the fractional alteration rate is as high as $10^{-4}$ to $10^{-3} / \mathrm{a}$, as might occur in an wxidizing environment, alteration-controlle? release can be of concern in meeting regulatory limits. 


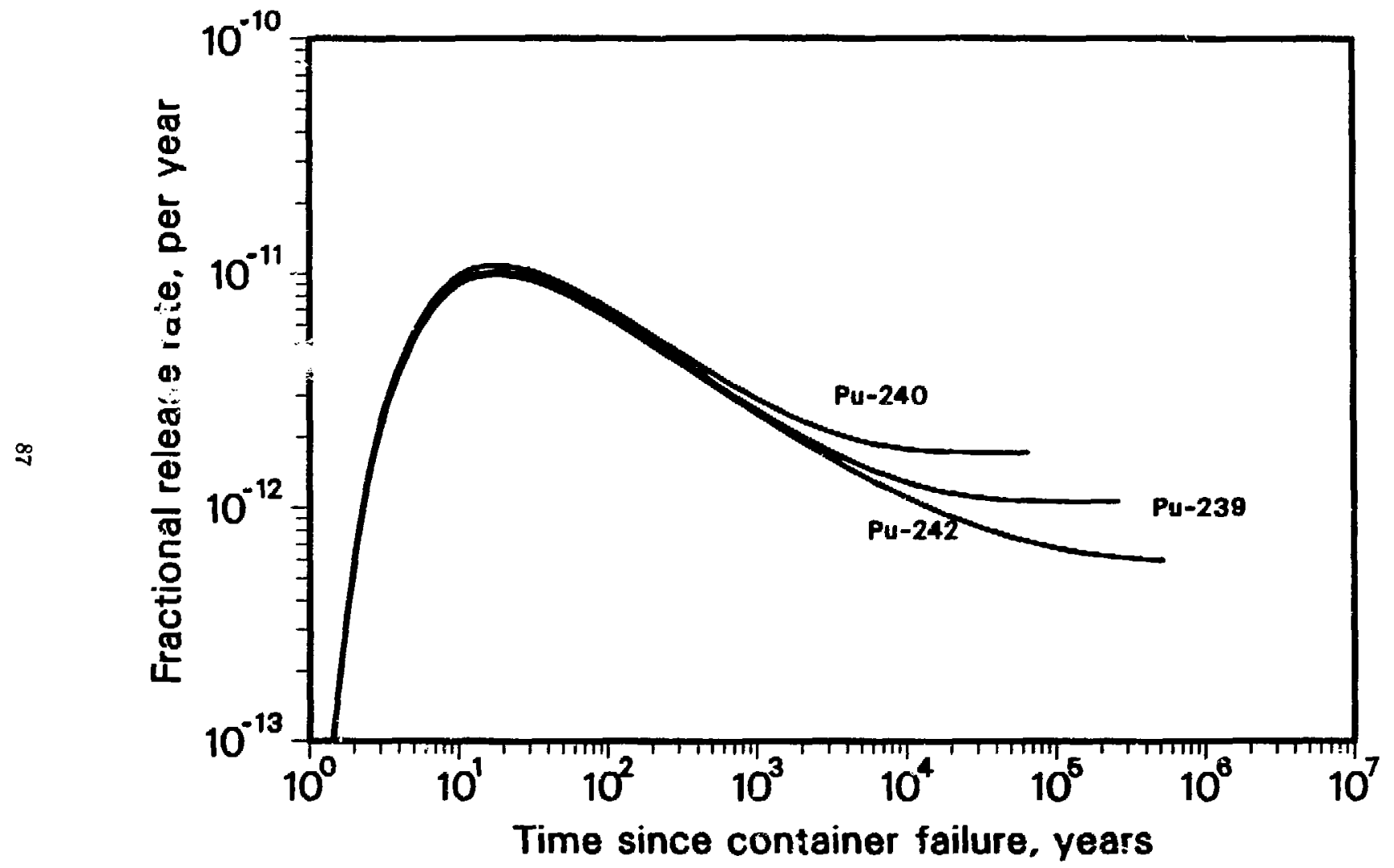

Figure 7.4. The Wet-Continuous Frsctionel Release Rate of Plutonium 


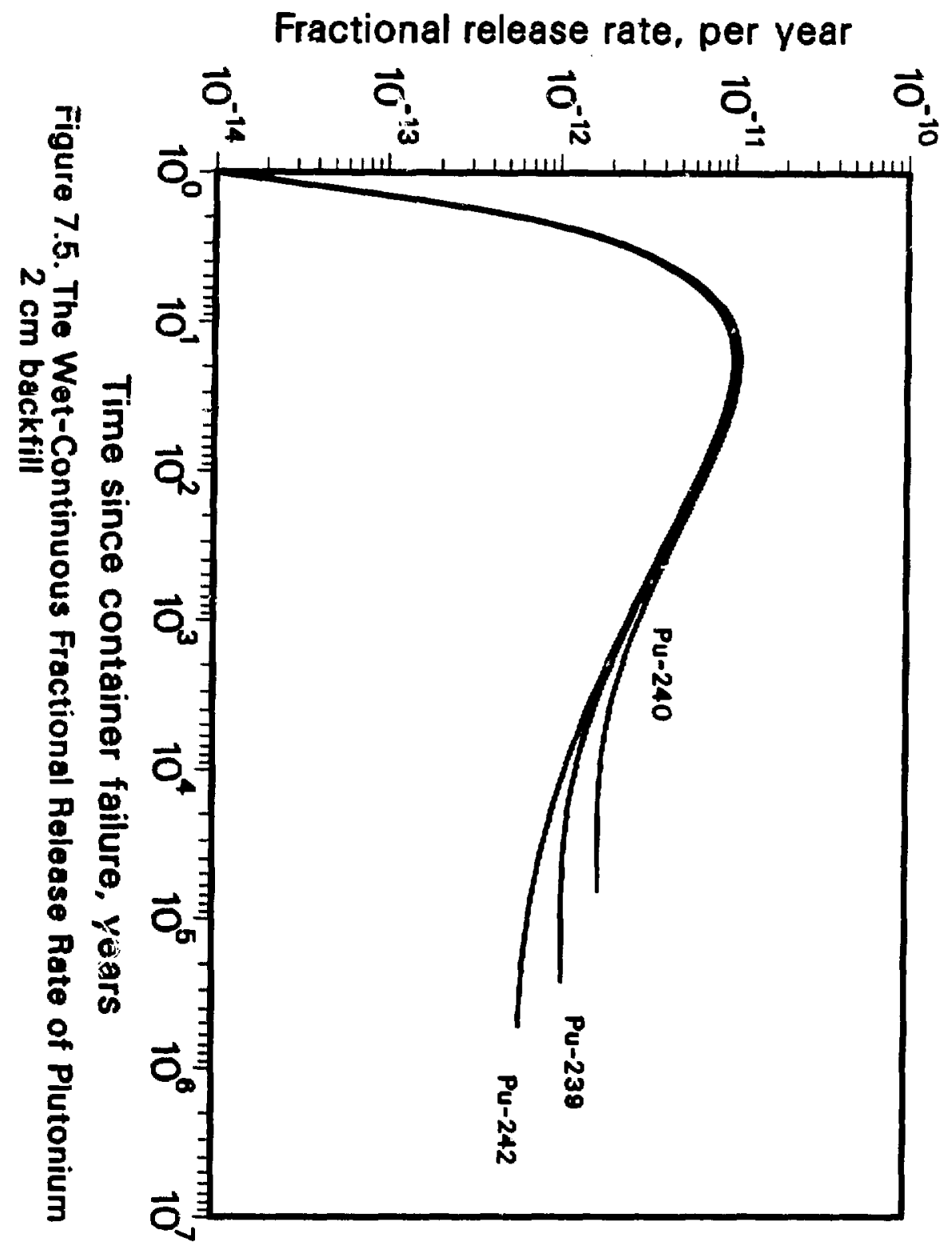




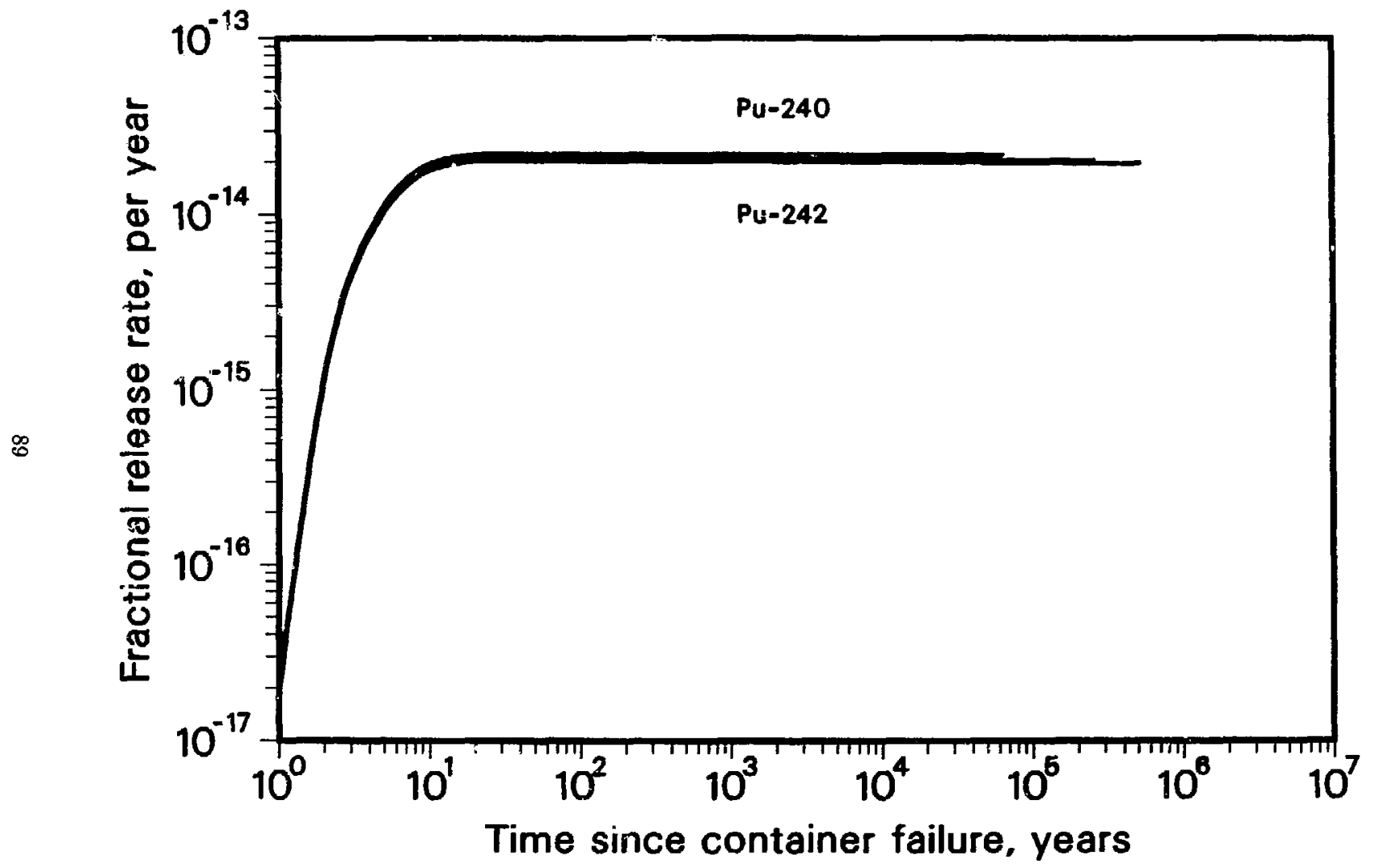

Figure 7.6. The Wet-Continuous Fractional Release Rate of Plutonium

$2 \mathrm{~cm}$ backfill, 1,000-fold reduction in diffusion coefficient 


\section{P.O SUMMART}

The foregoing is a comprehensive review of much of our res:arch results on predicting near-field mass transfer. Further work is in progress and will be published separately.

Readers should refer to the original reports for details of mathematical derivations, methods of solutions and calculations.

\section{ACKNOWLEDGEMENT}

Work supported in part by the Director, Office of Civilian Radioactive Waste Management, Office of Systems Integration and Regulation, Licensing and Compliance Division, under contract DE-AC03-76SF00098.

\section{NOTATION}

$A$ is the area over which mass transport is taking place

$a$ is the dimension of gap or void

$B$ is the pore-pressure modulus, where $\frac{1}{B}=1+\epsilon \frac{\mathcal{K}\left(1-\mathcal{K}_{\rho} / K_{s}^{\prime \prime}\right)}{\mathcal{K}_{f}\left(1-\mathcal{K}_{1} / \mathcal{K}_{s}^{\prime}\right)}$

$B$ is a geometrical factor

$b^{\prime}$ is a constant involving material properties, eq. (6.1.2)

$b=R_{0}-R$ is the thickness of the backfill

$b_{1}$ is the semiminor axis of a prolate spheroid

$b_{2} \equiv \epsilon_{3} \hat{b} \hat{K}_{3} / \epsilon_{1} \hat{R}_{1} \hat{K}_{1}$, eq. (2.4.16)

$2 \hat{b}$ is the thickness of a rock fracture/salt interbed

$c$ is the concentration of the species

$c_{1}$ is the concentration in the backfill (Layer 1)

$c_{2}$ is the concentration in the rock (Layer 2)

$c_{3}$ is the concentration in the fracture

$c_{4}$ is the concentration in Layer 1 after precipitation starts

$c_{5}$ is the concentration in Layer 2 after precipitation starts

$c_{a}$ is the mass of the species adsorbed on the solid phase per unit bulk dry mass of the $y$ orous material

$c^{0}$ is the initial concentration of the species in the void water

$c_{\boldsymbol{r}}$ is the solubility limit after precipitation

$c_{s}$ is the saturation concentration

$c_{i}^{*}$ is the average concentration of the nuclide outside of the backfill

$c^{*}$ is the critical concentration

$c^{\prime}(t)$ is the time-dependent well-mixed soncentration of the soluble species in the water in the void

$\bar{c}$ is the concentration in the unsat: ated zone

$d$ is fluid diffusivity, eq. (6.1.2)

$D$ is the diffusion coefficient

$D_{f}$ is the diffusion coefficient for the liquid continuum

$\mathcal{D}_{f}$ is the one-dimensional finite domain

$\mathrm{E}(x)$ is the complete elliptic integral of the second kind, and

$\mathcal{E}$ is the eccentricity of a prolate spheroid

$f$ is the fractiona' dissolution rate of the species

$f(t), g(t)$ are dimensionless functions of time 
$\mathcal{F}$ is the saturation concentration in the solid phase

$G$ is the shear modulus

$\mathcal{G}(t)$ is the location of the saturation front

$h$ is a mass transfer coefficient

$j_{0}$ is the experimental forward reaction rate of the dissolved species per unit surface area

$j_{1}(z, t)$ is the dimensionless flux into the fracture/interbed

$j_{3}(t)$ is the dimensionless flux directly into the rock/salt

$k$ is the permeability

$k_{1}$ is the mass-transfer coefficient for the spherical waste surface

$k_{2}$ is a reaction-rate constant

$K$ is the species retardation coefficient

$K_{d}$ is the sorption distribution coefficient

$\mathcal{K}$ is the bulk modulus, eq. $(0.1 .2)$

$\mathcal{K}_{f}$ is the fluid bulk modulus

$\mathcal{K}^{\prime}, \mathcal{K}_{\text {, }}^{\prime \prime}$ are the solid bulk moduli

$L$ is the length of the waste cylinder

$M$ is the inventory

$\mathcal{M}$ is the number of isotopes in an element

$\dot{m}$ is the mass flux

$i_{f}(t)$ is the rate of dissolution of the species from the waste matrix into the void volume $V$

$\dot{m}_{c}$ is the mass transfer rate of the controller or dominant species

$\dot{M}$ is the total mass loss from the surface of the waste solid

$\mathcal{N}$ is the bulk density of the elemental species in the waste

$P$ is the relative pore pressure

$\mathrm{Pe}=U R / D$ the Peclet number

$\hat{q}(\hat{r}, \hat{t})$ is the diffusive flux from the fracture to the rock through the interface

$Q_{0}$ is the initial heat flux of the wante package

$Q_{o}(\varsigma) \equiv \ln (\operatorname{coth} \varsigma / 2)$

$r_{p}$ is the location of the precipitation front

$R$ is the radius of spherical waste solid

$R_{0}$ is the radius of waste sphere including backfill

$R_{1}$ is the waste cylinder radius

$R_{2}$ is the emplacement hole radius

$R_{p}$ is the location of the precipitation front

$S$ is the surface area of gap or void

$S$ is the spacing between interbeds

$\mathrm{Sh}=k_{1} R / \epsilon D$ is the Sherwood number

$t$ is time

$t_{p}$ is the time of precipitation onset

$t$, is the time necessary for the mass flux at the surface to reach within five percent of the steady-state value

$T_{b}$ is the breakthrough time

$T$ is the temperature

$U$ is the ground-water pore velocity upstream of the waste solid

$V$ is the volume of gap or void

$v$ is the Darcy velocity

$w$ is a mass transport coefficient in salt 
$\bar{z}$ is the distance from the rock/fracture interface

$\alpha=j_{0} R / \epsilon D c$, is the Thiele modulus

$\alpha_{f}$ is the fluid-phase thermal expansion coefficient

$\alpha_{s}^{\prime \prime}$ is the second cubical thermal expansion coefficient of the solid

$\beta \equiv \sqrt{D_{0} K \epsilon^{2} / a^{2}}$

$\beta_{\mathrm{l}}=\sqrt{K_{2}^{\prime} / K_{1}^{\prime}}$ in eq. (2.3.1.9)

$\gamma$ is the isotopic fraction

$\delta_{\ell j}$ is the Kronecker delta

$\delta=\sqrt{\frac{K_{1}}{K_{2}} \frac{c_{1}}{c_{2}}}$ eq. (3.2.11)

$c$ is the porosity of the rock

$\zeta$ is the prolate spheroid surface coordinate

$\theta$ is relative temperature

$r$ is the thermal diffusivity

$\lambda$ is the species decay cunstant

$\Lambda$ is the thermal conductivity

$\mu$ is the absolute viscosity

$\nu$ is Poisson's ratio for the solid phase

$\nu_{u}$ is the undrained Poisson's ratio

$\phi\left(c, c_{0}\right)$ is the interphase reaction rate

$\nabla=U t / K R$

$\sigma_{1}$ and $\sigma_{2}$ are tortuosity correction factors for the two layers

$\tau \equiv(1+\alpha)^{2} D t / K R^{2}$

$\Omega_{1}=K \lambda R^{2} / D$

$\Omega_{2}=K \lambda R / U$ is the Thiele modulus for convective mass transport

$\omega=K_{1} \epsilon_{1} S / V$, eq (3.2.11)

$\rho=\cosh ^{-1}(1 / \mathcal{E})$ prolate spheroid coordinate

\section{SUBSCRIPTs}

c crushed salt region

e element

$\mathrm{i}$ isotope or interbed

s stable or solubility

se elemental solubility

f fluid phase

s solid phase

1 backfill or Layer 1 or inner layer

2 rock or Layer 2 or outer layer 


\section{REFERENCOS}

Ahn, J., P. L. Chambré, and T. H. Pigford, Transient Diffusion From a Cylindrical Waste Solid Into Fractured Porous Rock, Rad. Waste Mgt \& the Nucl. Fuel Cycle, 19, 263, 1989.

Ahn, J., P. L. Chambré, T. H. Pigford, and W. W.-L. Lee, Radionuclide Dispersion From Multiple Patch Sources Into a Rock Fracture, Report LBL-29425, Lawrence Berkeley Laboratory, 1987.

Ahn, T. M., K. S. Czyscinski, E. M. Franz, C. J. Kiamut, B. S. Lee, N. S. McIntyre, K. J. Swyler, and R. J. Wilke, Nuclear Waste Management Technical Support in the Development of Nuclear Waste Form Criteria for the NRC, Repori NUREG/CR-2999-4, Brookhaven National Laboratory, 1982a.

Ahn, T. M., R. Dayal, and R. J. Wilke, Evaluation of Backfill as a Barrier to Radionuclide Migration in a High Level Waste Repository, Report NUREG/CR-2999. App. A, Brookhaven National I.aboratory, 1982b.

Andersson, G., A. Rasmuson, and I. Neretnieks, Migration model for the near field, Final Report, Report $S K B F / K B S$ Report 82-24, 1982.

Bennington, K. O., R. P. Beyer, and G. K. Johnson, Thermodynamics Properties of Pollucite, Report Report of Investigations 8779, U. S. Bureau of Mines, 1983.

Brandshaug, T., Estimate of Consolidation of Crushed Salt Around a Spent Fuel Waste Package, Report RST-\$15, RE/SPEC Inc., 1987.

Browne, E., and R. B. Firestone, Table of Radioactive Isolopes, Wiley, New York, 1986.

Bruton, C. J., Geochemical Simulation of Dissolution of Weat Valley and DWPF Glasses in J-13 Water at $90 \mathrm{C}$, in Scientifir Basis for Nuclear Waste Management XI, edited by M.J. Apted, and R.E. Westerman, Materials Research Society, 607, 1988.

Camphell, J. E., and R. M. Cranwell, Performance Assessment of Radioactive Waste Repositories, Science, 299, 1389, 1988.

Chambré, P. L., Y. Hwang, W. W.-L. Lee, and T. H. Pigford, Release Rates from Waste Packages in a Sall Repository, Trans. Am. Nucl. Soc, 55, 131, 1987.

Chambre, P. L., C. H. Kang, W. W.-L. Lee, and T. H. Pigford, Mass Transfer of Soluble Species Into Backfill and Rock, Trans. Amer. Nuc. Soc., 59, 136, 1986.

Chambré, P. L., C. H. Kang, W. W.-L. Lee, and T. H. Pigford, The Role of Chemical Reaction in WasteForm Performance, in Scientific Besis for $N$ wciear Weste Management XI, edited by M.J. Apted, and R.E. Westerman, Materials Research Society, 125, 1988.

Chambré, P. L., C. H. Kang, and T. H. Pigford, Flow of Ground Water Around Buried Waste, Trans. Am. Nuc. Soc., 52, 77, 1986.

Chambré, P. L., H. Lung, and T. H. Pigford, Time-Dependent Mass Transfer Through Backfil, Trans. Amer. Nucl. Soc., $\{6,132,1984$.

Chambrè, P. L., and T. H. Pigford, Prediction of Waste Performance in a Geologic Repository, in Scientific Basis for Nuclear Waste Management VIII, edited by G.L. McVay, Materials Research Society, 985, 1984.

Chambré, P. L., T. H. Pigford, W. W.-L. Lee, J. Ahn, S. Kajiwara, C. L. Kim, H. Kimura, H. Lung, W. J. Williams, and S. J. Zavoshy, Mass Transfer and Transport in a Geologic Environment, Report LBL-19490, Lawrence Berkeley Laboratory, 1985.

Chambré, P.L., T. H. Pigford, Y. Sato, A. Fujita, H. Lung, S. J. Zavoshy, and R. Kobayashi, Analytical Performance Models, Report LBL-14842, Lawrence Berkeley Laboratory, 1982. 
Chambré, P. L., W. J. Williams, C. L. Kim, and T'. IT. Pigford, Time-Temperature Dissolution and Radionuclide Transport, Trans. Am. Nuc. Soc., 46, 131, 1984.

Garisto, F., Solid Dissolution: Effect of Mass Transport-Precipitation Coupling, Chem. Eng. Sci., 41, 3219, 1986.

Garisto, F., and N. C. Garisto, The Effect of Precipitation on Radionuclide Release from Used Fuel, in 2nd Intl Conf. on Radioactive Waste Management, 645, $1986 \mathrm{a}$.

Garisto, N. C., and F. Garisto, The Effect of Precipitation on the Long-Term Release of Radionuclides from Used Fuel, Ann. Nuc. Energy, 19, 591, 1986 b.

Garisto, N. C., and F. Garisto, Mass Transport-Precipitation Coupling in : Sul. Sy:tems, Report AECL$9568,1988$.

Garisto, N. C., K. B. Harvey, F. Garisto, and L. M. Johnson, Source Terin vi': is for the Assessment of Nuclear Fuel Waste, in Waste Management ' $86,2,397,1886$.

Garisto, N. C., E. R. Vance, S. Stroes-Gascoyne, and L. H. Johneon, Instant-Release Fractions for the Assessment of Used Nuclear Fuel Disposal, Report AECL-9892, AECL, 1989.

Hwang, Y., P. L. Chambré, W. W. L. Lee, and T. H. Pigford, Pressure-Induced Brine Migration in Consolidated Salt in a Repository, Trans. Am. Nucl. Soc., 55, 132, 1987.

Hwang, Y., P. L. Chambré, T. H. Pigford, and W. W.-L. Lee, Presure-driven Brine Migration in a Salt Repository, Report $L B L$-25768, Lawrence Berkeley Laboratory, 1989a.

Hwang, Y., W. W.-L. Lee, P. L. Chambré, and T. H. Pigford, Mass Transport in Salt Repositories: SteadyState Transport Through Interbeds, Report LBL-26704, Lawrence Berkeley Laboratory, $1989 \mathrm{~b}$.

Hwang, Y., W. W.-L. Lee, P. L. Chambré, and T. H. Pigford, Mass Transport in Salt Repositories: Transient Diffusion into Interbeds, Report LBL-2670s, Lawrence Berkeley Laboratory, 1989c.

Hwang, Y., W. W.-L. Lee, P. L. Chambré, and T. H. Pigford, Release Rates in Salt by Diffusion, Report $L B L-25767$, Lawrence Berkeley Laboratory, 1989d.

Isayama, Y., W. W.-L. Lee, T. H. Pigford, and P. L. Chambré, Isotopic Effects of Solubility-Limited Mass Transfer, Trans. Am. Nec. Soc., 60, 110, 1989.

Kang, C.-H., Mass Transfer and Transport of Radionuclides Through Backfill in a Geologic Nuclear Waste Repository, Ph. D., University of California, Berkeley, 1989.

Kang, C. H., P. L. Chambre, and T. H. Pigford, One-Dimensional Advective Transport with Variable Dispersion, Trans. Am. Nucl. Soc., 50, 140, 1985.

Kang, C. H., and W. W.-L. Lee, UCB-NE-108 User's Manual, Report LBL-27014, Lawrence Berkeley Laboratory, 1989.

Kerrisk, J. F., Solubility Limits on Radionuclide Dissolution At a Yucca Mountain Repository, Report LA9995-MS, Los Alamos National Laboratory, 1984.

Kerrisk, J. F., Solubility Limits on Radionuclide Dissolution, in Scientific Basis for Nuclear Waste Management VIII, edited by C.M. Jantzen, J.A. Stone, and R.C. Ewing, Materials Research Society, 237, 1986.

Kim, C.-L., W. B. Light, P. L. Chambré, W. W.-L. Lee, and T. H. Pigford, Variable Temperature Effects on Release Rates of Readily Soluble Nuclides, in SPECTRUM '88, 536, 1988.

Kim, C.-L., P. L. Chambrè, and T. H. Pigford, Mase-Transfer Limited Release of a Soluble Waste Species, Trens. Am. Nuc. Soc.,52, 80, 1986. 
Kim, C. L., P. L. Chambré, W. W.-L. Lee, and T. H. Pigford, Radionuclide Transport From an Array of Waste Packages in a Geologic Repository, Trens. Am. Nucl. Soc., 5\&, 109, 1987.

Lee, W. W.-L., UCB-NE-102 User's Manual, Report LBL-26700, Lawrence Berkeley Laboratory, $1989 \mathrm{a}$.

Lee, W. W.-L., UCB-NE-107 User's Manual, Report LBL-26672, Lawrence Berkeley Laboratory, $1989 \mathrm{~b}$.

Light, W. B., P. L. Chambré, T. H. Pigford, and W. W.-L. Lee, The Effect of Precipitation on Contaminant Dissolution and Transport: Analytic Sislutions, Report LBL-25769, Lawrence Berkeley Laboratory, 1988.

Lung, H.-C., P. L. Chambré, T. H. Pigford, and W. W.-L. Lee, Transport of Radioactive Decay Chains in Finite and Semi-Infinite Porous Media, Report $L B L-29987$, Lawrence Berkeley Laboratory, 1987.

Lung, II. C., P. L. Chambré, and T. H. Pigford, Nuclide Migration in Backfill With a Nonlinear Sorption Isotherm, Trans. Amer. Necl. Soc., 15, 107, 1983.

McTigue, D. F., Thermoelastic Response of Fluid-Saturated, Porous Rock, J. Geophy. Res., 91, B9, 9533, 1986.

Neretnieks, 1., Transport of Oxidants and Radionuclides Through a Clay Barrier, Report KBS TR-79, 1978.

Nowak, E. J., The Barkfill Barrier a Component in a Multiple Barrier Nuclear Waste Isolation System, Report SAND 79-1109, Sandia National Laboratory, 1979.

O'Connell, W. J., Status of Integrated Performance Assessment of the Waste Packages and Engineered Barrier System, in International High-Level Radioactive Waste Management Conference, 1990.

O'Connell, W. J., and R. S. Drach, Waste Package Performance Assesoment: Deterministic System Model Program Scope and Specification, Report UCRL-59761, Lawrence Livermore National Laboratory, 1986.

Pederson, L. R., C. Q. Buckwalter, and G. L. McVay, The Effect of Surface Area to Solution Volume on Waste Glass Leaching, Nucl. Tech, 6\&, 151, 1983.

Pfannkuch, H. O., Contribution a l'etude des deplacement de fluides miscible dans un milieu poreux, Rev. Inst. Fr. Petrol., \&, 215, 1963.

Pigford, T. H., J. O. Blomeke, T. L. Brekke, G. A. Cowan, W. E. Falconer, N, J. Grant, J. R. Johnson, J. M. Matusek, R. R. Parizek, R. L. Pigford, and D. E. White, A Study of the Isolation Syatem for Geologic Disposal of Radioactive Wastes, National Academy Press, Washington, D.C., 1983.

Pigford, T. H., and P. L. Chambré, Mass Transfer in a Salt Repcitory, Report $L B L$-19918, Lawrence Berkeley Laboratory, 1985.

Pigford, T. H., and P. L. Chambré, Near-Field Mass Transfer in Geologic Disposal Systems: a Review, in Scientific Basis for Nuclear Waste Management XI, edited by M.J. Apted, and R.E. Westerman, Materials Research Society, 125, 1988.

Pigford, T. H., P. L. Chambré, M. Albert, M. Foglia, M. Harada, F. Iwamoto, T. Kanki, D. Leung, S. Masuda, S. Muraoka, and D. Ting, Migration of Radionuclides Through Sorbing Media: Analytical Solutions - II, Report $L B L-11616$, Lawrence Berkeley Laboratory, 1980.

Pigford, T. H., P. L. Chambre, and S. J. Zavoshy, Effect of Repository Heating on Dissolution of Glass Waste, Trans. Am. Nucl. Soc., H, 115, 1983.

Rai, D., and R. G. Strickert, Maximum Concentrations of Actinides in Geologic Media, Trans. Amer. Nucl. Soc, 39, 185, 1980.

Roddy, J. W., H. C. Claiborne, R. C. Ashline, P. J. Johnson, and B. T. Rhyne, Physical and Decay Characteristics of Commercial LWR Spent Fuel, Report ORNL/TM-9591/VIER1, Oak Ridge National Laboratory, 1986. 
Ross, B., Models for Calculating Dissolution Rates of High-Level Waste, Nuclear Safety, 28, 362, 1987.

Sadeghi, M. M., W. W.-L. Lee, T. H. Pigford, and P. L. Chambré, The Effective Diffusion Coefficient for Porous Rubble, in 1990 American Nuclear Society Annwal Meeting, 1990.

Sadeghi, M. M., T. H. Pigford, P. L. Chambré, and W. W.-L. Lee, Equations for Predicting Release Rates for Waste Packages in Unsaturated Tuff, Lawrence Berkeley Laboratory, 1989a.

Sadeghi, M. M., T. H. Pigford, P. L. Chambré, and W. W.-L. Lee, Prediction of Release Rates for a Waste Repository at Yucca Mountain, Lawrence Berkeley Laboratory, 1989b.

Scott, J. I., and C. M. Koplik, Analytic Models for Assessing the Performance of Engineered Barriers in a Basalt Repository, in Scientific Basis for Nwclear Waste Management VII, edited by G.I. McVay, Materials Research Society, 1077, 1984.

Sherwood, T. K., R. L. Pigford, and C. R. Wilke, Mass Transfer, McGraw-Ilill, New York, 1975.

U.S. Department of Energy, Environmental Asuessment: Reference Repository Location, Ilanford Site, Washington, Report DOE/RW=0070, 1986.

U.S. Department of Energy, Site Characterization Plan: Yucca Mountain Sile, Nevada Researclı and Devel* opmeni Area, Nevada, Report DOE/RW-0199, 1988.

U.S. Nuclear Regulatory Commission, Disposal of High-Level Radioactive Wastes in Geologic Repositories Technical Criteria, Code of Fed. Reg., 10, 60.113(a)(1)(ii)(B), 1983.

Van Luik, A. E., M. J. Apted, W. J. Bailey, J. H. Haberman, J. S. Shade, R. E. Guenther, R. J. Serne, E. R. Gilbert, R. Peters, and R. E. Williford, Spent Nuclear Fuel as a Waste Form for Geologic Disposal: Assessment and Recommendations on Data and Modeling Needs, Report PNL-6929, Pacific Northwest Laboratory, 1987.

Wilson, C. N., and C. J. Bruton, Studies on Spent Fuel Dissolution Behavior Under Yucca Mountain Repository Conditions, Report PNL-SA-16892, Pacific Northwest Laboratory, 1989.

Yung, S. C. , C. F. McLane, R. P. Anantatmula, R. T. Toyooka, and W. K. Terry, Waste Package Preliminary Reliability Analysis Report, Report SD-BWI-TI-287, Rockwell, 1987.

Zavoshy, S. J., P. L. Chambre, and T. H. Pigford, Mass Transfer in a Geologic Environment, in Scientific Basis for Nuclear Waste Manegement VIII, edited by C.M. Jantzen, J.A. Stone, and R.C. Ewing, Materials Research Society, 311, 1985. 